NBER WORKING PAPER SERIES

\title{
IMPLEMENTATION OF MONETARY POLICY: HOW DO CENTRAL BANKS SET INTEREST RATES?
}

\author{
Benjamin M. Friedman \\ Kenneth N. Kuttner \\ Working Paper 16165 \\ http://www.nber.org/papers/w16165 \\ NATIONAL BUREAU OF ECONOMIC RESEARCH \\ 1050 Massachusetts Avenue \\ Cambridge, MA 02138 \\ July 2010
}

We are grateful to Ulrich Bindseil, Francesco Papadia, and Huw Pill for thoroughgoing and very helpful comments on earlier drafts; to Spence Hilton, Warren Hrung, Darren Rose and Shigenori Shiratsuka for their help in obtaining the data used in the original empirical work developed here; to Toshiki Jinushi and Yosuke Takeda for their insights on the Japanese experience; and to numerous colleagues for helpful discussions of these issues. The views expressed herein are those of the authors and do not necessarily reflect the views of the National Bureau of Economic Research.

NBER working papers are circulated for discussion and comment purposes. They have not been peerreviewed or been subject to the review by the NBER Board of Directors that accompanies official NBER publications.

(C) 2010 by Benjamin M. Friedman and Kenneth N. Kuttner. All rights reserved. Short sections of text, not to exceed two paragraphs, may be quoted without explicit permission provided that full credit, including $\odot$ notice, is given to the source. 
Implementation of Monetary Policy: How Do Central Banks Set Interest Rates?

Benjamin M. Friedman and Kenneth N. Kuttner

NBER Working Paper No. 16165

July 2010, Revised March 2011

JEL No. E43,E52,E58

\begin{abstract}
$\underline{\text { ABSTRACT }}$
Central banks no longer set the short-term interest rates that they use for monetary policy purposes by manipulating the supply of banking system reserves, as in conventional economics textbooks; today this process involves little or no variation in the supply of central bank liabilities. In effect, the announcement effect has displaced the liquidity effect as the fulcrum of monetary policy implementation. The chapter begins with an exposition of the traditional view of the implementation of monetary policy, and an assessment of the relationship between the quantity of reserves, appropriately defined, and the level of short-term interest rates. Event studies show no relationship between the two for the United States, the Euro-system, or Japan. Structural estimates of banks' reserve demand, at a frequency corresponding to the required reserve maintenance period, show no interest elasticity for the U.S. or the Euro-system (but some elasticity for Japan). The chapter next develops a model of the overnight interest rate setting process incorporating several key features of current monetary policy practice, including in particular reserve averaging procedures and a commitment, either explicit or implicit, by the central bank to lend or absorb reserves in response to differences between the policy interest rate and the corresponding target. A key implication is that if reserve demand depends on the difference between current and expected future interest rates, but not on the current level per se, then the central bank can alter the market-clearing interest rate with no change in reserve supply. This implication is borne out in structural estimates of daily reserve demand and supply in the U.S.: expected future interest rates shift banks' reserve demand, while changes in the interest rate target are associated with no discernable change in reserve supply. The chapter concludes with a discussion of the implementation of monetary policy during the recent financial crisis, and the conditions under which the interest rate and the size of the central bank's balance sheet could function as two independent policy instruments.
\end{abstract}

\author{
Benjamin M. Friedman \\ Department of Economics \\ Littauer Center 127 \\ Harvard University \\ Cambridge, MA 02138 \\ and NBER \\ bfriedman@harvard.edu \\ Kenneth N. Kuttner \\ Department of Economics \\ Williams College \\ South Academic Building \\ 24 Hopkins Hall Drive \\ Williamstown, MA 01267 \\ and NBER \\ kenneth.n.kuttner@williams.edu
}




\section{Contents}

1 Introduction 1

2 Fundamental Issues in the Mode of Wicksell 5

3 The Traditional Understanding of "How They Do That" 12

3.1 The Demand for and Supply of Reserves, and the Determination of Market Interest Rates . . . . . . . . . . . . . . . . . . . . . . . 12

3.2 The Search for the "Liquidity Effect": Evidence for the United States . . . 18

3.3 The Search for the "Liquidity Effect": Evidence for Japan and the Eurosystem ............................ 22

4 Observed Relationships between Reserves and the Policy Interest Rate 25

4.1 Comovements of Reserves and the Policy Interest Rate: Evidence for the United States, the Euro-system and Japan . . . . . . . . . . . . . . . 25

4.2 The Interest Elasticity of Demand for Reserves: Evidence for the U.S., Europe and Japan . . . . . . . . . . . . . . . . . . . . . 27

5 How, Then, do Central Banks Set Interest Rates?

5.1 Bank Reserve Arrangements and Interest Rate Setting Procedures in the United States, the Euro-System and Japan . . . . . . . . . . . . . . . 32

5.2 A Model of Reserve Management and the Anticipation Effect . . . . . . . . 35

6 Empirical Evidence on Reserve Demand and Supply Within the Maintenance Period

6.1 Existing Evidence on the Demand for and Supply of Reserves Within the Maintenance Period . . . . . . . . . . . . . . . . . . . . . 40

6.2 Within-Maintenance-Period Demand for Reserves in the U.S. . . . . . . . . 43

6.3 Within-Maintenance-Period Supply of Reserves . . . . . . . . . . . . . . 47

7 New Possibilities Following the 2007-9 Crisis 51

7.1 The Crisis and the Policy Response . . . . . . . . . . . . . . . . . 52

7.2 Implications for the Future Conduct of Monetary Policy . . . . . . . . . . . 57

7.3 Some Theoretical and Empirical Implications . . . . . . . . . . . . . 60

8 Conclusion $\quad 63$ 


\section{Introduction}

A rich theoretical and empirical literature, developed over the past half century and more, has explored numerous aspects of how central banks do, and optimally should, conduct monetary policy. Oddly, very little of this research addresses what central banks actually do.

The contrast arises from the fact that, both at the decision level and for purposes of policy implementation, what most central banks do, most of the time, is set some short-term interest rate. To be sure, in most cases they do so not out of any inherent preference for one interest rate level versus another but as a means to influence dimensions of macroeconomic activity like prices and inflation, or output and employment, or sometimes designated monetary aggregates. But inflation and output are not variables over which the central bank has direct control, nor is the quantity of deposit money, at least over the horizons considered here. Instead, a central bank normally exerts whatever influence it has over any or all of these macroeconomic magnitudes via its setting of a short-term interest rate.

At a practical level, the fact that setting some interest rate is the central bank's way of implementing monetary policy is clear enough. Especially once most central banks abandoned or at least downgraded the money growth targets that they used to set-this happened mostly during the 1980s and early 1990s, although some exceptions still remain-the centerpiece of how economists and policymakers think and talk about monetary policy has become the relationship directly between the interest rate that the central bank fixes and the economic objectives, like those for inflation and output, that policymakers are seeking to achieve. (Even when central banks had money growth targets, what they mostly did in the attempt to achieve them was set a short-term interest rate anyway.)

This key role of the central bank's policy interest rate is likewise reflected in what economists write and teach about monetary policy. In place of the once-ubiquitous HicksKeynes "IS-LM" model, based on the joint satisfaction of an aggregate equilibrium condition for the goods market (the "IS curve") and a parallel equilibrium condition for the money market for either given money supply or a given supply of bank reserves supposedly fixed by the central bank (the "LM curve"), today the standard basic workhorse model used for macroeconomic and monetary policy analysis is the Clarida-Galí-Gertler "new Keynesian" model consisting of an IS curve, relating output to the interest rate as before but now including expectations of future output too, together with a Phillips-Calvo pricesetting relation. The LM curve is gone, and the presumption is that the central bank simply sets the interest rate in the IS curve. The same change in thinking is also reflected in more fundamental and highly elaborated explorations of the subject. In contrast to Patinkin's classic treatise (1956, with an important revision in 1965), which was titled Money, Interest, and Prices, Woodford's 2003 treatise is simply Interest and Prices.

Taking the interest rate as a primitive for purposes of monetary policy analysis - or, alternatively, adding to the model a Taylor-type interest rate rule to represent the central bank's systematic behavior in choosing a level for the short-term interest rate-seems unproblematic from a practical perspective. Central banks do take and implement decisions about short-term interest rates. With few exceptions, they are able to make those decisions 
effective in the markets in which they operate. Even so, from a more fundamental viewpoint merely starting from the fact that central banks implement monetary policy in this way leaves open the "how do they do that?" question. Nothing in today's standard workhorse model, nor in the analysis of Taylor rules, gives any clue to how the central bank actually goes about setting its chosen policy interest rate, or suggests any further elements worthy of attention in how it does so.

The question would be trivial, in the short and probably the medium run too, if central banks simply maintained standing facilities at which commercial banks and perhaps other private agents too could borrow or lend in unlimited volume at a designated interest rate. But this situation does not correspond to reality-not now, nor within recent experience. Most central banks do maintain facilities for lending to private-sector banks, and some also have corresponding facilities at which private-sector banks can lend to them. Many of these facilities operate subject to explicit quantity restrictions on their use, however. Further, even when these facilities are in principle unlimited, in practice the volume of lending or borrowing that central banks do through them is normally very small despite what are often wide movements in the policy-determined interest rate. By contrast, as Wicksell pointed out long ago, for the central bank to maintain interest rates below the "ordinary," or "normal" rate (which in turn depends on the profitability of investment) it should have to supply an ever greater volume of reserves to the banking system, in which case its standing facility would do an ever greater volume of lending. Conversely, maintaining interest rates above the ordinary/normal rate should require the central bank to absorb an ever greater part of banks' existing reserves. Neither in fact happens.

How, then, do central banks set interest rates? The traditional account of how this process works involves the central bank's varying the supply of bank reserves, or some other subset of its own liabilities, in the context of an interest-elastic demand for those liabilities on the part of the private banking system and perhaps other holders as well (including the nonbank public if the measure of central bank liabilities taken to be relevant includes currency in circulation). It is straightforward that the central bank has monopoly control over the supply of its own liabilities. What requires more explanation is that there is a demand for these liabilities, and that this demand is interest-sensitive. Familiar reasons for banks to hold central bank reserves include depository institutions' need for balances with which to execute interbank transfers as part of the economy's payment mechanism, their further need for currency to satisfy their customers' everyday demands (in systems, like that in the United States, in which vault cash is counted as part of banks' reserves), and in some systems (the Eurosystem, for example, or Japan, or again the United States) to satisfy outright reserve requirements imposed by the central bank. The negative interest elasticity follows as long as banks have at least some discretion in the amount of reserves that they hold for any or all of these purposes, and the interest that they earn on their reserve holdings differs from the appropriately risk-adjusted rates of return associated with alternative assets to which they have access. Although this long-standing story has now largely disappeared from most professional discussion of monetary policy, as well as from graduate-level teaching of macroeconomics, it remains a staple of undergraduate money-and-banking texts.

At a certain level of abstraction, this traditional account of the central bank's setting an 
interest rate by changing the quantity of reserves supplied to the banking system is isomorphic to the concept of a standing borrowing/lending facility with a designated fixed rate. It too, therefore, is problematic in the context of recent experience in which there is little if any observable relationship between the interest rates that most central banks are setting and the quantities of reserves that they are supplying. A substantial empirical literature has sought to identify a "liquidity effect" by which changes in the supply of bank reserves induce changes in the central bank's policy interest rate and, from there, changes in other market-determined short-term interest rates as well. For a phenomenon that supposedly underlies such a familiar and important aspect of economic policymaking, this effect has been notoriously difficult to document empirically. Even when researchers have found a significant relationship, the estimated magnitude has often been hard to reconcile with actual central bank monetary policymaking.

Further, developments within the most recent two decades have rendered the reserve supply-interest rate relationship even more problematic empirically. In the United States, for example, as Figure 1 shows, a series of noticeably large increases in banks' nonborrowed reserves did accompany the steep decline in the Federal Reserve System's target for the federal funds rate (the interest rate on overnight interbank transfers of reserves) in 1990 and throughout 1991 - just as the traditional account would suggest. The figure plots the target federal funds rate (solid line, right-hand axis) and the change in nonborrowed reserves on days in which the target changed (bars, left-hand axis) from November 1990 until June 2007, just before the onset of the 2007-9 financial crisis. ${ }^{1}$ Because the figure shows the change in reserves divided by the change in the target interest rate, the bars extending below the horizontal axis-indicating a negative relationship between the reserve change and the interest rate change-are what the traditional view based on negative interest elasticity of reserve demand would imply. ${ }^{2}$

Once the Federal Reserve began publicly announcing its target federal funds rate, however-a change in policy practice that took place in February 1994-the relationship between reserve changes and changes in the interest rate became different. During the remainder of the 1990s, the amount by which the Federal Reserve increased or decreased bank reserves in order to achieve its changed interest rate target was not only extremely small but mostly becoming smaller over time. On many occasions, moving the federal funds rate appears to have required no, or almost no, central bank transactions at all. The largest movement in the target federal funds rate during this period was the increase from 3 percent to 6 percent between early 1994 and early 1995. Figure 2 provides a close-up view of the movement of nonborrowed reserves and the target federal funds rate during this period. A relationship between the two is impossible to discern.

As Figure 1 shows, since 2000 the amount by which reserves have changed on days of policy-induced movements in the federal funds rate has become noticeably larger on average. But in a significant fraction of cases - one-third to one-fourth of all movements in the target federal funds rate- the change in reserves has been in the wrong direction: the

\footnotetext{
${ }^{1}$ The Federal Reserve's daily data on reserve quantities begin in November, 1990.

${ }^{2}$ Each bar shown indicates the change in nonborrowed reserves (in billions of dollars) on the day of a change in the target interest rate, divided by the change in the target interest rate itself (in percentage points).
} 
bars above the horizontal axis indicate, the change that accompanied a decline in the interest rate (for example, during the period of monetary policy easing in 2000-1) was sometimes a decrease in reserves, and the change that accompanied an increase in the interest rate (for example, during the period of policy tightening in 2004-6) was sometimes an increase in reserves! The point, of course, is not that the "liquidity effect" sometimes has one sign and sometimes the other. Rather, at least on a same-day basis, even in the post-2000 experience the change in reserves associated with a policy-induced move in the federal funds rate is sufficiently small to be impossible to distinguish from the normal day-to-day variation in reserve supply needed to offset fluctuations in float, or Treasury balances, or other nonpolicy factors that routinely affect banks' reserve demand. As Figures 3 and 4 show, for these two periods of major change in interest rates, no relationship between the respective movements of nonborrowed reserves and the federal funds rate is apparent here either. ${ }^{3}$

Yet a further aspect of the puzzle surrounding central banks' setting of interest rates is the absence of any visible reallocation of banks' portfolios. The reason the central bank changes its policy interest rate is normally to influence economic activity, but few private borrowers whose actions matter for that purpose borrow at the central bank's policy rate. The objective, therefore, is to move other borrowing rates, and indeed the evidence indicates that this is usually what happens: changes in the policy rate lead to changes in private short-term rates as well. But the traditional story of how changes in the central bank's policy rate are transmitted to other interest rates involves banks' increasing their loans and investments when reserves become more plentiful/less costly, and cutting back on loans and investments when reserves become less plentiful/more costly. What is missing empirically is not the end result - to repeat, other short-term market interest rates normally do adjust when the policy rate changes, and in the right direction-but any evidence of the mechanism that is bringing this result about.

The goal of this chapter is to place these empirical puzzles in the context of the last two decades of research bearing on how central banks set interest rates, and to suggest avenues for understanding "how they do that" that are simultaneously more informative on the matter than the stripped-down professional-level workhorse model, which simply takes the policy interest rate as a primitive, and more consistent with contemporary monetary policy practice than the traditional account centered on changes in reserve supply against an interest-elastic reserve demand. Section 2 anchors this policy-level analysis in more fundamental thinking by drawing links to the theory of monetary policy dating back to Wicksell. Section 3 sets out the traditional textbook conception of how central banks use changes in reserve supply to move the market interest rate, formalizes this conception in a model of the overnight market for reserves, and summarizes the empirical literature of the "liquidity effect." Section 4 compares the implications of the traditional model to the recent experience in the United States, the Euro-system and Japan, in which the changes in reserve supply that are supposedly responsible for changes in short-term interest rates are mostly not to be seen, and presents new evidence showing that, except in Japan, there is little indication of negatively interest-elastic reserve demand either. Section 5 describes the

\footnotetext{
${ }^{3}$ Other researchers, using different metrics, have found a similar lack of a relationship; see, for example, Thornton (2007).
} 
basic institutional framework that the Federal Reserve System, the European Central Bank and the Bank of Japan use to implement monetary policy today, and provides a further theoretical framework for understanding how these central banks operate in the day-to-day reserves market and how their banking systems respond; the key implication is that, because of the structure of the reserve requirement that banks face, on any given day the central bank has the ability to shift banks' demand for reserves at a given market interest rate. Section 6 reviews the relevant evidence on these relationships for the Euro-system and Japan, and presents new evidence for the United States on the daily behavior of banks' demand for reserves and the Federal Reserve System's supply of reserves. Section 7 reviews the extraordinary actions taken by the Federal Reserve System, the European Central Bank and the Bank of Japan during the 2007-9 financial crisis, many of which stand outside the now-conventional rubric of monetary policy as interest rate setting, and goes on to draw out the implications for monetary policymaking of the new institutional framework put in place by the Federal Reserve and the Bank of Japan; the most significant of these implications is that, in contrast to the traditional view in which the central bank in effect chooses one point along a stable interest-elastic reserve demand curve, and therefore has at its disposal a single instrument of monetary policy, over time horizons long enough to matter for macroeconomic purposes the central bank can choose both the overnight interest rate and the quantity of reserves, with some substantial independence. Section 8 briefly concludes.

\section{Fundamental Issues in the Mode of Wicksell}

Historically, what came to be called "monetary" policy has primarily meant the fixing of some interest rate - and hence often a willingness to lend at that rate-by a country's central bank or some other institution empowered to act as if it were a central bank. Under the gold standard's various incarnations, raising and lowering interest rates was mainly a means to stabilize a country's gold flows and thereby enable it to maintain the gold-exchange value of its currency. It was only in the first decades following World War II, with most countries no longer on gold as a practical matter, that setting interest rates (or exchange rates) per se emerged as central banks' way of regulating economic activity.

As rapid and seemingly chronic price inflation spread through much of the industrialized world in the 1970s, many of the major central banks responded by increasingly orienting their monetary policies around control of money growth. Because policymakers mostly chose to focus on monetary aggregates consisting of outstanding deposits and currency (as opposed to bank reserves), however, over time horizons like a year or even longer the magnitudes that they designated for the growth of these aggregates were necessarily targets to be pursued rather than instruments to be set. Deposits are demanded by households and firms, and supplied by banks and other issuers, in both cases in ways that are subject to central bank influence but not direct central bank control; and although a country's currency is typically a direct liability of its central bank, and hence in principle subject to exact control, in modern times no central bank has attempted to ration currency as a part of its monetary policymaking process. Hence with only a few isolated excep- 
tions (for example, the U.S. Federal Reserve System's 1979-82 experiment with targeting nonborrowed reserves), central banks were still implementing monetary policy by setting a short-term interest rate.

In the event, monetary targeting proved short-lived. In most countries it soon became apparent that, over time horizons that mattered importantly for monetary policy, different monetary aggregates within the same economy exhibited widely disparate growth rates. Hence it was important to know which specific measure of money presented the appropriate benchmark to which to respond, something that the existing empirical literature had not settled (and still has not). More fundamentally, changes in conditions affecting the public's holding of deposits - the introduction of new electronic technologies that made possible both new forms of deposit-like instruments (money market mutual funds, for example) and new ways for both households and firms to manage their money holdings (like sweep accounts for firms and third-party credit cards for households), banking deregulation in many countries (for example, removal of interest rate limits on consumer deposits in the United States, which permitted banks to offer money market deposit accounts), and the increasing globalization of the world's financial system, which enabled large deposit holders to substitute more easily across national boundaries in the deposits and alternative instruments they held in their portfolios-destabilized what had at least appeared to be long-standing regularities in the demand for money. In parallel, the empirical relationships linking money growth to the increase of either prices or income, which had been the core empirical underpinning of the insight that limiting money growth would slow price inflation in the first place, began, in one country after another, to unravel. Standard statistical exercises that for years had shown a reasonably stable relationship of money growth to either inflation or nominal income growth (specifically, stable enough to be reliable for policy purposes) no longer did so.

As a result, most central banks either downgraded or abandoned altogether their targets for money growth, and turned (again) to setting interest rates as a way of making monetary policy without any specific intermediate target. With the memory of the inflation of the 1970s and early 1980s still freshly in mind, however, policymakers in many countries were also acutely aware of the resulting lack of any "nominal anchor" for the economy's price level. In response, an increasing number of central banks adopted various forms of "inflation targeting," under which the central bank both formulated monetary policy internally and communicated its intentions to the public in terms of the relationship between the actual inflation rate and some designated numerical target. As Tinbergen had pointed out long before, in the absence of a degeneracy the solution to a policy problem with one instrument and multiple targets can always be expressed in terms of the intended trajectory for any one designated target. ${ }^{4}$ Monetary policy, in the traditional view, has only one instrument to set: either a short-term interest rate or the quantity of some subset of central bank liabilities. Inflation targeting, therefore, need not imply that policymakers take the economy's inflation rate to be the sole objective of monetary policy. ${ }^{5}$ But whether inflation is the central bank's

\footnotetext{
${ }^{4}$ See Tinbergen (1952).

${ }^{5}$ This point is most explicit in the work of Svensson (1997). As a practical matter, King (1997) has argued that few central bankers are what he called "inflation nutters." Although some central banks (most obviously,
} 
sole target or not, for purposes of the implementation of monetary policy what matters is that the economy's inflation rate (like the rate of money growth, but even more so) stands at far remove from anything that the central bank can plausible control in any direct way. Under inflation targetingas with other policymaking frameworks, the central bank has to implement monetary policy by setting the value of some instrument over which it actually exerts direct control. For most central banks, including those that are "inflation targeters," that has meant setting a short-term interest rate.

Economists have long recognized, however, that fixing an interest rate raises more fundamental issues. The basic point is that an interest rate is a relative price. The nominal interest rate that the central bank sets is the price of money today relative to the price of money at some point in the future.

The economic principle that is therefore involved is quite general. Whenever someone (the government, or perhaps a private firm) fixes a relative price, either of two possible classes of outcomes ensues. If whoever is fixing the relative price merely enforces the same price relation that the market would reach on its own, then fixing it does not matter. If the relative price is fixed differently from what the market would produce, however, private agents have incentives to substitute and trade in ways they would otherwise not choose to do. Depending on the price elasticities applicable to the goods in question, the quantitative extent of the substitution and trading motivated in this way-arbitrage, in common parlance — can be either large or small.

When the specific relative price being fixed is an interest rate (that is, the rate of return to holding some asset) and when the entity fixing it is the central bank (that is, the provider of the economy's money), the matters potentially involved in this line of argument also assume macroeconomic significance, extending to the quantity and rate of growth of the economy's productive capital stock and the level and rate of increase of absolute prices. More than a century ago, Wicksell (1907) articulated the potential inflationary or deflationary consequences of what came to be known as interest rate "pegging": "If, other things remaining the same, the leading banks of the world were to lower their rate of interest, say 1 per cent. below its ordinary level, and keep it so for some years, then the prices of all commodities would rise and rise and rise without any limit whatever; on the contrary, if the leading banks were to raise their rate of interest, say 1 per cent. above its normal level, and keep it so for some years, then all prices would fall and fall and fall without any limit except Zero."6 (It is interesting, in light of the emphasis of recent years on providing a "nominal anchor," that Wicksell thought keeping prices stable would be less of a problem in a pure paper-money economy freed from the gold standard: "if the free coining of gold, like that of silver, should cease, and eventually the bank-note itself, or rather the unity in which the accounts of banks are kept, should become the standard of value, then, and not until then, the problem of keeping the value of money steady, the average level of money prices at a constant height, which evidently is to be regarded as the fundamental problem of monetary science, would be solvable theoretically and practically to any extent.")

the ECB) at least purport to place inflation above other potential policy objectives in a strict hierarchy, whether they actually conduct monetary policy in this way is unclear.

${ }^{6} \mathrm{Here}$ and below, italics in quotations are in the original. 
As Wicksell explained, his proposition was not simply a mechanical statement connecting interest rates and inflation (or deflation) but rather the working out of an economic model that had as its centerpiece "the productivity and relative abundance of real capital"-in other words, the rate of return that investors could expect from non-monetary applications of their funds: "the upward movement of prices, whether great or small in the first instance, can never cease so long as the rate of interest is kept lower than its normal rate, i.e., the rate consistent with the then existent marginal productivity of real capital." Wicksell made clear that the situation he described was purely hypothetical. No one had observed-or, he thought, would observe-an economy's price level increasing or falling without limit. The remaining question, however, was what made this so. Was it merely that banks never would make their interest rates depart from the "normal rate" anchored to the economy's marginal product of capital? And what if somehow they did? Would the marginal product of capital ultimately move into alignment? If so, what change in the economy's capital stock, and in the corresponding investment flows along the transition path, would be required?

Sargent \& Wallace (1975) highlighted Wicksell's proposition in a different context by showing that in a traditional short-run IS-LM model, but with flexible prices and "rational" (in the sense of model-consistent) expectations, identifying monetary policy as fixing the interest rate led to an indeterminacy. Under those conditions the model would degenerate into two disconnected sub-models: one, over-determined, including real output and the real interest rate; the other, under-determined, including the price level and the money stock. Hence with an exogenous interest rate the price level would be indeterminate-not as a consequence of the central bank's picking the wrong level for the interest rate, but no matter what level it chose. Given such assumptions as perfect price flexibility, what Wicksell envisioned as the potentially infinite rise or fall of prices over time translated into indeterminacy immediately.

Parkin (1978) and McCallum (1981) subsequently showed that although this indeterminacy would obtain under the conditions Sargent and Wallace specified if the central bank chose the exogenous interest rate level arbitrarily, it would not if policymakers instead fixed the interest rate at least in part as a way of influencing the money stock. ${ }^{7}$ But the same point held for the price level, or, for that matter, any nominal magnitude. Even if the price level (or its rate of increase) were just one argument among others in the objective function policymakers were seeking to maximize, therefore-and, in principle, even if the weight they attached to it were small compared to that on output or other arguments-merely including prices (or inflation) as a consideration in a systematically responsive policy would be sufficient to break the indeterminacy.

Taken literally, with all of the model's implausible assumptions in force (perfectly flexible prices, model-consistent expectations, and so on), this result too strains credulity. It is difficult to believe that whether an economy's price level is determinate or not hinges on whether the weight its central bank places on inflation in carrying out monetary policy is almost zero or exactly zero. But in Wicksell's context, with prices and wages that adjust over time, the insight rings true: If the central bank simply fixes an interest rate without

\footnotetext{
${ }^{7}$ See also McCallum $(1983,1986)$.
} 
any regard to the evolution of nominal magnitudes, there is nothing to prevent a potentially infinite drift of prices; to the extent that it takes nominal magnitudes into account and systematically resets the interest rate accordingly, that possibility is precluded. The aspect of Wicksell's original insight that this line of inquiry still leaves unexplored, however, is how, even if there is no problem of indeterminacy of the aggregate price level, the central bank's fixing a relative price that bears some relation to the marginal product of capital potentially affects asset substitutions and, ultimately, capital accumulation.

Taylor's (1993) work on interest rate rules for monetary policy further clarified the indeterminacy question but left aside the implications of central bank interest rate setting for private asset substitutions and capital accumulation. Taylor initially showed that a simple rule relating the federal funds rate to observed values of inflation and the output gap, with no elaborate lag structure and with the two response coefficients simply picked as round numbers (1/2 and 1/2, respectively), roughly replicated the Federal Reserve's conduct of monetary policy during 1987-92. This finding quickly spurred interest both in seeing whether similarly simple rules likewise replicated monetary policy as conducted by other central banks, or by the Federal Reserve during other time intervals. ${ }^{8}$ It also prompted analysis of what coefficient values would represent the optimal responsiveness of monetary policy to inflation and to movements of real economic activity for specific policy objectives under given conditions describing the behavior of the economy. ${ }^{9}$

The aspect of this line of analysis that bore in particular on the Wicksell/SargentWallace indeterminacy question concerned the responsiveness to observed inflation. For a general form of the "Taylor rule" as in

$$
r_{t}^{F}=a+b^{\pi}\left(\pi_{t}-\pi^{*}\right)+b^{y}\left(y_{t}-y^{*}\right)
$$

where $r^{F}$ is the interest rate the central bank is setting, $\pi$ and $\pi^{*}$ are, respectively, the observed inflation rate and the corresponding rate that policymakers are seeking to achieve, and $y$ and $y^{*}$ are, respectively, observed output and "full employment" output, the question turns on the magnitude of $b^{\pi}$. (If the terms in $\pi-\pi^{*}$ and $y-y^{*}$ have some nontrivial lag structure, what matters for this purpose is the sum of the coefficients analogous to $b^{\pi}$.) Brunner \& Meltzer (1964), among others, had earlier argued that under forms of monetary policymaking that are equivalent to the central bank's setting an interest rate, it was not uncommon for policymakers to confuse nominal and real interest rates in a way that led them to think they were tightening policy in response to inflation when in fact they were easing it. The point was that if inflation expectations rise one-for-one with observed inflation, as would be consistent with a random-walk model for the time-series process describing inflation, then any response of the nominal interest rate that is less than onefor-one results in a lower rather than higher real interest rate. In what later became known as the "Taylor principle," Taylor (1996) formalized this insight as the proposition that $b^{\pi}$ in interest rate rules like (1) above must be greater than unity for monetary policy to be exerting an effective counter-force against an incipient inflation.

\footnotetext{
${ }^{8}$ Prominent examples include Judd \& Rudebusch (1998), Clarida et al. (1998), and Peersman \& Smets (1999). See Taylor (1996) for a summary of earlier research along these lines.

${ }^{9}$ See, for example, Ball (1999), Clarida et al. (1999, 2000), and Levin et al. (2001).
} 
Together with a model in which inflation responds to monetary policy with a lagfor example, a standard New Keynesian model in which inflation responds to the level of output via a Calvo-Phillips relation, while output responds to the expected real interest rate via an "IS curve," with a lag in at least one relation if not both-the Taylor principle implies that if $b^{\pi}<1$ then once inflation exceeds $\pi^{*}$ the expectation is for it to rise forever over time, with no limit. Under this dynamic interpretation of what an indeterminate price level would mean, as in Wicksell, Parkin's and McCallum's argument that any positive weight on inflation would suffice to pin down the price level, no matter how small, clearly does not obtain. (In Parkin's and McCallum's original argument, the benchmark for considering the magnitude of $b^{\pi}$ was $b^{y}$; here the relevant benchmark is instead an absolute, namely 1.) Because of the assumed lag structure in the Calvo-Phillips and/or IS relation, however, an immediate indeterminacy of the kind posited by Sargent and Wallace does not arise.

Although the primary focus of Wicksell's argument was the implication for prices, it is clear that arbitrage-like substitutions-in modern language, holding debt instruments versus holding claims to real capital, holding one debt instrument versus any other, holding either debt or equity assets financed by borrowing, and the like-were at the heart of his theory. If the interest rate that banks were charging departed from what was available from "investing your capital in some industrial enterprise ... after due allowance for risk," he argued, the nonbank public would respond accordingly; and it was the aggregate of those responses that produced the cumulative movement in the price level that he emphasized. As Wicksell further recognized, this chain of asset-liability substitutions, because they involved bank lending, would also either deplete or free up banks' reserves. With an interest rate below the "normal rate," the public would borrow from banks and (with rising prices) hold greater money balances; "in consequence, the bank reserves will melt away while the amount of their liabilities very likely has increased, which will force them to raise their rate of interest."

How, then, can the central bank induce the banks to continue to maintain an interest rate below "normal"? In the world of the gold standard, in which Wicksell was writing, it went without saying that the depletion of banks' reserves would cause them to raise their interest rates-hence his presumption that interest rates could not, and therefore would not, remain below the "normal rate." His theory of the consequences of such a maintained departure, he noted at the outset, "cannot be proved directly by experience because the fact required in its hypothesis never happens."

In a fiat money system regulated by a central bank, however, the central bank's ability to replenish banks' reserves creates just that possibility. Although Wicksell did not draw out the point, the required continuing increase in bank reserves that he posited completes his theory of a cumulative movement in prices. What underpins the unending rise in prices (unending as long as the interest rate remains below "normal") is a correspondingly unending increase in the quantity of reserves supplied to the banking system. Hence prices and reserves - and, presumably, the public's holdings of money balances-all rise together. In effect, Wicksell therefore provided the monetary (in the sense that includes bank reserves) dimension of the Phelps-Friedman "accelerationist" view of what happens when monetary policy keeps interest rates sufficiently low to push aggregate demand beyond the econ- 
omy's "natural" rate of output. As Wicksell emphasized, in the world of the gold standard in which he lived this causal sequence was merely a theoretical possibility. Under a fiat money system it can be, and sometimes is, a reality.

In either setting, however, the continual provision of ever more bank reserves is essential to the story. In Wicksell's account, it is what keeps the interest rate below "normal"and therefore, by extension, what keeps aggregate demand above the "natural" rate of output. (It is also presumably what permits the expansion of money balances, so that money and prices rise in tandem as well.) As McCallum likewise (2001) pointed out, any model in which the central bank is assumed to set an interest rate is inherently a "monetary" model-regardless of whether it explicitly includes any monetary quantity-because the central bank's control over the chosen interest rate presumably stems from its ability to control the quantity of its own liabilities. ${ }^{10}$

Two key implications for (at least potentially) observable relationships follow from this line of reasoning. First, if the central bank's ability to maintain a market interest rate different from "normal" depends on the provision of incremental reserves to the banking system, then unless there is reason to think that the "normal rate" (to recall, anchored in the economy's marginal product of capital) is changing each time the central bank changes its policy rate - and, further, that all policymakers are doing is tracking those independently originating changes - the counterpart to the central bank's interest rate policy is what is happening to the quantity of reserves. At least in principle, this relationship between movements in interest rates and movements in reserves should be observable. The fact that it mostly is not frames much of the theoretical and empirical analysis that follows in this chapter.

Second, if the interest rate that the central bank is setting is the relative price associated with an asset that is substitutable for other assets that the public holds, at least in principle including real capital, but the central bank does not itself normally hold claims to real capital, the cumulative process triggered by whatever policy-induced departures of its policy interest rate from "normal" do occur will involve arbitrage-like asset and asset-liability substitutions by the banks and the nonbank public. Unless the marginal product of capital immediately responds by moving into conformity with the vector of other asset returns that follow from the central bank's implementation of policy-including the asset whose return comprises the policy interest rate that the central bank is setting-these portfolio substitutions should also, at least in principle, be observable. These private-sector asset and liability movements likewise feature in the theoretical analysis in this chapter, though not in the empirical work presented here.

\footnotetext{
${ }^{10} \mathrm{McC}$ allum also argued that if the marginal benefit to holding money (from reduced transactions costs) increases with the volume of real economic activity, then the model is properly "monetary" in yet a further way: in principle the "IS curve" should include an additional term - that is, in addition to the real interest rate and the expected future level of output-reflecting the difference between the current money stock and what households and firms expect the money stock to be in the future. His empirical analysis, however, showed no evidence of a statistically significant effect corresponding to this extra term in the relationship. Bernanke \& Blinder (1988) had earlier offered a model in which some quantitative measure of monetary policy played a role in the IS curve, but there the point was to incorporate an additional effect associated with credit markets and lending conditions, not the demand for deposit money.
} 


\section{The Traditional Understanding of "How They Do That"}

The traditional account of how central banks go about setting a short-term interest ratethe staple of generations of "money and banking" textbooks - revolves around the principle of supply-demand equilibrium in the market for bank reserves. The familiar Figure 5 plots the quantity of reserves demanded by banks, or supplied by the central bank, against the difference between the market interest rate on the asset taken to be banks' closest substitute for reserves and the rate (assumed to be fixed, perhaps but not necessarily at zero) that banks earn on their holdings of reserves. A change in reserve supply leads to a movement along a presumably downward-sloping reserve demand schedule, resulting in a new equilibrium with a larger (or smaller) reserve quantity and a lower (or higher) market interest rate for assets that are substitutable for reserves.

\subsection{The Demand for and Supply of Reserves, and the Determination of Market Interest Rates}

What is straightforward in this conception is that the reserves held by banks, on deposit at the central bank (or, in some countries' banking systems, also in the form of currency), are a liability of the central bank, and that the central bank has a monopoly over the supply of its own liabilities and hence can change that supply as policymakers see fit. What is less obvious, and in some aspects specific to the details of individual countries' banking systems, is why banks hold these central bank liabilities as assets in the first place, and why banks' demand for them is negatively interest elastic.

Four rationales have dominated the literature on banks' demand for reserves. First, in many countries-including the United States, countries in the Euro-area, and Japan—banks are required to hold reserves at the central bank at least in stated proportions to the amounts of some or all kinds of their outstanding deposits. ${ }^{11}$ Second, banks' role in the payments mechanism regularly requires them to execute interbank transactions; transfers of reserves held at the central bank are often the most convenient way of doing so. In some countries (Canada, for example), banks are not required to hold any specific amount or proportion of reserves at the central bank but they are required to settle certain kinds of transactions via transfers of balances held at the central bank. ${ }^{12}$ In other countries (again, the United States, for example), banks enter into explicit contracts with the central bank specifying the minimum quantity of reserves that they will hold, at a below-market interest rate, in

\footnotetext{
${ }^{11}$ As of 2009, reserve requirements in the United States were 3 percent on net transactions balances in excess of $\$ 10.3$ million and up to $\$ 44.4$ million (for an individual bank), 10 percent on transactions balances in excess of $\$ 44.4$ million, and 0 on non-transactions accounts (like time deposits) and eurocurrency liabilities, regardless of amount. In the Euro-system, reserve requirements were 2 percent on all deposits with term less than two years, and 0 on all longer-term deposits. In Japan, reserve requirements ranged from 0.05 percent to 1.3 percent, depending on the type of institution and the volume of deposits.

${ }^{12}$ Canadian banks' net payment system obligations are settled at the end of each day through the transfer of balances held at the Bank of Canada. Any shortfalls in a bank's account have to be covered by an advance from the Bank of Canada, with interest normally charged at 25 basis points above the target overnight interest rate. (From April 2009 through the time of writing, with interest rates near zero, the charge has been at the target overnight rate.) See Bank of Canada (2009).
} 
exchange for the central bank's provision of settlement services. Third, banks also need to be able to satisfy their customers' routine demands for currency. In the United States, the currency that banks hold is included in their reserves for purposes of satisfying reserve requirements, and many U.S. banks' currency holdings are more than sufficient to meet their reserve requirements in full. ${ }^{13}$ Fourth, because the prospect of the central bank's defaulting on its liabilities is normally remote, banks may choose to hold reserves (deposits at the central bank and conceivably currency as well) as a nominally risk-free asset. Because other available assets are very close to being riskless in nominal terms, however, at least in economies with well developed financial markets whether this rationale accounts for any significant amount of banks' actual demand for reserves depends on whether the interest rate that banks receive on their reserve holdings is competitive with the market rates on those other assets.

Under each of these four reasons for banks to hold reserves, the resulting demand, for a given interest rate credited on reserve balances (which may be zero, as it is for currency), is plausibly elastic with respect to the market interest rates on other assets that banks could hold instead: With stochastic deposit flows and asymmetric costs of ending up over- versus under-satisfying the applicable reserve requirement (which takes the form of a weak inequality), a bank optimally aims, in expectation, to over-satisfy the requirement. But the margin by which it is optimal to do so clearly depends on the differential between the interest that the bank would earn on those alternative assets and the interest it earns on its reserve holdings. Standard models of optimal inventory behavior analogously imply negative interest elasticity for a bank's holdings of clearing balances to use in settling a stochastic flow of interbank transactions, as well as for its holdings of currency to satisfy customers' stochastic currency needs. Standard models of optimal portfolio behavior similarly render the demand for risk-free assets in total-and, depending on the relationship between the interest rate paid on reserves and the rates on other risk-free assets, perhaps the demand for reserves-negatively elastic to the expected excess return on either the market portfolio of risky assets or, in a multi-factor model, the expected excess return on the one risky asset that is most closely substitutable for the risk-free asset.

Under any or all of these rationales, therefore, banks' demand for reserves is plausibly elastic with respect to market interest rates, including especially the rates on whatever assets are most closely substitutable for reserves. By analogy to standard portfolio theory, a convenient way to formalize this short-run relationship between interest rates and reserves is through a demand system in which each bank allocates a portfolio of given size $L$ across three liquid assets: reserves that they hold at the central bank (or in currency), $R$; reserves that they lend or borrow in the overnight market, $F$; and government securities, $T$ :

\footnotetext{
${ }^{13}$ When currency held by banks is counted as part of banks' reserves, it is usually excluded from standard measures of currency in circulation. In the United States, as of mid-2007, banks' currency holdings totaled $\$ 52$ billion, while their required reserves were $\$ 42$ billion; but because some banks held more currency than their required reserves, only $\$ 35$ billion of the $\$ 52$ billion in currency held counted toward the satisfaction of reserve requirements.
} 


$$
\left(\begin{array}{c}
R_{t}^{d} \\
F_{t}^{d} \\
T_{t}^{d}
\end{array}\right)=L\left(\alpha+\mathbf{B r}_{\mathbf{t}}+\mathbf{e}_{\mathbf{t}}\right)=L\left[\left(\begin{array}{c}
\alpha^{R} \\
\alpha^{F} \\
\alpha^{T}
\end{array}\right)+\left(\begin{array}{ccc}
\beta^{R R} & -\beta^{R F} & -\beta^{R T} \\
-\beta^{R F} & \beta^{F F} & -\beta^{F T} \\
-\beta^{R T} & -\beta^{F T} & \beta^{T T}
\end{array}\right)\left(\begin{array}{c}
r_{t}^{R} \\
r_{t}^{F} \\
r_{t}^{T}
\end{array}\right)+\left(\begin{array}{c}
e_{t}^{R} \\
e_{t}^{F} \\
e_{t}^{T}
\end{array}\right)\right]
$$

where $\mathbf{r}_{\mathbf{t}}$ represents the vector of expected returns on the three assets and $\mathbf{e}$ is a vector of stochastic disturbances (which sum to zero). If at least two of these three assets expose the holder to some risk, and if the decision-maker choosing among them is maximizing an objective characterized by constant relative risk aversion, a linear homogeneous (of degree one) asset demand system of this form follows in a straightforward way and the Jacobean $\mathbf{B}$ is a function of the risk aversion coefficient and the covariance matrix describing the risky asset returns. $^{14}$

In standard portfolio theory, the risk in question is simply that associated with the respective expected returns that are elements of $\mathbf{r}$. In this application, the direct rate of return on reserves held is risk-free, as is the direct return on reserves lent in the interbank market (except perhaps for counterparty risk); the return associated with Treasury securities is not risk-free unless the security is of one-day maturity. In line with the discussion above, however, the additional consideration that makes lending in the interbank market also risky is that deposit flows are stochastic, and hence so is any given bank's minimum reserve requirement. For each bank individually, therefore, and also for the demand system in aggregate, holdings of both $F$ and $T$ bear risk. In a manner that is analogous to a standard asset demand system with one risk-free asset and two risky assets, therefore, the off-diagonal elements $-\beta^{R F}$ and $-\beta^{R T}$ imply that, all else equal, an increase (decrease) in either the market rate on interbank funds, or the return on government securities, would reduce (increase) the demand for reserves, giving rise to a downward-sloping reserve demand curve as a function of either the interbank rate or the Treasury rate. ${ }^{15}$

In the traditional view of monetary policy implementation, the rate paid on reserves $r^{R}$ is held fixed. ${ }^{16}$ By setting $r^{R}=0$, and eliminating the third equation as redundant given the other two (because of the usual "adding-up" constraints), it is possible to simplify the model, with no loss of generality, to

$$
\begin{gathered}
R_{t}^{d}=L\left(\alpha^{R}-\beta^{R F} r_{t}^{F}-\beta^{R T} r_{t}^{T}+e_{t}^{R}\right) \\
F_{t}^{d}=L\left(\alpha^{F}+\beta^{F F} r_{t}^{F}-\beta^{F T} r_{t}^{T}+e_{t}^{F}\right)
\end{gathered}
$$

For a fixed distribution of the size of liquid asset portfolios across individual banks, equations (3) and (4) also represent banks' aggregate demand for reserves held at the central

\footnotetext{
${ }^{14}$ See, for example, Friedman \& Roley (1987).

${ }^{15} \mathrm{~A}$ further distinction compared to standard portfolio theory is that some rationale for the decision-maker's risk-averse objective is necessary. The most obvious rationale in this setting arises from the penalties associated with failure to meet the minimum reserve requirement.

${ }^{16}$ As the discussion in Sections 3 and 4 below emphasizes, this assumption is not appropriate for central banks, like the ECB, that operate a "corridor" system under which setting $r^{R}$ is central to policy implementation. The fixed $r^{R}$ assumption is appropriate, at least historically, for the U.S., where the rate was fixed at zero until the payment of interest on excess reserves was authorized in 2008. Similarly, the BOJ began to pay interest on reserves only in 2008.
} 
bank and for interbank transfers of reserves. With the supply of reserves $R$ set by the central bank, and the net supply of overnight reserve transfers necessarily equal to 0 , this system of two equations then determines the two interest rates $r_{t}^{F}$ and $r_{t}^{T}$, for given values of the two shocks.

In its simplest form, the traditional view of monetary policy implementation is one in which the central bank supplies a fixed quantity of reserves, consistent with the vertical supply curve in Figure 5. Given a fixed reserve supply $R^{*}$, and net supply $F=0$ for interbank reserve transfers, the equilibrium market-clearing interbank rate is

$$
r_{t}^{F}=\frac{\alpha^{R}+e_{t}^{R}-\beta^{R T}\left(\beta^{F T}\right)^{-1}\left(\alpha^{F}+e_{t}^{F}\right)-R^{*} L^{-1}}{\beta^{R F}+\beta^{R T}\left(\beta^{F T}\right)^{-1} \beta^{F F}} .
$$

To the extent that the central bank pursues a near-term interest rate target for interbank reserve transfers, however, it will typically vary the quantity of reserves in response to observed deviations of the market rate from the target. The simplest form of such an adjustment process is

$$
R_{t}^{S}=R^{*}+\Theta L\left(r_{t}^{F}-\bar{r}^{F}\right)
$$

where $\bar{r}^{F}$ is the target rate, the presence of $L$ reflects the central bank's realization that its actions need to be scaled according to the size of the market in order to be effective, and $R^{*}$, the "baseline" level of reserve supply that achieves $r_{t}^{F}=\bar{r}^{F}$ in expectation (that is, in the absence of any shocks) is

$$
R^{*}=L\left\{\alpha^{R}-\beta^{R T}\left(\beta^{F T}\right)^{-1} \alpha^{F}-\bar{r}^{F}\left[\beta^{R F}+\beta^{R T}\left(\beta^{F T}\right)^{-1} \beta^{F F}\right]\right\} .
$$

A positive value of the adjustment parameter $\Theta$ implies an upward sloping reserve supply curve, in contrast to the vertical curve depicted in Figure 5. With reserve supply now positively elastic according to (6), the equilibrium interbank rate is

$$
r_{t}^{F}=\frac{\Theta \bar{r}^{F}+\alpha^{R}+e_{t}^{R}-\beta^{R T}\left(\beta^{F T}\right)^{-1}\left(\alpha^{F}+e_{t}^{F}\right)-R^{*} L^{-1}}{\Theta+\beta^{R F}+\beta^{R T}\left(\beta^{F T}\right)^{-1} \beta^{F F}} .
$$

or equivalently, if the "baseline" reserve supply $R^{*}$ is set according to (7),

$$
r_{t}^{F}=\bar{r}^{F}+\frac{e_{t}^{R}-\beta^{R T}\left(\beta^{F T}\right)^{-1} e_{t}^{F}}{\Theta+\beta^{R F}+\beta^{R T}\left(\beta^{F T}\right)^{-1} \beta^{F F}} .
$$

The central bank's increasing (decreasing) the supply of reserves, while keeping fixed the rate that it pays on those reserves, therefore lowers (raises) the equilibrium interbank rate by an amount that depends, all else equal, on the interest elasticity of banks' reserve demand.

In parallel, the central bank's actions also determine the interest rate in the market for government securities. With fixed (vertical) reserve supply $R^{*}$, the Treasury rate is

$$
r_{t}^{T}=\beta^{F F}\left(\beta^{F T}\right)^{-1} \bar{r}^{F}+\left(\beta^{F T}\right)^{-1} \alpha^{F}+\frac{\left(\beta^{F T}\right)^{-1}\left(\beta^{R F}+\beta^{F F}\right) e^{R}}{\beta^{R F}+\beta^{R T}\left(\beta^{F T}\right)^{-1} \beta^{F F}} .
$$


If the central bank adjusts the supply of reserves in response to observed deviations of the interbank rate from its target, as in (6), the Treasury rate is instead

$$
r_{t}^{T}=\beta^{F F}\left(\beta^{F T}\right)^{-1} \bar{r}^{F}+\left(\beta^{F T}\right)^{-1} \alpha^{F}+\frac{\left(\beta^{F T}\right)^{-1}\left[\Theta e^{F}+\left(\beta^{R F}+\beta^{F F}\right) e^{R}\right]}{\Theta+\beta^{R F}+\beta^{R T}\left(\beta^{F T}\right)^{-1} \beta^{F F}}
$$

Hence the central bank has the ability to influence the Treasury rate as well, while keeping fixed the rate it pays on reserve holdings, by varying the supply of reserves. Once again the magnitude of this effect, for a given change in reserve supply, depends on the relevant interest elasticities including the elasticity of demand for reserves.

In a system in which banks face reserve requirements (again, the U.S., the Euro-system and Japan are all examples), this traditional account of the central bank's ability to set a short-term interest rate also embodies one obvious potential explanation for the observation that modern central banks are normally able to effect what are sometimes sizeable interest rate movements with little or no change in the supply of reserves: The central bank could be effecting those interest rate movements not by supplying more or less reserves, as in Figure 5, but by changing reserve requirements so as to shift banks' demand for reserves, as depicted in Figure 6. In the context of the model developed above, such an action by the central bank would correspond to an increase in $\alpha^{R}$ (and corresponding decrease in either $\alpha^{F}$ or $\alpha^{T}$, or both) in the demand system (2).

This explanation fails to fit the facts, however. In practice, central banks-with the notable exception of the People's Bank of China—do not generally vary reserve requirements for this purpose. ${ }^{17}$ Instead, they mostly change reserve requirements for other reasons, such as motivating banks to issue one kind of deposit instead of another, or reallocating the implicit cost of holding reserves (from the foregone higher interest rate to be earned on alternative assets) among different kinds of banking institutions. ${ }^{18}$ Indeed, when central banks change reserve requirements for such reasons they often either increase or decrease the supply of reserves in parallel—precisely in order to offset the effect on interest rates that would otherwise result. Similarly, some central banks normally report reserve quantities as adjusted to remove the effect of changes in reserve requirements. ${ }^{19}$

Instead of shifts in reserve demand, therefore, the traditional account of how central banks set interest rates has revolved around their ability to change the supply of reserves, against a fixed interest-elastic reserve demand schedule, as depicted in Figure 5. The question still remains, therefore, of how what normally are relatively small movements of reserve supply suffice to change the interest rates on market assets that exist and trade in far larger volume. Compared to the roughly $\$ 40$ billion of reserves that banks normally

\footnotetext{
${ }^{17}$ The Federal Reserve actively used reserve requirements as a monetary policy tool in the 1960s and 1970s, but by the mid-1980s they were no longer used for that purpose. See Feinman (1993b) for details and a history of the Federal Reserve's reserve requirements and their use in policy.

${ }^{18}$ The exclusion of time deposits from reserve requirements in the United States grew out of the Federal Reserve's effort, during the 1979-82 period of reliance on money growth targets, to gain greater control over the M1 aggregate (which included demand deposits but not time deposits).

${ }^{19}$ Both the Federal Reserve and the BOJ report reserve quantities in this way. There is no experience for the ECB, since as of the time of writing the ECB has never changed its 2 percent reserve requirement (nor the set of deposits to which it applies).
} 
hold in the United States, for example, or more like $\$ 60$ billion in reserves plus contractual clearing balances, the outstanding volume of security repurchase agreements is normally more than $\$ 1$ trillion. So too is the volume of U.S. Treasury securities due within one year, and likewise the volume of commercial paper outstanding. The small changes in reserve supply that move the federal funds rate move the interest rates on these other short-term instruments as well. Indeed, that is their purpose.

The conventional answer, following Tobin \& Brainard (1963), is that what matters for this purpose is not the magnitude of the change in reserve supply but the tightness of the relationships underlying reserve demand. ${ }^{20}$ In a model in which banks' demand for reserves results exclusively from reserve requirements, for example, a 10 percent requirement that is loosely enforced, and that applies to only a limited subset of banks' liabilities, would give the central bank less control over not only the size of banks' balance sheets but also the relevant market interest rates (on federal funds and on other short-term instruments too) than a 1/10 percent requirement that is tightly enforced and that applies to all liabilities that banks issue. In a model also including nonbank lenders, the central bank's control over the relevant interest rate is further impaired by borrowers' ability to substitute nonbank credit for bank loans.

Under this view of the interest rate setting process, the mechanism that "amplifies" the effect of what may be only small changes in reserve supply, so that they determine interest rates in perhaps very large markets, therefore rests on the tightness of the connection, or "coupling," between reserve demand and the demands for and supplies of other assets. Indeed, if $\beta^{R F}$ and $\beta^{R T}$ in (2) were both close to zero, implying a nearly-vertical reserve demand curve against either $r^{F}$ or $r^{T}$, then changes in the equilibrium overnight rate and/or the Treasury rate would require only infinitesimally small changes in reserves. Moreover, the volume of reserves, which is determined also by the $\alpha^{R}$ intercept in the reserve demand equation, would have no direct bearing on the linkages between markets. What is required for changes in the equilibrium overnight rate to affect other market interest rates is the assumption that overnight funds are substitutable, in banks' portfolios, for other assets such as government bonds-in the model developed above, that $\beta^{F T}<0$; if not, then the overnight market is effectively "decoupled" from other asset markets, and the central bank's actions would have no macroeconomic consequences except in the unlikely case that some private agents borrow in the overnight market to finance their expenditures. ${ }^{21}$

The relevant question, therefore, is whether, and if so to what extent, changes in market institutions and business practice over time have either strengthened or eroded the linkages between the market for bank reserves and those for other assets. In many countries the relaxation of legal and regulatory restrictions, as well as the more general evolution of the financial markets toward more of a capital-markets orientation, has increased the scope for nonbank lending institutions (which do not hold reserves at the central bank at all) to play a larger role in the setting of market interest rates. Within the traditional model as depicted in Figure 5, such a change would presumably weaken the coupling between market interest

\footnotetext{
${ }^{20}$ The point is made more explicitly in the "money multiplier" example given in Brainard (1967).

${ }^{21}$ See, for example, Friedman (1999) and Goodhart (2000) on the concept of "decoupling" of the interest rate that the central bank is able to set from the rates that matter for private economic activity.
} 
rates and the central bank's supply of reserves-because these other institutions' demands for securities (though not for interbank reserve transfers) is part of the supply-demand equilibrium that determines those rates, even though these institutions' portfolio choices are not directly influenced by the central bank's actions. Similarly, advances in electronic communications and data processing have widened the range and increased the ease of market participants' transaction capabilities, sometimes in ways that diminish the demand for either currency or deposits against which central banks normally impose reserve requirements. ${ }^{22}$ Within the traditional model, these developments too would presumably erode the tightness of the "coupling" that would be needed to enable central banks to exert close control over market interest rates using only very small changes in reserves.

\subsection{The Search for the "Liquidity Effect": Evidence for the United States}

Beginning in the early 1990s, an empirical literature motivated by many of these concerns about the traditional model of central bank interest rate setting sought not only to document a negatively interest elastic reserve demand but also to find evidence, consistent with the traditional view of policy implementation as expressed in Figure 5, that changes in reserve supply systematically resulted in movements in the relevant interest rate. Initially this inquiry focused primarily on the United States, but in time it encompassed other countries' experience as well. Part of what gives rise to the issues addressed in this chapter is that, both in the U.S. and elsewhere, evidence of the effect of reserve changes on interest rates along these lines has been difficult to establish. Further, as Figure 1 above suggests for the U.S., since the early 1990s what evidence there was has become substantially weaker; the response of interest rates to reserves, as measured by conventional time series methods, has all but disappeared in recent years. For these reasons, recent research aimed at understanding the link between reserves and interest rates has increasingly shifted to a more fine-grained analysis of day-to-day policy implementation, with careful attention to the institutional environment.

One of the key initial studies of the liquidity effect was Leeper \& Gordon (1992). Using distributed lag and vector autoregression (VAR) models, they were able to establish that exogenous increases in the U.S. monetary base (and to a lesser extent the M1 and M2 monetary aggregates including deposit money) were associated with subsequent declines in the federal funds rate, consistent with a "liquidity effect." ${ }^{23}$ Their results were fragile, however: The negative correlation that they found between the interest rate and movements of the monetary base appeared only if such variables as output and prices, and even lagged interest rates, were excluded from the estimated regressions; their efforts to isolate an effect associated with the unanticipated component of monetary base growth showed either no correlation or even a positive one; and their findings differed sharply across different subperiods of the 1954-90 sample that they examined.

\footnotetext{
${ }^{22}$ See again Friedman (1999).

${ }^{23} \mathrm{~A}$ prior literature had focused on the relationship between interest rates and measures of deposit money like M1 and M2, but especially over short horizons it is not plausible to identify movements of these "inside" monetary aggregates with central bank policy actions. See Thornton (2001a) and Pagan \& Robertson (1995) for reviews of this earlier literature.
} 
These results clearly presented a challenge to the traditional view of monetary policy implementation. In response, numerous other researchers conducted further attempts to establish empirically the existence, with a practically plausible magnitude, of the liquidity effect. Given the fact that central banks normally supply whatever quantity of currency the market demands, however, most of these efforts focused on narrowly defined reserves measures rather than the monetary base (or monetary aggregates) as in Leeper and Gordon's original analysis. ${ }^{24}$ With the change to a focus on reserves, this effort was somewhat more successful.

An early effort along these lines was Christiano \& Eichenbaum (1992), followed in time by its sequels, Christiano \& Eichenbaum (1995) and Christiano, Eichenbaum and Evans (1996a, 1996b, 1999). Using VAR methods, and U.S. data for 1965Q3-1995Q2, they found, consistent with the traditional view, that shocks to nonborrowed reserves generated a liquidity effect. The results reported in Christiano et al. (1999), for example, showed an interest rate movement of approximately 40 basis points in response to a $\$ 100$ million shock to nonborrowed reserves. ${ }^{25}$ Just as important, they showed that no liquidity effect was associated with shocks to broader aggregates, like the monetary base or M1, on which Leeper and Gordon had focused.

Strongin (1995) employed a different empirical strategy, exploiting the fact that because many of the observed changes in the quantity of reserves merely reflect the central bank's accommodation of reserve demand shocks, even conventionally orthogonalized changes in nonborrowed reserves would fail to identify the correct exogenous monetary policy impulse. He therefore proposed using instead a structural VAR with an identification scheme motivated by the Federal Reserve's use at that time of a borrowed reserves operating procedure, which relied on the mix of borrowed and nonborrowed reserves as the relevant policy indicator. Applying this approach to monthly U.S. data for 1959-1991, he likewise found a significant liquidity effect. ${ }^{26}$ Bernanke \& Mihov (1998) subsequently extended Strongin's analysis to allow for changes over time in the Federal Reserve's operating procedures. ${ }^{27}$ They found a large and highly significant impact of monetary policy on the federal funds rate in their preferred just-identified biweekly model. However interpreting this response in terms of the impact of reserves per se on the interest rate is complicated by the fact that the policy shock in their model is, in effect, a linear combination of the policy indicators included in their structural VAR, which includes total reserves, nonborrowed reserves, and the funds rate itself. $^{28}$

\footnotetext{
${ }^{24}$ Christiano et al. (1999) provided a comprehensive survey of the early years of this large literature; the summary given below here is therefore highly selective.

${ }^{25}$ This estimate is inferred from the results that Christiano et al. reported on p. 84 and in Figure 2 on p. 86.

${ }^{26}$ Because the monetary policy variable in Strongin's specification is the ratio of nonborrowed reserves to total reserves, it is difficult to infer the magnitude of the liquidity effect as a function of the dollar amount of nonborrowed reserves. Christiano et al. (1996b) reported a set of results using an identification scheme similar to Strongin's but in which nonborrowed reserves enter in levels, rather than as a ratio; they found results that are quantitatively very close to those based on defining the policy innovation in terms of shocks to nonborrowed reserves.

${ }^{27} \mathrm{See}$, for example, Meulendyke (1998) for an account of the operating procedures the Federal Reserve has employed over the years.

${ }^{28}$ Another empirical investigation of the liquidity effect in the context of the borrowed reserves operating
} 
After this initial burst of activity in the 1990s, however, the attempt to provide empirical evidence of the liquidity effect using aggregate time series methods largely ceased. One important reason was the continual movement of the major central banks away from quantity-based operating procedures, toward a focus on explicit interest rate targets. ${ }^{29}$ In the United States, the Federal Reserve's public announcements of the target for the federal funds rate, which began in February 1994, finally erased any lingering pretense that it was setting a specific quantity of reserves in order to implement its policy. The Bank of Japan had already adopted the practice of announcing a target for the call loan rate before then. Although the ECB in principle included a target for a broad monetary aggregate as one of the two "pillars" of its policy framework, since inception it had characterized its monetary policy in terms of an explicitly announced interest rate target. As Strongin had pointed out, when the central bank is fixing a short-term interest rate at some given level, part of the observed movement in the supply of reserves - arguably a very large part-reflects not any independent movement intended to move interest rates but rather the attempt to accommodate random variations in reserve demand so as to keep the chosen interest rate from changing. ${ }^{30}$ Hence simply using a regression with the interest rate as dependent variable and a measure of reserves as an independent variable is at best problematic.

At the same time, further empirical research was casting additional doubt on the existence of a liquidity effect, at least as conventionally measured. Pagan \& Robertson (1995), for example, criticized the robustness of the conventional VAR results along a number of dimensions. $^{31}$ For purposes of the questions at issue in this chapter, the most important aspect of their work was the finding that the effects of changes in nonborrowed reserves on the federal funds rate had diminished over time, and had, at the time of their writing, already become statistically insignificant. In the model that they took to be most representative, for example, a 1 percent change in nonborrowed reserves_again, about $\$ 400$ million-resulted in an estimated impact of only 13 basis points on the interest rate when the model was estimated on data from 1982 through 1993. As they pointed out, these findings, if taken at face value, would imply that most of the observed variation in the federal funds rate is not due to any action by the central bank.

Like Pagan and Robertson, Christiano et al. (1999) reported a quantitatively smaller liquidity effect in the 1984-1994 sample than earlier on, although they emphasized that the results remained marginally significant. Extending the sample through 1997, however, Vilasuso (1999) found no evidence at all of a liquidity effect in the post-1982 sample in VAR specifications similar to those of either Strongin or Christiano et al. Carpenter \& Demiralp (2008) also found no liquidity effect in the 1989-2005 sample using conventional structural VAR methods. ${ }^{32}$ The evidence of disappearance of the liquidity effect over time,

procedure was by Thornton (2001a).

${ }^{29}$ As described by Meulendyke (1998), and documented more particularly by Hanes (2004), this shift was in part precipitated by the virtual disappearance of discount window borrowing in the years following the 1984 failure of Continental Illinois.

${ }^{30} \mathrm{~A}$ much earlier literature had long emphasized this point; see, for example, Roosa (1956).

${ }^{31}$ Pagan \& Robertson (1998) further criticized the VAR literature on the liquidity effect on the grounds that it relies on weak identifying assumptions.

${ }^{32}$ Carpenter \& Demiralp (2008) showed that the level of contractual clearing balances held at the Federal 
as successive changes in policy practice took effect, is consistent with the proposition that changes in reserves have played a diminishing role in the Federal Reserve's implementation of monetary policy.

Partly in response to these findings, Hamilton (1996, 1997, 1998) adopted a different approach to empirically investigating the liquidity effect, using daily data and taking account of the fact that in the United States, in most other systems in which banks face explicit minimum reserve requirements, the time unit for satisfaction of these requirements is not a single day but an average across a longer time period: two weeks in the U.S., and one month in both the Eurosystem and Japan. Using U.S. data from March 1984 to November 1990, Hamilton (1996) found that there was some, but not perfect, substitutability of banks' demand for reserves across different days within the two-week reserve maintenance period, thereby establishing at least some form of negative interest elasticity of demand for reserves on a day-to-day basis, and hence at least some empirically based foundation by which the traditional view centered on changes in the supply of reserves might be the central bank's way of implementing changes in the policy interest rate.

Hamilton (1997) then directly assessed the liquidity effect over the 1989-91 period, using econometric estimates of the Federal Reserve's error in forecasting Treasury balancesand hence that part of the change in reserve supply that the Federal Reserve did not intend to have occur - to estimate the interest rate response to exogenous reserve changes. He concluded that the liquidity effect measured in this way was sizeable, but only on the final day of the maintenance period: a $\$ 1$ billion unintended decrease in reserve supply, on that final day, would cause banks to borrow an additional $\$ 560$ million at the discount window, and the tightness due to the remaining $\$ 440$ million shortfall in nonborrowed reserves would cause a 23 basis point movement in the market-clearing federal funds rate. ${ }^{33}$ No statistically significant response of the interest rate to changes in reserves was observed on the other days of the maintenance period.

Even this finding of 23 basis points per $\$ 1$ billion of independent (and unanticipated) change in the quantity of reserves is based, however, on a very specific conceptual experiment that bears at best only loose correspondence to how central banks carry out monetary policy: in particular, a one-time unanticipated change in reserves on the final day of the reserve maintenance period. In an effort to assess more plausibly the volume of reserve additions or withdrawals necessary to change the target federal funds rate on an ongoing basis, Hamilton reported an illustrative (and admittedly speculative) calculation in which he assumed that a change in reserves on the final day of the maintenance period has the same effect, on a two-week average basis, as a comparable change distributed evenly over the 14 days of the maintenance period: in other words, for purposes of influencing the interest rate, a $\$ 1$ billion addition (or withdrawal) of reserves on the single final day would be the same as a $\$ 71$ million addition (or withdrawal) maintained steadily over the 14 days.

Reserve responded inversely to innovations in the federal funds rate. However this result does not directly bear on the liquidity effect as the term has been used in the literature, since it pertains to the effect of an interest rate shock on a reserve quantity, not vice versa.

${ }^{33}$ Hamilton did not test for asymmetries. Because of the limited amount of borrowed reserves, however, at the very least the effect that he estimated would be limited in the case of an unanticipated increase in reserve supply. 
Any calculation of interest rate effects based on this assumption would represent an upper bound, since on the last day of the maintenance period a bank has no ability to offset any unplanned reserve excesses or deficiencies on subsequent days. Even so, the resulting calculation is instructive. It indicates that in order to move the two-week average of the federal funds rate by 25 basis points, the Federal Reserve would have to maintain reserves, throughout the two weeks, at a level $\$ 1.1$ billion higher or lower than what would otherwise prevail. ${ }^{34}$ Applied to the 4 percentage point increase in the target federal funds rate that occurred between mid-2004 and mid-2006 (see again Figure 1), the implication is that the Federal Reserve would have had to reduce the quantity of reserves by nearly $\$ 18$ billion to achieve this movement - a huge amount compared to the roughly $\$ 45$ billion of nonborrowed reserves that U.S. depository institutions held during that period, and clearly counter to actual experience. Further, since this calculation based on applying Hamilton's finding for the last day of a maintenance period to the average for the two weeks represents an upper bound on the size of the effect on the interest rate, it therefore gives a lower bound on the size of reserve change needed to achieve any given interest rate change. Subsequent research covering more recent time periods has produced even smaller estimates of the liquidity effect. Using 1992-94 data, Hamilton (1998) estimated a liquidity effect of only 7 basis points per $\$ 1$ billion change in nonborrowed reserves (compared to 23 basis points in the earlier sample), thereby implying correspondingly larger reserve changes needed to achieve comparable movements in the interest rate.

In work closely related to Hamilton's, Carpenter and Demiralp (2006a, 2006b) used the Federal Reserve's internal forecasts of the shocks to reserve demand to estimate the error made in offsetting these shocks. ${ }^{35}$ Their estimate of the liquidity effect, based on U.S. data for 1989-2003, was smaller than either of Hamilton's previous estimates: in Carpenter \& Demiralp (2006b), an impact on the interest rate of only 3.5 basis points in the federal funds rate (measured relative to the Federal Reserve's target rate) for a $\$ 1$ billion increase or decrease in nonborrowed reserves on the final day of the maintenance period. Taking this estimate at face value (and also holding to the model's linearity), Carpenter and Demiralp's finding implied that the reserve withdrawal needed to effect the 400 basis point increase in the federal funds rate during 2004-6 would have been $\$ 114$ billion-nearly three times the amount of reserves that banks in the aggregate then held.

\subsection{The Search for the "Liquidity Effect": Evidence for Japan and the Euro-system}

Analogous questions about the existence and strength of the liquidity effect have naturally arisen in the context of other central banks as well. Research on this issue has been less extensive for either Japan or the Euro-system, however. In particular, there have been few VAR analyses using either monthly or quarterly data.

The analysis for Japan that is most comparable to the work on the U.S. discussed above

\footnotetext{
${ }^{34}$ Hamilton appeared to place a different interpretation on this upper-bound calculation, but the interpretation here, in terms of two-week averages for both the interest rate and the reserve quantity, seems what is logically implied.

${ }^{35}$ This procedure not only simplified the estimation but also sidestepped a criticism of Hamilton's approach made by Thornton (2001b).
} 
is that of Jinushi et al. (2004), who analyzed the interactions between financial flows and banking system reserves along the lines of Christiano et al. (1996a), using quarterly data for 1970-1999. Although Jinushi et al. documented a tendency for the Bank of Japan to accommodate shocks to reserve demand, they were unable to detect a statistically significant response of the call loan rate (measured relative to the BOJ's target) to shocks to total reserves. Indeed, in their results a positive reserve supply shock on average increased the spread between the call rate and the BOJ's target, although the response was not statistically significant at the 5 percent level.

By contrast, Shioji (2000) reported a statistically significant inverse relationship between the Japanese monetary base and the call loan rate spread over target, based on a structural VAR estimated using monthly data for 1977-1995. His results do not speak directly to the presence of a classic liquidity effect, however, in that he estimated the effect of an interest rate shock on the monetary base, not vice versa. Nonetheless, Shioji's results are consistent with the existence of a downward-sloping reserve demand schedule, so that interest rate reductions (increases) would require a larger (smaller) supply of high-powered money.

The first paper to look for daily liquidity effects in Japan is that of Hayashi (2001). Using methods very similar to those devised by Hamilton, Hayashi analyzed the response of the call loan rate to unforecastable changes in cash (i.e., the volume of banknotes on the BOJ's balance sheet) and Treasury balances. He found a statistically significant but economically negligible effect of reserve supply shocks: an exogenous $¥ 100$ billion increase (decrease) in reserve balances on the penultimate day of the one-month maintenance period triggered, on average, only a 0.5 basis point decrease (increase) in the call loan rate compared to the BOJ's target. Hayashi's parameterization did not allow the liquidity effect to be estimated on the final day of the reserve maintenance period, when the effect is presumably stronger.

Uesugi (2002) extended Hayashi's work using a somewhat broader definition of reserve shocks, and adopting a specification that allowed for the estimation of the liquidity effect on the final day of the maintenance period. He reported a statistically significant liquidity effect, with an exogenous $¥ 100$ billion increase (decrease) in reserve balances on the final day of the one-month maintenance period producing a 2.3 basis point decrease (increase) in the call loan rate spread. Like Hamilton, Uesugi detected no statistically significant effect on preceding days. Even so, while these results are considerably larger than Hayashi's estimates, taken at face value they imply that in order to move the call rate by 25 basis points the Bank of Japan would have had to implement a $¥ 1.1$ trillion change in reservesat a time when the total level of bank reserves in Japan was approximately $¥ 3-4$ trillion, and the level of excess reserves was far smaller, typically between $¥ 2$ and $¥ 4$ billion. ${ }^{36}$ The liquidity effect estimated by Uesugi is far too small, therefore, to explain the BOJ's control over its target interest rate.

Despite the relatively brief history of the European Central Bank, at least two studies have examined the daily liquidity effect in the Euro-system. As is true for the U.S. and Japan, these studies have reported quantitatively small liquidity effects, and only on the

\footnotetext{
${ }^{36}$ These figures refer to the period prior to adoption of the BOJ's "quantitative easing" policy in 2001.
} 
last day (or in some cases two days) of the reserve maintenance period.

Würtz (2003) developed a detailed empirical model of high-frequency reserve demand in the Euro-system, which allowed him to assess the strength of the liquidity effect. His approach was to regress the spread of the EONIA rate relative to the ECB's target on various measures of reserve pressure, including the magnitude of banks' recourse to the ECB's deposit and lending facilities, the daily reserve surplus, and the cumulative reserve surplus over the maintenance period, together with a wide range of control variables and calendar dummies. Because the ECB generally refrains from undertaking "defensive" open market operations between regularly scheduled refinancing operations, the observed within-week fluctuations in these reserve-centered measures plausibly reflect exogenous supply variations, rather than the central bank's endogenous responses. Würtz therefore included as regressors the various liquidity measures themselves, rather than forecast errors like those used in studies based on Hamilton's methodology. With regard to the liquidity effect, Würtz's main finding was that daily fluctuations in the reserve surplus had only a trivial effect on the EONIA spread over target: 0.23 basis points for a $€ 10$ billion change in the daily reserve surplus (current account balances less required reserves).

Ejerskov et al. (2003) used a similar regression approach to examine the liquidity effect in the Euro-system, but distinguished more sharply than Würtz between the effects of reserve imbalances occurring after the last of the ECB's weekly main refinancing operation (MRO) for the maintenance period from those occurring prior to the last MRO. They found that $\mathrm{a} € 1$ billion reserve imbalance on the last day of the maintenance period would translate into a 4 basis point change in the EONIA spread-again a statistically significant but economically negligible effect. ${ }^{37}$

The broader issue that all of these studies raise-not just those for the Euro-system and Japan, but for the U.S. as well-is whether the liquidity effect that they are measuring, even if taken at face value, plausibly corresponds to the traditional story of how central banks set interest rates as illustrated in Figure 5. The interest rate variable in most of these analyses is not the level of the central bank's policy interest rate, as plotted on the figure's vertical axis, but rather the difference between that interest rate and the central bank's target. (Further, the quantity of reserves in most of them is not the overall reserve quantity, as plotted on the figure's horizontal axis, but instead the difference between that quantity and the reserves that the central bank presumably would have supplied if it had correctly foreseen the relevant shocks that in fact occurred.) In effect, the action most of concern-changes in the supply of reserves made deliberately for the purpose of moving the interest rate when the target rate changes, as illustrated in Figure 5-is omitted from the empirical phenomena used to draw the key inferences in this line of research.

The operative presumption, therefore, is that the impact of other reserve changes, not associated with moving the interest rate in step with a changed target (and not even intended by the central bank), is informative also for the part of the variation that the empirical strategy excludes from the observed data. Even if it is, the resulting estimates for the most part do not resolve the puzzle of the observed ability of these central banks to move the market interest rate with only trivially small changes in the supply of reserves.

\footnotetext{
${ }^{37}$ Bindseil \& Seitz (2001) reported similar results for an earlier period.
} 


\section{Observed Relationships between Reserves and the Policy Interest Rate}

The empirical literature of the liquidity effect, reviewed in Section 3 immediately above, makes the phenomenon highlighted at the outset of this chapter all the more of a puzzle. According to the estimates that most researchers have found, the impact on the central bank's policy interest rate of changes in the supply of bank reserves is extremely small-if it is present at all. Yet central banks do move their policy interest rates over time, sometimes across a large range. According to the liquidity effect literature, these changes should require very large changes in reserves. But as Figures 1-4 above illustrate for the United States, the changes in reserves that typically accompany movements in the policy interest rate are not only not large, often they are not present at all.

\subsection{Comovements of Reserves and the Policy Interest Rate: Evidence for the United States, the Euro-system and Japan}

The absence of a clear relationship between interest rate movements and changes in the supply of reserves is not merely a feature of the United States, or a consequence of some unique aspect of how the Federal Reserve System implements monetary policy. There is no such clear relationship in Europe or Japan either. Figure 7 shows the comovement between each system's reserves and policy interest rate since 1994 (when the Federal Reserve first started announcing its target federal funds rate) for the U.S, since the inception of the European Central Bank in 1999, and since 1992 for Japan-in each case ending at mid 2007, just before the onset of the 2007-9 financial crisis. ${ }^{38}$ At a visual level, the suggestion of some systematic relationship is perhaps most evident in panel (a), for the U.S. Episodes in which nonborrowed reserves (plotted here on a biweekly-average basis) and the Federal Reserve's target federal funds rate were at least moving in opposite directions, as the traditional theory with a negative interest elasticity of demand for reserves would imply, include the periods of rising interest rates in 1994-5, 1999-2000 and 2005-6, and the period of falling interest rates in 2001-3. But reserves were contracting on average during 1995-6, when interest rates were falling, and they were growing on average when interest rates were rising in 1994. Further, aside from the downward trend of the 1990s, which had nothing particular to do with interest rate movements one way or the other (required reserves were steadily shrinking during this period as banks introduced "sweep" accounts that routinely shifted customers' funds into non-reservable deposits at the end of each day), the change in reserves that accompanied each of these episodes of changing monetary policy was small in any case. For the entire period, the correlation between reserves and the interest rate is just -0.06 in levels, and -0.14 in the changes.

Europe and Japan have each exhibited even more irregular relationships. As panel (b) shows, in the Euro-system reserves have increased more or less continuously since the es-

\footnotetext{
${ }^{38}$ Japan's sample period was chosen to begin well past the BOJ's November 1988 announcement of a "new scheme for monetary control," which completely liberalized interbank market rates and likely affected the relationship between the call rate and reserve demand. See Okina et al. (2001).
} 
tablishment of the ECB. By contrast, the ECB's main refinancing rate rose in 2000, declined in 2001 and again in late 2002 and early 2003, and then rose again beginning in late 2005 . The correlation in monthly data between reserves and the interest rate for the Euro-system is -0.29 in levels, and 0.29 in the changes. Panel (c) shows yet another completely different pattern for Japan. There the Bank of Japan's uncollateralized call loan rate dropped enormously throughout 1992-5, with little change in BOJ current account balances. The small further drop in the interest rate in 1998 occurred with only a tiny increase in reserve balances, although these balances did shrink visibly at the time of the small interest rate rise in 2000. During most of 2001-5 the call loan rate was at the zero lower bound, while reserve balances first increase enormously and then returned approximately to the trend line extrapolated from the beginning of the decade. For Japan, the correlation in monthly data is -0.44 in levels and -0.02 in the changes.

Figure 8 shows the relationship_-in this case, actually the lack thereof-between reserve changes policy interest rate changes in each system on a more precise time scale. In each panel the 0 point corresponds to the time period within which a change in the policy interest rate has occurred, and the successive negative and positive integers indicate the number of time periods before and after the interest rate change. For each country, the time unit used corresponds to the length of the reserve maintenance period: biweekly in the U.S., and monthly in the Euro-system and Japan. For each time lead or lag, in each country, the figure shows the average movement of excess reserves (total reserves supplied minus required reserves, are predetermined for the maintenance period in the U.S. and the Euro-system, and partly predetermined in Japan), together with the associated 90 percent confidence intervals, corresponding to all movements in the policy interest rate within the designated sample, scaled to express the reserve change per 1 percentage point increase in the interest rate.

There is no evidence of any systematic movement of excess reserves before, simultaneously with, or after movements in the policy interest rate in either the U.S. or the Eurosystem, and only the barest hint of any such evidence in Japan. In panel (a), for the U.S., the average reserve changes are negative in all four biweekly periods leading up to a move in the target federal funds rate, but only by tiny amounts (between 0 and $\$ 100$ million). From the time of the interest rate movement through four biweekly periods later, the average changes are sometimes negative and sometimes positive, and again very small. All nine average changes lie well within the 90 percent confidence range around zero. In panel (b), for the Euro-system, the average reserve changes in the three months prior to a move in the ECB's main financing rate are positive (the opposite of the U.S. pattern), while thereafter they are of mixed sign. As is the case in the U.S. data, however, all seven averages are very small — in each case roughly within $\pm € 0-100$ million - and all are well within the 90 percent confidence range around zero. In panel (c), for Japan, there is no consistency in the averages for the months either before or after a move in the BOJ's target call loan rate. Here too, all of the monthly averages are small (within $\pm ¥ 0-20$ billion). Only one, the negative reserve change of about $¥ 20$ billion in the month immediately preceding the move in the policy rate, is statistically distinguishable from zero with 90 percent confidence, and that only barely so. 


\subsection{The Interest Elasticity of Demand for Reserves: Evidence for the U.S., Europe and Japan}

Viewed from the perspective of the traditional theory of how central banks implement monetary policy, the two bodies of evidence summarized above present a striking contrast. The findings of the empirical liquidity effect literature mostly indicate that changes in the supply of reserves induce only very small movements in interest rates. The implication is that banks' demand for reserves is highly interest elastic: the empirical counterpart to the downward sloping schedule shown in Figure 5 is nearly horizontal. By contrast, the comovement of reserves and central bank policy interest rates over time, as shown in Figure 7, and also more fine-grained event studies based on data for individual reserve maintenance periods, as shown in Figure 8, indicate that small changes in reserve supply are apparently sufficient to induce quite large movements in interest rates-in other words, reserve demand is highly inelastic with respect to interest rates, or nearly vertical.

Table 1 shows estimates of banks' demand for reserves, in the United States, for the sample spanning 1990 to mid 2007 and for three sub-samples within that period. ${ }^{39}$ In order to abstract from the progressive shrinkage in required reserves associated with the introduction of sweep accounts and other such non-policy-related influences, the estimated equation focuses on (the log of) banks' excess reserves. (Moreover, in the U.S. banks meet reserve requirements on a lagged basis-required reserves for each two-week maintenance period are based on banks' average deposits outstanding during the previous two weeksso that required reserves are predetermined on a biweekly basis anyway. ${ }^{40}$ ) The righthand-side variables of central interest are the current and first-lagged values of the target federal funds rate, which is plausibly independent of the disturbance to reserve demand: if banks' demand for reserves during the two-week period is greater than expected, there is no reason to think the Federal Reserve would therefore change its target interest rate in response. Hence ordinary least squares is a satisfactory estimator for this purpose. The regression also includes two lags of the dependent variable. The table reports estimates of all coefficients, together with the associated Newey-West standard errors.

None of the coefficient estimates for the individual interest rate terms is significantly different from zero, even at the 10 percent level, nor is the sum of the two interest rate coefficients significant, for any of the four sample periods. The only period for which there is even weak evidence of an economically meaningful interest elasticity is the time before February 1994, when the Federal Reserve first began publicly announcing its target for the federal funds rate. For this period only, the coefficient estimates (which are close to significance at the 10 percent level) indicate that a 1 percentage point increase in the target federal funds rate leads banks to reduce their holdings of excess reserves by 38 percent — but only

\footnotetext{
${ }^{39}$ The sample begins in 1990 because the Federal Reserve's use of a policy procedure based on targeting borrowed reserves had ended by then (and discount window borrowing had shrunk to virtually zero). As above, the reason for ending the sample at mid 2007 is to exclude the 2007-9 financial crisis. Observations associated with Y2K (the 1999-2000 yearend) and 9/11/2001 are omitted.

${ }^{40}$ Given that required reserves are predetermined, using excess reserves as the dependent variable is equivalent to using total reserves instead and including required reserves as a regressor with coefficient constrained to equal one.
} 
within the current maintenance period. Two weeks later, according to the estimated coefficients, they almost exactly reverse the movement. Hence the level of the interest rate does not matter outside of a single two-week period. Since this effect is visible in the data only before February 1994, the most likely interpretation is not that banks' reserve demand was interest elastic in a meaningful way, but that the Federal Reserve was reducing reserve supply — which, given the predetermined required reserves, necessarily reduces excess reserves within the maintenance period-as a way of signaling an unannounced increase in its target interest rate. Once the Federal Reserve started publicly announcing its interest rate target, such actions were unnecessary. Neither in the pre-1994 experience nor after, therefore, is there any indication of a negative interest elasticity of demand for reserves. ${ }^{41}$

Table 2 presents analogous estimates for the Euro-system, for two different measures of banks' reserve demand: excess reserves, as in Table 1 for the U.S., and the sum of excess reserves and banks' deposits with the ECB's standing deposit facility. The funds that banks deposit at this ECB facility do not count towards satisfying their statutory reserve requirements, but they are automatically converted to reserves again on the next business day and they are similar to reserves in the sense that they represent another dimension along which banks can substitute between reserve-like assets and other assets like government or privately issued liquid securities. ${ }^{42}$ The interest rate is the ECB's main refinancing rate. In line with the Euro-system's reserve maintenance period, the data are monthly (and so there is no lagged value of the interest rate). The equations estimated over the sample beginning in mid 1999 include dummy variables for the first two months of 2002, when the Euro currency first went into circulation. The table also shows estimates for the same two equations beginning in March 2002.

For excess reserves, the interest elasticity estimated over the full 1999-2007 sample is negative, but very small and not significantly different from zero. For excess reserves plus ECB deposits, the estimated elasticity over this sample is statistically significant, but positive. For the sample beginning after the Euro currency went into use, the estimated elasticity is again positive, but it is very small for both reserves measures and far from statistical significance at any persuasive level. None of the four equations therefore indicates a meaningful negative interest elasticity.

Japan is the one system among the three for which there is systematic evidence of a negative interest elasticity of demand for reserves. Table 3 presents results, analogous to those described above, for an equation relating Japanese banks' holdings of excess reserves to the (log of the) BOJ's call loan rate. ${ }^{43}$ In all three sample periods shown the estimated

\footnotetext{
${ }^{41}$ By contrast, Carpenter \& Demiralp (2008) found that in the U.S., that banks' holdings of contractual clearing balances (held, at a zero interest rate, to compensate the Federal Reserve for payments services that it provides) are interest elastic. These contractual holdings adjust only slowly over time, however-at most a bank will renegotiate its holdings with the Federal Reserve once per quarter, and this gradualism is reflected in Carpenter and Demiralp's estimated impulse responses. This evidence therefore does not bear on the question of how the central bank implements changes in interest rates. Rather, as expected if the purpose is to return a roughly fixed dollar amount of compensation to the Federal Reserve, a higher market interest rate means that it is possible to achieve that goal while holding smaller balances.

${ }^{42}$ Moreover, banks have until 15 minutes before the close of business each day to decide whether to deposit excess reserves in the deposit facility.

${ }^{43}$ Using the log of the interest rate for Japan is appropriate because so much of Japan's experience, even
} 
interest elasticity is large, and it is significantly different from zero at the 1 percent level. For the sample period ending in early 1999-before the BOJ's adoption of its Zero Interest Rate Policy (ZIRP) - the estimated elasticity indicates that a reduction in the call rate from, say, 5 percent to 4 percent (a 20 percent log-reduction) would lead banks to increase their holdings of excess reserves by approximately 7 percent.

The results are very similar for the full 1992-2007 sample, with or without dummy variables included for the post-ZIRP period (March 1999 through the end of the sample) and the BOJ's Quantitative Easing Policy (March 2001 through March 2006). Panel (c) of Figure 9 plots the relationship between Japanese banks' excess reserves and the BOJ's call rate (both in logs) for the entire sample, using different symbols to distinguish observations in five respective time periods within the sample: pre-ZIRP, the ZIRP period, the brief period when the target call rate was 0.25 percent, the QEP period, and post-QEP. The negative elasticity is readily visible. By contrast, as panels (a) and (b) show, there is no such relationship for the U.S. or the Euro-system. ${ }^{44}$

\section{How, Then, do Central Banks Set Interest Rates?}

The two key empirical findings documented above - the absence of a negative interest elasticity of banks' demand for reserves (in the United States and the Euro-system), and the absence also of significant movement in the supply of reserves when the central bank's policy interest rate changes (in the U.S., the Euro-system and Japan)—present major challenges to the traditional view of how central banks set interest rates as represented in Figure 5. If reserve demand is interest inelastic, then not just each individual bank but the market as a whole is, in effect, a price taker in the market for bank reserves. In that case one can represent the central bank as supplying reserves perfectly elastically, as in panel (a) of Figure 10 , or with some upward-sloping interest elasticity as in panel (b); but with an inelastic reserve demand the difference is not observable. Either way, the central bank is, in effect, simply choosing a point on a vertical demand schedule. The most immediate question that follows is how the central bank communicates to the market which point it has chosen. The further question, given the lack of substitutability between reserves and other assets that the vertical demand schedule implies, is what aspect of banks' behavior then causes other market interest rates to move in parallel with movements in the policy rate.

By contrast, even if the demand for reserves is interest elastic (as it seems to be in Japan), for the central bank to be able to move the policy interest rate without changing

before the 2007-9 crisis, involved near-zero interest rates, including values as low as 0.001 percent (1/10 of a basis point). Not surprisingly, reserve demand exhibits strong nonlinearity in the close neighborhood of a zero interest rate. The sample excludes three observations for which the measured call rate was literally zero.

${ }^{44} \mathrm{~A}$ potential reason why reserve demand in Japan was so different is that, unlike in the U.S. the BOJ does not allow Japanese banks to have "daylight overdrafts"- that is, deficiencies in their reserve holdings that are covered by the end of the day's settlements; see, for example, Hayashi (2001)—and unlike in the Eurosystem, during this period there was no standing BOJ facility against which Japanese banks could freely borrow reserves to prevent deficiencies. The resulting need to avoid overdrafts would presumably give rise to an asymmetry in banks' demand for excess reserves, which might also induce a source of interest elasticity. Investigating this quite specific hypothesis lies beyond the scope of this chapter. 
the supply of reserves (or with a change smaller that what the demand elasticity implies) requires that the demand schedule shift, as shown in Figure 6. As noted above, in this case a shift of the demand schedule takes the place of the traditionally conceived movement along the demand schedule. The crucial question then is what would cause the demand for reserves to shift in this way-other than changes in reserve requirements, which central banks mostly do not use for this purpose.

A class of explanation that is familiar in other asset demand contexts turns on expectations of future asset returns. A bank choosing today between making a loan at $X$ percent and holding a Treasury bill at $Y$ percent might decide differently depending on whether the rate on loans of that risk category were expected to remain at $X$ percent for the foreseeable future or move to some different level. The expectation of an imminent movement to some higher (lower) rate would make the bank less (more) eager to extend the loan now, and therefore more (less) eager to hold the Treasury bill and wait to make the loan after the rate had risen. Hence the bank's willingness to add loans to its portfolio, for a given array of current interest rates, would have shifted.

Extending this logic to one-day loans is problematic, however. If today the interest rate in the U.S. market for overnight federal funds is $X$ percent, and the Treasury bill rate $Y$ percent, the expectation that the overnight rate is going to be different from $X$ percent some time in the future does not directly affect a bank's willingness to lend in the federal funds market today. The reason is that there is no substitution opportunity between a one-day loan in the future and a one-day loan today. The usual logic of "term structure" arbitrage does not apply. ${ }^{45}$

A feature of the reserves market that some parts of the existing empirical literature have emphasized, however, is that in many countries' banking systems the accounting procedures under which banks meet their reserve requirement create exactly this kind of "term structure" arbitrage possibility over short time horizons. In the United States, reserve requirements are based on a bank's holdings of reserves on average over a two-week reserve maintenance period. In the Euro-system, and in Japan, the corresponding period is one month.

Apart from the potential risk of not being able to borrow in the overnight market on some future day, which is normally remote, within such a system a bank therefore does have an incentive to arbitrage holding reserves today versus holding them at some future day within the maintenance period. If a U.S. bank anticipates needing to borrow reserves in the market in order to meet its reserve requirement, then wholly apart from any expectation of change in the rates on other assets, the expectation that the federal funds rate will be lower (higher) on some future day within the maintenance period reduces (increases) the bank's willingness to borrow reserves at a given federal funds rate today. Alternatively, if the bank anticipates that it will have more reserves than it needs to meet its requirement, the expectation that the federal funds rate will be lower (higher) on some future day within the maintenance period increases (reduces) the bank's willingness to lend those reserves

\footnotetext{
${ }^{45}$ This discussion, like that throughout most of this chapter, treats a day as a single trading period. If banks in the morning expect the rate to be different by afternoon, then the opportunity for what amounts to multi-period substitution exists even within the context of a single day.
} 
out at a given federal funds rate today. In both situations, the expectation of a future rate change shifts the demand for reserves, for given interest rates, today - that is, precisely the curve that is shifting in Figure 6. The literature analyzing the link between interest rates and reserves, for countries whose banking systems operate under this kind of multi-day reserve-maintenance-period system, has frequently emphasized this kind of "anticipation effect." 46

One question to which this line of argument gives rise is where these anticipations of a future change in the overnight interest rate for borrowing and lending reserves come from. Since the interest rate whose future movements are being anticipated is one that the central bank sets, or at least targets, one immediate possibility is an indication of intent originating from the central bank itself. Most obviously, the central bank could simply announce its intention to raise or lower the relevant interest rate in the future. ${ }^{47}$ If it credibly did so- and if the future change were announced for a time within the current maintenance period - the anticipation effect would then be an "announcement effect": the central bank's announcement of a future movement of the policy rate would create an arbitrage incentive such that the rate would immediately go to that level unless the central bank acted to resist this movement.

But importantly, the logic of the "anticipation effect" applies to any anticipation of a forthcoming interest rate change, whether based on a central bank announcement or not, as long as it is expected to take place within the current maintenance period. Section 6 below shows evidence, for the United States, that the Federal Reserve systematically acts to resist just such tendencies-based not on its announcements (the Federal Reserve's announcements of interest rate changes are effective immediately), but rather on market expectations of forthcoming monetary policy decisions.

By contrast, over longer time horizons - those extending beyond the length of the twoweek or one-month reserve maintenance period - this kind of "anticipation effect" (even in the form of an "announcement effect") that shifts the prevailing reserve demand schedule and hence enables the central bank to move its policy interest rate without necessitating any change in reserve supply would presumably not be operative. Once the reserve maintenance period ended, the logic accounting for the shift in reserve demand (as in Figure 6) would no longer apply, and only by changing reserve supply (as in Figure 5) could the central bank keep the interest rate from reverting to its prior level. As the discussion in Section 7 below emphasizes, for a given structure of reserve requirements the link-or absence of onebetween reserves and interest rates at longer horizons hinges on patterns of deposit growth, which in turn depend on households' and firms' demand for different kinds of deposits as well as on the behavior of banks in supplying those deposits, including in particular banks effort and ability to induce their customers to substitute low-reserve-requirement deposits for high-requirement deposits when reserves are more costly. Those issues, centering on

\footnotetext{
${ }^{46}$ See, for example, Carpenter \& Demiralp (2006a).

${ }^{47}$ Alternatively, the central bank could publicly announce what it expects its future policy rate to be. At the time of writing this is the current practice of some central banks, including those of Sweden, Norway. Typically, however, these "projections" of the future trajectory of the policy rate are for horizons that extend well beyond the reserve maintenance period, so that they do not shift reserve demand in the way under analysis here.
} 
the demand for and supply of deposits, lie well beyond this chapter's focus on the market for reserves.

\subsection{Bank Reserve Arrangements and Interest Rate Setting Procedures in the United States, the Euro-System and Japan}

For purposes of modeling the short-horizon implementation of monetary policy, including in particular the working of these "anticipation" effects, it is useful to take explicit account of several features of the operating procedures currently in place at central banks like those of the U.S., the Euro-system and Japan. ${ }^{48}$ Table 4 provides a schematic summary of the Federal Reserve's, the ECB's and the BOJ's procedures that are most relevant in this context.

First, as the discussion in Section 3 above has emphasized, there needs to be a regular and predictable demand by banks for the reserves that the central bank supplies. The Federal Reserve, the ECB and the BOJ all impose reserve requirements. At the ECB and the BOJ these requirements must be met by holding reserve balances at the central bank. The Federal Reserve also allows banks to satisfy reserve requirements by their holdings of vault cash-that is, currency; but U.S. currency is also a liability of the Federal Reserve System. ${ }^{49}$

Second, as highlighted in the account of the origin of the "anticipation effect" immediately above, the reserve requirement imposed by each of these central banks applies to an individual bank's average holding of reserves over some reserve maintenance period: two weeks at the Federal Reserve, and one month at the ECB and the BOJ. ${ }^{50}$

Third, in each case the reserve requirement applies with a time lag. In both the U.S. and the Euro-system, the lag is identical to the maintenance period, so that each individual bank's required reserves are predetermined with respect to any action it might take within the current maintenance period, as is the total quantity of required reserves for the banking

\footnotetext{
${ }^{48}$ See Borio (1997) for an earlier review of the institutional operating frameworks at fourteen central banks, many of which were subsequently subsumed into the Euro-system, and Bank for International Settlements (2008) for a more recent reference. Blenck et al. (2001) provided a comparative treatment of the Federal Reserve, the ECB and the BOJ as of the beginning of the new millennium. Ho (2008) provided a comparable survey for the BOJ (along with other Asian central banks). More detailed expositions are available in Meulendyke (1998) for the U.S., European Central Bank (2008) for the ECB and Miyanoya (2000) for Japan. The most significant changes in the Federal Reserve's and the BOJ's procedures since the publication of Blenck et al. (2001) are the change in the two central banks' discount window procedures and the payment of interest on banks' holdings of excess reserves-both of which Section 7 below discuss in some detail.

${ }^{49}$ A variety of more specific features of these systems' reserve requirements are significant in the context of some aspects of how these central banks operate, but are not of major importance for the questions at issue in this chapter-for example, the role of required clearing balances (which have bulked larger in banks' overall reserve holdings over time) and whether daylight overdrafts are allowed (which affects banks' precautionary demand for reserves).

${ }^{50}$ At the Federal Reserve, but not the ECB or the BOJ, banks are also able to carry over reserve excesses to the following maintenance period. (The provision is asymmetric; banks cannot make up a deficiency in one maintenance period by holding more in the next.) The limit on such carry-overs is relatively small, howeverthe greater of $\$ 50,000$ or four percent of the bank's total requirement — and so the model developed here does not incorporate it.
} 
system as a whole. With current-day information processing and reporting systems, they are also known almost from the beginning of the maintenance period. As soon as the bank finishes assembling its daily deposit reports for the two-week or one-month period that has just ended (a process that normally takes only a day or so), both the bank and the central bank will know in advance what amount of reserves the bank is required to hold during the maintenance period that is just beginning. In Japan, the time lag is only half the length of the maintenance period, so that required reserves for the one-month period become determined (and, with a day or so delay, become known) only half-way through the month.

Fourth, at least at the time of writing, the institutional structure at all three of these central banks includes what amounts to standing facilities for either advancing reserves to banks or absorbing reserves back from banks, in potentially unlimited quantity, with the interest rate charged or credited set in relation to each central bank's target for its policy rate. Importantly, in each case the interest rate paid on deposited reserves is below the central bank's target for its policy interest rate, while the rate charged on reserve borrowings is above that target. ${ }^{51}$ The most straightforward case among the three is the ECB, which since its inception has maintained a "marginal lending facility" to lend reserves to banks on request and, in parallel, a "deposit facility" to absorb from banks reserves that they do not need to satisfy their reserve requirements and therefore choose to deposit at the central bank, in each case on an overnight basis. The interest rates paid and charged by these facilities have varied in a range from 1 percent above and below, to 50 basis points above and below, the ECB's main refinancing rate.

Since 2008 both the BOJ and the Federal Reserve have had similar institutions in place, although because of the near-zero level of overnight market interest rates in each country, to date the mechanism for paying interest on banks' excess reserve holdings has remained largely unused. The BOJ introduced its "complementary lending facility" to lend overnight reserves to banks, in place of its traditional discount window, in 2001, with the rate normally set at 25 basis points above the call rate target. Only in 2008, when the target call rate was back to near zero in the context of the 2007-9 financial crisis, did the bank introduce its "complementary deposit facility," under which all holdings of excess reserves are automatically deemed to be deposited overnight for purposes of receiving the stated interest rate. $^{52}$

The Federal Reserve augmented its discount window with a "primary credit facility" in 2003 , with the rate charged set at 1 percent above the target federal funds rate. ${ }^{53}$ Like

\footnotetext{
${ }^{51}$ The resulting system therefore differs importantly from the form of "corridor" system used earlier on by the Reserve Bank of New Zealand, under which the two interest rates were set in relation to the market interest rate rather than the central bank's policy rate. As Guthrie \& Wright (2000) and Woodford (2000) argued in their analyses of the New Zealand system, the fact that these two interest rates were not therefore under the central bank's direct control led to a deeper level of indeterminacy.

${ }^{52}$ The BOJ announcement called the new facility a "temporary measure to facilitate the supplying of funds," but at the time of writing it remains in place. The rate paid is set at the BOJ's discretion; at the time of writing it was 0.1 percent, the same as the call rate target.

${ }^{53}$ See again Meulendyke (1998) for a description of the working of the older discount window and the role once played by reserve borrowings in the Federal Reserve's operating procedures. From 1984 on (after the
} 
the BOJ, in 2008 it began paying interest on excess reserves, with no specific action on a bank's part needed to "deposit" them. In principle, the rate paid is $3 / 4$ percent below the target federal funds rate, although from the inception of this new mechanism through the time of writing the near-zero level of the target rate has rendered the matter moot. (As part of the same 2008 change, the Federal Reserve also began paying interest, at the target federal funds rate, on required reserves; but because each bank's required reserves are predetermined as of the beginning of the maintenance period, this payment has no impact on banks' management of their reserve positions within the maintenance period. From this perspective it is merely a lump-sum transfer to the banks.)

Finally, although there is no evidence of systematic changes in reserve supply to effect movements in the central bank's policy interest rate in any of these three systems, in each one the central bank does intervene in the market on a regular basis in response to either observed or anticipated deviations of the market interest rate from its target. Both the Federal Reserve and the BOJ conduct open market operations once per day, normally at the beginning of the day. The ECB does so only once per week. If these interventions were done on a continuous basis, and in unlimited volume, there would be little reason for deviations between the market rate and the central bank's target to persist more than momentarily. The fact that they occur only once per day, however, or (in the Euro-system) even more so once per week, means that such deviations do occur and are a regular feature of these systems' markets for overnight reserves.

Further, these market interventions, when they occur, are normally not unlimited in size. Both the Federal Reserve and the BOJ decide (along the lines modeled below) on the quantity of reserves to add or drain each morning. Before October 2008, the ECB's weekly intervention consisted of auctioning a fixed quantity of reserves, at or above the main refinancing rate (which is the bank's target for EONIA - the European overnight interest average), with an allotment mechanism in cases of overbidding (which often occurred prior to its shift in 2000 to a variable rate tender system). As Figure 11 shows, before the crisis set in the typical result was an upward bias, such that the policy interest rate was usually above target — an outcome not experienced in either the U.S. or Japan. A further result was greater volatility of the policy interest rate than in the U.S., especially on the final day of the monthly reserve maintenance period. Since the summer of 2008, however, the bias has been in the opposite direction: EONIA is typically below target. In October 2008, the ECB changed its procedure to an unlimited quantity allotment at the target rate. (This change was announced as a temporary response to the financial crisis-see the discussion in Section 7 below-but as of the time of writing it remains in place.)

failure of Continental Illinois), U.S. banks had become increasingly reluctant to borrow from the discount window; see Clouse (1994) and Hanes (2004). The older discount window facility still exists, in a vestigial form. As of yearend 2009, borrowings from the Federal Reserve-not counting those from the various special facilities set up during the crisis (and the special loan to AIG) — totaled $\$ 19,580$ million, of which $\$ 19,025$ million was primary credit. In principle, the board of directors of each individual Federal Reserve Bank sets that one bank's discount rate, subject to approval from the Board of Governors of the Federal Reserve System. In practice the twelve Federal Reserve Banks' respective discount rates rarely vary from one another for more than a day or two at a time. The rate on primary credit is always 1 percent above the target federal funds rate. 


\subsection{A Model of Reserve Management and the Anticipation Effect}

Given institutional arrangements of this generic form, a profit-maximizing bank has an incentive to manage its day-to-day reserve position so as to minimize the average cost of holding the reserves it needs on average across the maintenance period, while taking into account the potential costs of any end-of-period deficiency that would necessitate borrowing at what amounts to a penalty rate and also the opportunity cost of excess reserves on which it would earn no interest (or which it would deposit at a sub-market rate). The relevant margins, for the bank's decision making, are how much excess to hold on average across the maintenance period, and what substitution to make between holding reserves on one day versus another within the maintenance period. On the supply side of the market, a central bank operating as the Federal Reserve or the BOJ did before 2008 is implicitly committing to intervene as necessary, also on a daily basis, to keep the policy interest rate within some unstated bounds of its target. A central bank operating as the ECB did before 2008 has an explicit commitment to provide or absorb reserves in unlimited quantity at the interest rates on the two standing facilities, together with some presumably lesser (because it occurs only once per week) commitment to intervene within those bounds. A key implication of the resulting interaction, on the assumption that banks understand the central bank's operating system and anticipate its actions, is a daily reserve demand function that depends on the difference between the market rate and the target rate even if the reserve demand is inelastic with respect to the level of either rate. ${ }^{54}$ It is this feature that, in effect, give the central bank the ability to shift the reserve demand schedule along the lines illustrated in Figure 6.

The three-asset demand and supply model developed in Section 3 provides a useful way to formalize these relationships. While the resulting model does not incorporate many of the complexities and unique features of individual central banks' operating frameworks, it nonetheless captures the essential features that give rise to the anticipation effect. The key point is that, because the reserve requirement applies not to each day separately but on average over the maintenance period, banks' demand for reserves on day $t$ depends not only on the current configuration of interest rates, as in equation (3), but also on the expected future rate for borrowing or lending reserves. It is convenient to express this aspect of the demand for reserves in terms of the difference between the current overnight rate $r_{t}^{F}$ and the expected future rate $E_{t} r_{t+1}^{F}$, as in

$$
R_{t}^{d}=L\left[\alpha^{R}-\beta^{R F} r_{t}^{F}-\beta^{R T} r_{t}^{T}-\gamma\left(r_{t}^{F}-E_{t} r_{t+1}^{F}\right)+e_{t}^{R}\right]
$$

where $\gamma$ is a parameter representing the degree of substitutability in reserve holdings across days in the maintenance period. ${ }^{55}$ Presumably $\gamma$ becomes smaller as the maintenance pe-

\footnotetext{
${ }^{54}$ See, for example, the expositions in Woodford (2000) and Bindseil (2004).

${ }^{55}$ In a more fully specified model, $\gamma$ will in turn depend on structural features of the operational framework, such as the width of the corridor constituted by the central banks' standing facilities, perceptions of the central bank's willingness to intervene within that corridor, the penalty associated with any end-of-period reserve deficiency, the availability of daylight overdrafts, the spread between the target rate and the bank's deposit and lending rates, the joint distribution of the relevant shocks, and so on. Because the expectation in equation
} 
riod progresses, becoming zero on the final day of the period.

For purposes of analyzing the inter-day substitutability of reserve demand within the maintenance period, it is reasonable to assume that banks are concerned primarily with the trade-off between holding reserves and lending them on the overnight market, so that the interest rates on other securities (here represented by the Treasury rate) are largely irrelevant to this decision. ${ }^{56}$ With $\beta^{R T}=0$,equation (12) simplifies to

$$
R_{t}^{d}=L\left[\alpha^{R}-\beta^{R F} r_{t}^{F}-\gamma\left(r_{t}^{F}-E_{t} r_{t+1}^{F}\right)+e_{t}^{R}\right]
$$

Equation (13) embodies the well-known property that in the limit, as $\gamma \rightarrow \infty$, the overnight interest rate $r_{t}^{F}$ becomes a martingale: $E_{t} r_{t+1}^{F}=r_{t}^{F}$. If banks are able to rearrange their reserve holdings without limit across days within the maintenance period, in response to expected deviations between the current and expected future overnight rate, then any difference between them will be arbitraged away.

A useful way to represent the central bank's adjustment of the supply of reserves in response to anticipated deviations of the overnight rate from the corresponding target is

$$
R_{t}^{S}=R^{*}+\phi L\left(E_{t} r_{t+1}^{F}-\bar{r}_{t}^{F}\right)+L u_{t}^{R}
$$

where $\bar{r}^{F}$ again represents the target rate and $E_{t} r_{t+1}^{F}$ is the coming day's expected rate. ${ }^{57}$ As in section $3, R^{*}$ refers to the "baseline" quantity of reserves that, if supplied by the central bank, would render the market-clearing interest rate $r_{t}^{F}$ equal to the target $\bar{r}^{F}$ in the absence of shocks. Equation (14) also includes a reserve supply shock, $u_{t}^{R}$, representing exogenous factors affecting the level of reserves such as fluctuations in Treasury balances. ${ }^{58}$

The parameter $\phi$ in equation (14) represents the degree to which the central bank adjusts the supply of reserves in response to its expectations of the future overnight rate, so that $\phi$ inversely reflects the extent to which the central bank is willing to allow those expectations to affect the current rate. ${ }^{59}$ If $\phi=0$ the central bank is passive, making no adjustment

(12) refers to the rate expected to prevail on average over all future days in the maintenance period, the substitution parameter ( presumably varies depending on the number of days remaining in the maintenance period. Detailed optimizing models of within-period reserve demand have been developed in Furfine (2000), Clouse \& Dow (2002), and Bartolini et al. (2002).

${ }^{56}$ Alternatively, one could assume that at this frequency overnight funds and Treasury bills are viewed as nearly perfect substitutes, so that the Treasury rate can be subsumed within the federal funds rate term. Putting the matter in terms of a focus on the inter-day substitutability of reserve holdings within the maintenance period seems the more appealing formulation.

${ }^{57}$ Under the procedures used in the U.S. and Japan, in which the central bank conducts open market operations at the beginning of each day, the expectation term in equation (14) actually refers to what the central bank expects the interest rate to be on that day, given information available from the day before. Hence the expectations in equations (13 and (14) are not precisely aligned. Although writing the expectation term in equation (14) as $E_{t-1} r_{t}^{F}$ would be more precise, the resulting model would be less transparent for purposes of the point at issue here.

${ }^{58}$ The resulting model, combining equations (13) and (14) is in the same spirit as that of Taylor (2001), but it also incorporates Orphanides' (2001) suggestion of a forward-looking reserve supply function. It is also similar to the model developed in Demiralp (2001).

${ }^{59}$ The adjustment of reserve supply in response to market conditions corresponds to Disyatat's 2008 “policy 
of reserve supply from $R^{*}$, and therefore no effort to prevent movements in $E_{t} r_{t+1}^{F}$ from affecting the current rate. In the limit as $\phi \rightarrow \infty$, the central bank adds or drains whatever volume of reserves is necessary to hold the overnight rate at $\bar{r}^{F}$ (apart from the disturbance term) regardless of expectations. Because the influence of expected future overnight rates on the current rate that the central bank is seeking to offset (unless $\phi=0$ ) comes from banks' behavior in seeking to substitute reserve holdings today versus those on a future day within the maintenance period, it is plausible to suppose that a larger value of $\gamma$, implying a greater willingness of banks to make such substitutions, leads the central bank to respond more aggressively to expected deviations of the overnight rate from target. At the simplest,

$$
\phi=\lambda \gamma
$$

where $\lambda$ represents the central bank's own degree of activism in the market for a given value of $\gamma$.

Equating reserve supply to reserve demand, and substituting from equation (7 for the baseline reserve quantity $R^{*}$, gives

$$
r_{t}^{F}=\frac{\beta^{R F}+\lambda \gamma}{\beta^{R F}+\gamma} \bar{r}^{F}+\frac{(1-\lambda) \gamma}{\beta^{R F}+\gamma} E_{t} r_{t+1}^{F}+\frac{1}{\beta^{R F}+\gamma}\left(e_{t}^{R}-u_{t}^{R}\right) .
$$

The market-clearing overnight rate is therefore a convex combination of the target rate and the expected future rate (within the maintenance period), plus a term involving the disturbances to both reserve supply and reserve demand. The larger is $\gamma$-that is, the greater is banks' ability to substitute reserve holdings on one day for another-the larger is the weight on the expected future interest rate target, and hence the stronger is the anticipation effect. By contrast, the larger is $\lambda$-the more actively the central bank intervenes in the market for given $\gamma$ - the weaker is the anticipation effect, and so the weight on the current target rate is larger relative to the expected future target.

A further feature of equation (16) is that the coefficient on the supply shock, $1 /\left(\beta^{R F}+\right.$ $\gamma)$, shows how banks' ability to shift reserve balances across periods of the maintenance period attenuates the impact of reserve demand and supply shocks on the overnight rate. With $\gamma>0$ the response of the overnight rate will be smaller than the $1 / \beta^{R F}$ response that would characterize reserve demand at frequencies extending beyond the maintenance period. Late in the maintenance period, as $\gamma$ shrinks in magnitude, this effect diminishes. On the final day of the maintenance period, when $\gamma=0$, the opportunity for forwardlooking reserve averaging disappears altogether and the effect of supply and demand shocks on the overnight rate is simply $1 / \beta^{R F}$. This implication of the model is consistent with the observed tendency for reserve supply shocks to have a larger effect on the overnight rate on the final day of the maintenance period. (See again Figure 11.) Similarly, the anticipation effect also weakens as the maintenance period advances, vanishing on the final day.

Equation (16) also illustrates the conditions under which a "pure" anticipation (or announcement) effect would prevail, allowing the central bank to change the equilibrium overnight interest rate without any change at all in the supply of reserves. The key require-

implementation reaction function." 
ment in this case is that changes in the current overnight rate have no effect on reserve demand-that is, $\beta^{R F}=0$. In this case, banks' reserve management decisions involve only the distribution of reserve balances across days of the maintenance period, rather than whether to change the average level of excess reserves held in response to the level of market interest rates. If this condition holds, then equation (16) shows that if $E_{t} r_{t+1}^{F}=\bar{r}^{F}$, then in the absence of shocks the market-clearing rate is $r_{t}^{F}=E_{t} r_{t+1}^{F}=\bar{r}^{F}$. If $\beta^{R F}=0$, therefore, the central bank is fully able to enforce its target, without any change in reserve supply required, as long as market participants believe it will do so. All that is required to move the overnight rate to a new level is a credible announcement of the new target (and implicitly, the new reserve supply function).

Figure 12 illustrates this situation as a vertical shift in the reserve demand schedule, drawn as a function of the current overnight rate, by an amount equal to the change in the target-which banks expect to become the new effective rate. Even with $\beta^{R F}=0$, so that banks' average demand for reserves across the maintenance period is completely interest inelastic, as long as they are able to substitute reserve holdings on one day versus another within the maintenance period $(\gamma>0)$, reserve demand on any given day (except the final day) is interest elastic. But the downward-sloping reserve demand schedule is conditioned on the interest rate that banks expect to prevail over the remainder of the maintenance period. Hence a change in expectations, brought about by the central bank's announcement (or by anything else, for that matter) vertically shifts the demand schedule. At the same time, because the central bank does not vary reserve supply contemporaneously in response to the interest rate (see again equation (14)), the vertical supply schedule remains unchanged.

The same logic applies in a multi-day setting as well. By solving equation (16) forward it is possible to express the current overnight rate as a function of the entire sequence of expected future target rates. Central bank announcements signaling a future change in the overnight rate target will therefore cause the current market rate to jump and then subsequently converge over time to the new target.

This logic does not imply that reserves are entirely irrelevant, however, nor that the central bank could achieve its target rate $\bar{r}^{F}$ with any arbitrary level of reserve supply. Two conditions are necessary for the policy interest rate to be determined solely by target rate announcements. First, the "baseline" (or "neutral") supply of reserves, $R^{*}$, must be as indicated in equation (7). ${ }^{60}$ The demand for reserves may or may not be elastic across days within the maintenance period, but at least for the U.S. and the Euro-system the evidence indicates that it is highly inelastic at lower frequencies (see again Tables 1 and 2). Further, in both the U.S. and the Euro-system required reserves for the maintenance period as a whole are predetermined when the period begins, and in Japan they are predetermined as of half-way through the period. Deficiencies or excesses of reserve supply persisting for the duration of the maintenance period would therefore presumably lead to large deviations

\footnotetext{
${ }^{60}$ As Borio \& Disyatat (2009, p. 3) argue, "The corresponding amount [of reserves] demanded is exceedingly interest-inelastic - effectively a vertical schedule. Supplying this amount is the fundamental task of monetary operations across all central banks, regardless of the policy regime. Failure to do so would result in significant volatility of the overnight interest rate."
} 
of the overnight rate from its target, limited only by banks' recourse to the central bank's lending and deposit standing facilities.

Second, an announcement effect of this form requires that the central bank commiteven if only implicitly-to adjust the supply of reserves in response to deviations of the overnight rate from its target, so that the announced target becomes credible. This implication is also evident from equation (16): with $\lambda=0$, implying no adjustment of reserve supply to deviations of the overnight rate from target, the market rate becomes detached from the target and depends only on the expected future rate. Differences in the value of $\lambda$, or $\phi$ after taking account of banks' ability to substitute across days within the maintenance period, are therefore a useful way to characterize the essential distinction between the "dealing rate" and "target rate" systems, used by the ECB and the Federal Reserve, respectively. ${ }^{61}$ The ECB's commitment to intervene is explicit at the boundaries of the "corridor" formed by the two standing facilities. If banks' stochastic deposit flows are such that they attach equal probability to reserve deficiencies versus excesses, then under plausible conditions the resulting equilibrium will maintain the market rate close to the midpoint between the rates on the two facilities even in the absence of central bank intervention. In fact, actual interventions by the ECB are infrequent, implying a relatively small value of $\lambda$ in the context of this model. By contrast, while the Federal Reserve's and the BOJ's commitment to intervene is only implicit, actual interventions occur both more frequently and within much narrower bounds, implying a larger value of $\lambda$.

These differences in the central bank's degree of activism in market intervention are reflected in the variability of the market interest rate around target in their respective systems. For 2001 through mid 2007, the daily standard deviation of EONIA from the ECB's target was 13 basis points. By contrast, in Japan, for 1998 through mid 2007 but excluding the periods when the interest rate was zero, the comparable standard deviation was only 5 basis points. In the U.S., the evolution of monetary policy implementation institutions is very evident. From the beginning of an announced federal funds target until the introduction of lagged reserve accounting, February 1994 through July 1998, the daily standard deviation of the effective federal funds rate around the Federal Reserve's target was 23 basis points. From then until the introduction of the Treasury Investment Program (TIP), August 1998 through June 2000, the daily standard deviation was 19 basis points. ${ }^{62}$ From then until the beginning of the crisis, July 2000 through June 2007, it was only 8 basis points. ${ }^{63}$

The degree of activism in the central bank's policy with respect to open market operations is also relevant to the question of how frequently the standing facilities that constitute the upper and lower bounds of the "corridor" around its target rate are likely to be used. (This point is all the more relevant in the context of both the Federal Reserve's and the BOJ's adoption of standing facilities similar to what the ECB has had all along.) In particular, the larger is $\lambda$, the less likely that the central bank's lending and deposit rates will

\footnotetext{
${ }^{61}$ See Manna et al. (2001) and Bartolini et al. (2003) for useful expositions.

${ }^{62}$ The Treasury Investment Program allowed the Treasury to monitor its cash flows much more closely, thus increasing the predictability of the Treasury balances held at the Federal Reserve; see Garbade et al. (2004).

${ }^{63}$ Similarly, Bindseil (2004) reported daily standard deviations of 5 basis points in the U.S. and 13 basis points in the Euro-system, for 2001-4.
} 
be reached. The fluctuation of EONIA around the ECB's main financing rate exhibited a standard deviation of 13 basis points before the crisis: larger than in the U.S. or Japan, but still small compared to the width of the "corridor" created by the ECB's two standing facilities (at that time, 1 percent on either side of the target). But as Figure 11 shows, this fluctuation frequently involves quite large departures from target-especially on the last day of the maintenance period. Some similar large departures are evident in Japan (see panel (c) in the figure). Since the introduction of TIP at mid 2000, none are evident in the U.S. except in conjunction with the attacks on September 11, 2001.

\section{Empirical Evidence on Reserve Demand and Supply Within the Maintenance Period}

For the central bank to be able to effect changes in its policy interest rate without adding or draining reserves (at least not in significant quantity) therefore requires one condition on reserve demand and another on reserve supply: First, banks' demand for reserves must be highly inelastic with respect to interest rates at the frequency of a maintenance period as a whole; in terms of the reserve demand curve as specified in equation (12) above, $\beta^{R F}$ (and also $\beta^{R T}$ ) must be zero, or nearly so at this horizon. (Because banks' required reserves are predetermined, before the maintenance period begins, what is at issue here is the demand for excess reserves.) Second, the central bank must credibly commiteven if only implicitly - to varying the supply of reserves, in response to deviations of the overnight rate from the target, in such a way as to bring the effective market rate within some proximity to the corresponding target. A further condition that is necessary for the central bank to be able to attenuate the day-to-day volatility of its policy interest rate, in the presence of what are sometimes sizeable disturbances to reserve supply (to recall, from mis-estimates of such factors as Treasury balances), is that the demand for reserves exhibit substantial interest elasticity on a day-to-day basis within the maintenance period.

Are these conditions satisfied in practice? The evidence presented in Section 4-see again Tables 1 and 2-documents that banks' demand for reserves is highly inelastic in the United States at a bi-weekly frequency (corresponding to the Federal Reserve's two-week reserve maintenance period) and in the Euro-system at a monthly frequency (corresponding to the ECB's maintenance period). What about the conditions relating to the central bank's supply of reserves, and to banks' demand for reserves within the maintenance period?

\subsection{Existing Evidence on the Demand for and Supply of Reserves Within the Maintenance Period}

Consistent with the model presented in Section 5, the empirical evidence on reserve demand in the Euro-system points to a high degree of substitutability across days of the ECB's month-long maintenance period, as well as a significant element of forward-looking behavior. As summarized in Section 4, research by Ejerskov et al. (2003), Würtz (2003), and Angelini (2008) consistently showed that transitory shocks to reserve supply have little or no effect on the spread between the EONIA rate and the ECB's main refinancing 
rate. These repeated findings are consistent with the hypothesis that daily reserve demand is highly elastic with respect to the spread between the current and the expected future overnight interest rate.

The same three studies also provided more direct evidence of the degree to which current reserve demand depends on the expected future interest rate. Würtz (2003) included in his 43-variable daily reserve demand regression the spread between the two- and one-month EONIA swap rates as a proxy for the expected rate change. His estimates revealed some degree of asymmetry in the effects of expected interest rate movements, with expected increases having a larger impact than expected reductions. In Würtz's results, expectations of future interest rate movements contributed modestly to fluctuations in the EONIA spread: as much as 14 basis points for expected increases, and 5 basis points for expected decreases.

Ejerskov et al. (2003) included in their weekly reserve demand regression two alternative market-based measures of interest rate expectations, the one-week and one-month EONIA forward rates. Corroborating Würtz's findings, Ejerskov et al. obtained positive and statistically significant estimates of the impact of an expected interest rate movement, although these too are rather small: on average a 25 basis point expected movement affected the spread by only 3.5 basis points.

Rather than regress the EONIA spread on expected interest rate changes, Angelini (2008) used daily data from January 1999 to January 2001 to estimate the effect of expected rate changes on the quantity of reserves demanded, again using market-based measures of expectations. His results also supported the hypothesis of an elastic short-run reserve demand schedule, with an expected 25 basis point increase in the overnight rate leading on average to a roughly 0.1 percent increase in reserve demand.

On the supply side, there are two mechanisms the ECB could in principle use to adjust the volume of reserves in response to changing market conditions. ${ }^{64}$ One is through the ECB's paired standing facilities, which clearly represent an explicit commitment to provide or absorb reserves if the market interest rate departs far enough from the target. But the much smaller observed deviations of the market rate from the target - a daily standard deviation of only 13 basis points during 2001-mid 2007, compared to the 1 percent difference between the EONIA target and either the lending rate or the deposit rate-indicate that the ECB is influencing the market rate in ways that are infra-marginal to the standing facilities that bound the relevant interest rate "corridor." 65 Because of the ECB's emphasis on the determination of the "benchmark allotment" and its use of the corridor mechanism to enforce a reputational equilibrium, most research on the Eurosystem has focused on issues other than the responsiveness of active reserve supply to deviations of the interest rate from its target. In the same regression model that he used to estimate the effects of liquidity shocks and anticipated rate changes, Würtz (2003) found that the increased use of the lending facility tends to be associated with increases in the spread between the EONIA and main refinancing rates. While it was not the focus of his study, a natural inference from this result is that recourse to the lending facility does, at least to some extent, serve to adjust reserve supply in response to deviations of the overnight rate from target.

\footnotetext{
${ }^{64}$ The ECB can also employ "fine tuning" operations, but has done so very rarely.

${ }^{65}$ See again Woodford (2000), Bindseil (2004) and the other references noted in Sections 3 and 5 above.
} 
The other mechanism available to the ECB for adjusting reserve supply is changing the allotments for the medium-term refinancing operations (MRO) that are its main form of open market operations. The evidence reported in Ejerskov et al. (2003) suggests that the ECB does adjust the volume of MRO in response to expected deviations of EONIA from the bank's main refinancing rate. Regressing the volume of MRO allotments on the deviation of EONIA from the main refinancing rate, using weekly data from mid-1999 through 2002, they obtained a positive and statistically significant coefficient on the spread. Their estimate indicated that a 10 basis point positive spread leads the ECB on average to supply an additional $€ 200$ million in reserves through its MRO.

Existing empirical work for Japan also bears on both the elasticity of Japanese banks' demand for reserves within the maintenance period and the BOJ's reserve supply behavior. As noted above in Section 2, both Hayashi (2001) and Uesugi (2002) found virtually no effect of liquidity shocks on the overnight call rate on all but the last day of the maintenance period, consistent with a high degree of substitutability across days within the maintenance period. Neither, however, explicitly examined the response of reserve demand to expected interest rate changes.

Hayashi also estimated a daily reserve supply function for the BOJ's open market operations, and found that the BOJ does systematically vary reserve supply in response to its expectation of deviations of the call rate from its target level. (Hayashi used intra-day data to estimate the expected deviation). His results, based on daily data for November 1997 through February 1999, indicated that the BOJ on average supplies $¥ 300$ billion more (fewer) reserves for each 10 basis points that it expects the call rate to deviate above (below) the target.

Some limited empirical work done for the United States bears on these issues as well. Hamilton's (1997, 1998) and Carpenter \& Demiralp (2006b) work described in Section 3 above, which showed the absence of a "liquidity effect" except on the final day of the maintenance period, is consistent with a high degree of substitutability of reserve demand across days within the period and therefore of day-to-day interest elasticity (except for the final day) as well. In a similar vein, Hilton \& Hrung (2010) analyzed the impact of reserve imbalances on the deviation of the beginning-of-day federal funds rate (that is, the rate prevailing in the market before any open market operations have been performed for that day) from target. Consistent with other work on the liquidity effect, they found that reserve imbalances had small and generally insignificant effects on the beginning-of-day funds rate during the first week of the maintenance period. Late in the maintenance period, however, and especially on the final two days, reserve excesses and deficiencies created significant divergences between the effective and target rates.

In an effort to assess more directly the response of reserve demand to anticipated changes in the federal funds rate, across days of the maintenance period, Carpenter \& Demiralp (2006a) used data on federal funds futures to gauge the "anticipation effect" implied by this substitutability. They found evidence for a strong anticipation effect, such that the market funds rate moves in advance of an expected change in the Federal Reserve's target when that change is expected to occur within the maintenance period. ${ }^{66}$ Specifically,

\footnotetext{
${ }^{66}$ Since 2004 the ECB has timed its policy rate decisions to coincide with the beginning of reserve mainte-
} 
their results indicated that a 1 percentage point expected increase in the federal funds rate is associated with a 46 basis point increase in the effective rate on the day preceding the change in the target rate. The estimated effect diminished for more distant rate changes, however, and they found no significant response to expected rate changes five or more days ahead. ${ }^{67}$

On the supply side of the market, Feinman (1993a) estimated a detailed "friction" model representing the volume of the Federal Reserve's daily open market operations as a function of within-maintenance-period reserve imbalances and same-day deviations of the federal funds rate from target. ${ }^{68}$ He found that the Federal Reserve responded predictably to reserve surpluses and deficiencies, as well as to beginning-of-day deviations of the federal funds rate from its "expected" level. ${ }^{69}$ Specifically, his results indicated that a 10 basis point beginning-of-day positive (negative) deviation, on average triggered open market operations that day adding (draining) \$81 million in reserves. These results clearly bear on the questions at issue here, but the sample period used in the analysis, ending in 1990, now renders them dated. ${ }^{70}$

The evidence presented in Tables 5 and 6 below extends this existing work on reserve demand and supply in the United States in four specific directions: first, documenting the high degree of substitutability of banks' reserve demand across days within the maintenance period; second, estimating the degree of interest elasticity of daily reserve demand with respect to the current level of the overnight interest rate; third, estimating the central bank's daily reserve supply response to expected deviations of the overnight rate from target; and fourth, determining the extent to which the central bank adds or drains reserves on the day of, or the days immediately following, changes in the target interest rate.

\subsection{Within-Maintenance-Period Demand for Reserves in the U.S.}

The basis for the estimates presented in Table 5 is the reserve demand equation (13):

$$
R_{t}^{d}=L\left[\alpha^{R}+\beta^{R F} r_{t}^{F}-\gamma\left(r_{t}^{F}-E_{t} r_{t+1}^{F}\right)+e_{t}^{R}\right]
$$

Because both the overall level of reserves and the size of banks' liquid asset holdings have moved only slowly in the U.S. over the period studied (see again panel (a) in Figure 7), for the purposes of empirical estimation using daily data it is reasonable to treat $L$ - the overall size of banks' liquid asset portfolios, including reserves as well as other liquid

nance periods, so that an anticipation effect of this form should not apply to the Euro-system.

${ }^{67}$ There is also some evidence that the anticipation effect is stronger for interest rate increases than for reductions. Carpenter and Demiralp attributed this pattern to asymmetries in the relative costs of reserve excesses versus deficiencies, and to banks' tendency to hold fewer reserves early in the maintenance period.

${ }^{68}$ The "friction" in Feinman's model consisted of allowing for a zone of inaction in the fluctuation of the federal funds rate, within which the central bank would perform no open market operations.

${ }^{69}$ Because Feinman's 1984-1990 sample period ended before the Federal Reserve began to announce an explicit target interest rate publicly, his paper referred to the deviation of the effective rate from its "expected" level.

${ }^{70}$ Demiralp \& Jordá (2002) estimated a similar model, using more recent data, and likewise found evidence of open market operations used to enforce changes in the target federal funds rate. The complex structure of their model makes it difficult to draw specific conclusions about magnitudes, however. 
instruments - as fixed within the period and therefore to subsume it into the estimated regression coefficients. Two key modifications are then needed to facilitate the estimation of the anticipation and liquidity effects within this framework. The first is to express the inter-day interest rate deviation term $r_{t}^{F}-E_{t} r_{t+1}^{F}$ as the difference between the current deviation of the interest rate from target and the expected future deviation from target - that is, $r_{t}^{F}-\bar{r}_{t}^{F}-E_{t}\left(r_{t+1}^{F}-\bar{r}_{t}^{F}\right)$. If market participants take the central bank's commitment to its interest rate target to be credible, for future days, then the expected future rate is equal to the expected target rate, so that this expression can in turn be written as the difference between the current deviation and the expected change in the target, $r_{t}^{F}-\bar{r}_{t}^{F}-E_{t}\left(\bar{r}_{t+1}^{F}-\bar{r}_{t}^{F}\right)$.

The second modification is to solve the demand equation for the current interest rate deviation, so that $r_{t}^{F}-\bar{r}_{t}^{F}$ becomes the left-hand variable for purposes of estimating the equation empirically:

$$
r_{t}^{F}-\bar{r}_{t}^{F}=\gamma^{-1} \alpha^{R}-\gamma^{-1} \beta^{R F} r_{t}^{F}-E_{t}\left(\bar{r}_{t+1}^{F}-\bar{r}_{t}^{F}\right)-\gamma^{-1} R_{t}+\gamma^{-1} e_{t}^{R}
$$

Because the interest rate $r_{t}^{F}$ and the quantity of reserves supplied $R_{t}$ are jointly determined, the regression's error term will be correlated with the regressor regardless of which way the regression is estimated. But the estimation strategy here, in the spirit of Hamilton (1997), is to use the central bank's "miss" in anticipating the reserve supply disturbance as an instrument for $R_{t}$. (By contrast, the "miss" would be a poor instrument for the interest rate deviation, $r_{t}^{F}-\bar{r}_{t}^{F}$, unless the "liquidity effect" were very strong.) It therefore makes sense to estimate the regression with instrumented $R_{t}$ as an independent variable.

The reserve demand equation underlying the results presented in Table 5 incorporates several further additions to enable this highly stylized representation of banks' demand for reserves to reflect the relevant U.S. institutional arrangements more closely. First, the estimated equation includes additional variables to capture calendar effects. For a variety of reasons, reserve demand tends to vary across days of the maintenance period, as well as within the month; for example, reserves that banks hold on Fridays count, for purposes of meeting their reserve requirements, as held on the following Saturday and Sunday as well. Banks' reserve demand is also sometimes greater, all else equal, on the last day of the reserve maintenance period, although this effect has diminished since the July 1998 shift to lagged reserve accounting. Further, because the adoption of lagged reserve accounting also increased the predictability of banks' demand for reserves, it also led to a significant reduction in reserve demand. The estimated equation includes a number of dummy variables to capture these and other calendar-driven factors affecting reserve demand.

Second, as the model developed above emphasizes, in the setting of a multi-day reserve maintenance period banks' demand for reserves on any given day depends on the interest rate that is expected to prevail over a horizon longer than just the next day. Because the actual length of the maintenance period in the U.S. is two weeks, the single $E_{t} \bar{r}_{t+1}^{F}-\bar{r}_{t}^{F}$ term in equation (17) should properly be an expanded term reflecting any target rate change expected to occur within the current maintenance period. Given the schedule of meetings of the Federal Reserve's key monetary policy decision-making committee (the Federal Open Market Committee) and also of the successive reserve maintenance periods - both of which are known to banks-and on the assumption that changes in the target interest rate are ex- 
pected to take place only on the days of scheduled FOMC meetings, it is straight forward to derive a market-based measure of the expected change in the interest rate using daily data from the federal funds futures market. ${ }^{71}$ Following Carpenter \& Demiralp (2006a), the variable used for this purpose in the estimated equation is the difference between the average federal funds rate expected for days within the maintenance period that follow the next scheduled FOMC meeting and the current target rate, denoted $\Delta^{e} \bar{r}_{t}^{F}$. As the discussion above has also emphasized, however, the degree of substitutability in reserve holdings across days presumably varies according to the specific day within the maintenance period. (In the limit, on the last day there is no scope for substitution. ${ }^{72}$ ) The estimated equation therefore also allows the coefficient on $\Delta^{e} \bar{r}_{t}^{F}$ to vary across days of the maintenance period.

Third, an important factor affecting a bank's demand for reserves on any given day, but omitted from the discussion above, is the cumulative excess or deficiency in its holdings of reserves, relative to its required reserves, thus far within the maintenance period. If a bank has accumulated a larger-than-needed level of reserves during previous days of the maintenance period, for whatever reason, then the bank will be able to maintain smaller balances on average over the remaining days within the period. The estimated equation therefore also includes a variable, $R_{t-1}^{X}$, reflecting the level of excess balances accumulated through the previous day. (By definition, cumulative excess reserves equals zero on the first day of the maintenance period.)

Fourth, because the current reserve demand shock $e_{t}^{R}$ will generally affect the market federal funds rate, in the estimated equation the target rate $\bar{r}_{t}^{F}$ is substituted for the market rate in the term capturing the effect of the level of interest rates on the average demand for reserves over the maintenance period. The focus of interest in this estimation using daily data is on banks' ability to substitute reserve holdings across days within the maintenance period - the $\gamma$ parameter in demand equation (13) — not on the interest elasticity for the maintenance period as a whole as represented by $\beta^{R F}$.

Finally, the estimated equation also includes lagged values of the interest rate deviation $r_{t}^{F}-\bar{r}_{t}^{F}$, in order to capture the day-to-day dynamics of banks' reserve management, within the reserve maintenance period, that are not explicitly modeled by the other explanatory variables included in the regression. The observed daily deviation $r_{t}^{F}-\bar{r}_{t}^{F}$ exhibits a firstorder serial correlation of 0.35 , and in the absence of the lagged dependent variable the estimated error term exhibits serial correlation as well.

With these further modifications, the equation to be estimated is

$$
\begin{aligned}
r_{t}^{F}-\bar{r}_{t}^{F}= & \rho_{1}^{d}\left(r_{t-1}^{F}-\bar{r}_{t-1}^{F}\right)+\rho_{2}^{d}\left(r_{t-2}^{F}-\bar{r}_{t-2}^{F}\right)+\rho_{3}^{d}\left(r_{t-10}^{F}-\bar{r}_{t-10}^{F}\right)+ \\
& \theta_{1}^{d} \bar{r}_{t}^{F}+\theta_{2}^{d} R_{t}+\theta_{3}^{d} R_{t-1}^{X}+\sum_{j=1}^{10} \varphi_{j}^{d} d_{j t} \Delta^{e} \bar{r}_{t}^{F}+\sum_{j=1}^{3} \psi_{j}^{d} c_{j t}+\tilde{e}_{t}^{R}
\end{aligned}
$$

\footnotetext{
${ }^{71}$ From February 1994 (the first official public announcement of a target federal funds rate) until the onset of the financial crisis in 2007, the FOMC changed the target rate between scheduled meetings on only four occasions other than the cut immediately following September 11, 2001.

${ }^{72}$ As the discussion in Section 5 notes, banks are allowed to carry over a small amount of excess reserves from one period to the next. This flexibility works in only one direction, however; banks are not permitted to make up for a deficiency in one period with an excess in the next.
} 
where $\theta_{1}^{d}$ corresponds to $\gamma^{-1} \beta^{R F}$, and $\theta_{2}^{d}$ and to $\gamma^{-1}$, in the original demand equation (13). The $d_{j t}$ variables, for $i=1, \ldots, 9$, successively take the value 1 on days 1 through 9 of the maintenance period, successively, and 0 otherwise; the $d_{10 t}$ variable takes on the value 1 during maintenance periods with no scheduled FOMC meeting. The coefficients $\varphi_{j}$ are inversely related to the corresponding $\gamma_{\mathrm{s}}$ applying to these successive days of the maintenance period. The $c_{j t}$ are the calendar and lagged reserve accounting dummy variables described above. The transformed error term $\tilde{e}_{t}^{R}$ is equal to $\gamma^{-1} e_{t}^{R}$ in equation (13).

The obvious econometric challenge in estimating equation (18) is that the reserve demand error term $\tilde{e}_{t}^{R}$ incorporates the influence of a number of factors some of which are known in advance on a daily basis, or at least anticipated with a reasonable degree of accuracy, by the central bank. Because its operational objective is to achieve a certain target for the funds rate, the central bank will accommodate these shifts through changes in reserves, thus mitigating these shocks' impact on the effective overnight rate; hence $\operatorname{Cov}\left(R_{t} e_{t}^{R}\right)>0$, leading to an downward bias in the ordinary-least squares estimate of $\theta_{2}$. As discussed above, empirical studies of the liquidity effect in the U.S. and Japan, where the central bank actively responds to reserve demand shocks-for example, Carpenter and Demiralp (2006a, 2006b) - a have therefore used the exogenous reserve supply forecast "miss" in place of the observed level of reserves.

Equation (18) is indeed similar to the regression equation used by Carpenter \& Demiralp (2006a) to assess the anticipation and liquidity effects. The two substantive differences are the use here of the instrumented reserve level instead of the "miss" (as indicated above, here the "miss" is used as an instrument for the level of excess reserves) and, in line with the model developed above, the inclusion of the level of the federal funds rate. With these modifications, it is possible to interpret the equation as a structural reserve demand equation, estimated so as to remove the simultaneity stemming from the central bank's response to its estimate of the shocks, rather than a reduced form.

Table 5 reports results from a two-stage least-squares estimate of the structural demand equation (18) and, for comparison purposes, an ordinary-least-squares estimate of the reduced-form equation in which the reserves "miss" is used as a regressor instead of as an instrument for excess reserves. Both estimations use weighted least squares methods to correct for the pronounced reduction in the observed day-to-day volatility of the federal funds rate following the adoption of lagged reserve accounting in July 1998. The sample in each case consists of daily data spanning January 26, 1994 to July 2, 2007. ${ }^{73}$

The two sets of estimates are similar to each other, as well as to those reported by Carpenter \& Demiralp (2006a). The first four coefficients on the expected interest rate change interacted with the day-of-maintenance-period dummies are positive and highly significant, providing strong evidence for the presence of an anticipation effect, at least early in the maintenance period.

A liquidity effect is present in the data as well, but it is extremely small in quantitative terms. The coefficient of -0.92 on the excess reserves term, in the two-stage least-squares regression, is comparable to Carpenter and Demiralp's estimate. It implies that a $\$ 1$ billion increase in reserves, on any given day, results on average in not even a 1 basis point increase

\footnotetext{
${ }^{73}$ We are grateful to Spence Hilton, Darren Rose and Warren Hrung for providing us with these data.
} 
in that day's effective federal funds rate. ${ }^{74}$

A third important result evident in Table 5 is that the coefficient on the level of the (target) federal funds rate is close to zero and statistically insignificant. This implies that the reserve demand curve is effectively vertical within the maintenance period. This finding is consistent with $\beta^{R F}=0$ in reserve demand equation (13)—which, as discussed above, is a necessary condition for the "pure" anticipation (or announcement) effect to be sufficient to move the interest rate without any change whatever in the reserve supply.

The estimates reported in Table 5 for the model's other parameters are unsurprising, and they do not add to the substantive discussion. The coefficients on the lagged dependent variables indicate further dynamic effects that the reserve demand equation does not represent. The introduction of lagged reserve accounting reduced banks' demand for reserves, on average, and therefore reduced the federal funds rate relative to the target, all else equal. The spread between the federal funds rate and the target is larger on the final day of the reserve maintenance period as one would expect, although only in the two-stage regression. The spread is systematically larger, and by an even larger magnitude (either 10 or 14 basis points) on the final day of the month-presumably for window-dressing reasons. Banks' cumulative excess of reserves already held during the maintenance period reduces banks' demand for reserves, all else equal, and therefore reduces the federal funds rate relative to the target; but the estimated effect is small (only 0.5 basis point per $\$ 1$ billion of excess). There is no effect of an implied change in the rate not tied to a meeting of the Federal Open Market Committee.

\subsection{Within-Maintenance-Period Supply of Reserves}

The supply of reserves-specifically, how the central bank responds to expected deviations of the policy rate from target-holds the key to understanding how target rate changes are implemented. Table 6 presents analogous results for an empirically estimated equation representing the Federal Reserve's reserve supply behavior, using the same daily data for January 26, 1994 to July 2, 2007. The starting point is equation (14),

$$
R_{t}^{S}=R^{*}+\phi L\left(E_{t} r_{t+1}^{F}-\bar{r}_{t}^{F}\right)+L u_{t}^{R}
$$

in which, following equation (15), the supply response $\phi$ can be interpreted as the product of $\gamma$, the sensitivity of banks' reserve demand to deviations of the overnight rate from target, and $\lambda$, the degree to which the central bank actively resists any change in the rate due to the anticipation effect. The level of the interest rate is implicit in the benchmark level of reserves $R^{*}$, which with $\beta^{R T}=0$ is equal to $\alpha^{R}-\beta^{R F} \bar{r}_{t}^{F}$.

As in the case of the reserve demand equation, it is necessary to make several modifications to render equation (14) a suitable representation of the Federal Reserve System's reserve supply behavior for purposes of empirical estimation. First, for reasons analogous

\footnotetext{
${ }^{74}$ In regressions (not shown in the table) that allow this effect to differ by day of the maintenance period, the effect is closer to 3 basis points, but still economically insignificant in the context of the substantive discussion of the liquidity effect. On the last day of the maintenance period the estimated effect is approximately 3 basis points.
} 
to the treatment of the reserve demand equation (13), for purposes of estimation with daily data it makes sense to treat $L$, the size of banks' liquid asset portfolios, as fixed and therefore to subsume it within the estimated coefficients.

Second, as the discussion above has repeatedly emphasized, the estimated equation should take into account the central bank's efforts to offset predictable changes in reserve demand. To the extent that regular calendar and day-of-maintenance-period demand shifts are known and therefore accommodated, the estimated equation should include dummy variables comparable to those included above in the estimated reserve demand equation. Similarly, on the assumption that the central bank takes into account previous days' reserve imbalances (which, in principle, it knows without error), the estimated equation should also include a term representing the response to the cumulative excess reserve position, $R_{t-1}^{X}$.

Third, it is important to define the dependent variable for purposes of estimation in such a way as to reduce the variance associated with shocks to reserve supply. Some part of the disturbance term $u_{t}^{R}$ is inevitably simply noise in any estimated relationship. But a second source of random variation in the supply of reserves is the "miss" associated with the central bank's errors in forecasting autonomous factors, such as Treasury balances, that affect reserve supply. These sources of supply shocks allow the reserve demand equation to be identified, but they represent an additional source of noise in the reserve supply equation. It is therefore best to model not the central bank's actual supply of reserves, including the unintended component due to the "miss" in forecasting the relevant autonomous factors, but rather its intended supply. In the estimated reserve supply equation, therefore, the "miss" element is subtracted from the observed level of reserves (on the assumption that the central bank intends to offset these reserve supply shocks one-for-one), and the dependent variable in the regression is the resulting adjusted level of reserves, $\tilde{R}_{t}^{s}$.

Fourth, it is necessary to interpret the time subscripts in equation (14) correctly so that the estimated equation will accurately reflect the timing of the central bank's reserve supply decision. The Federal Reserve's procedure for providing reserves to the market begins with a forecast of the autonomous factors affecting reserve supply and, in parallel, an assessment of influences affecting reserve demand, in both cases as of the beginning of the day. The central bank then chooses its preferred supply of reserves, given its assessment of the factors affecting reserve demand. It then carries out whatever open market operations are necessary to render the expected reserve supply, based on its forecast of the autonomous factors, equal to that desired level. Reserve supply and demand shocks are then realized throughout the day, and either will cause the federal funds rate to deviate from the Federal Reserve's target. ${ }^{75}$ It is most consistent with this sequence of events to think of the Federal Reserve as therefore setting any given day's reserve supply in response to that morning'sin effect, the previous day's - information. The appropriate regressor is therefore $E_{t-1} r_{t}^{F}-$ $\bar{r}_{t}^{F}$ - that is, the interest rate deviation for that day, expected on the basis of information available as of the previous day. This expected deviation would of course not include day- $t$ shocks, but it would include predictable deviations resulting from the "anticipation effect" discussed above to the extent that $\lambda>0$.

\footnotetext{
${ }^{75}$ Only very rarely does the Federal Reserve intervene later in the day in response to realized reserve supply or demand shocks.
} 
Fifth, as in the reserve demand equation estimate above, lagged values of the dependent variable are included as regressors in the estimated equation, in order to capture any dynamics of reserve adjustment - in this case, representing the Federal Reserve's behavior-not explicitly modeled by the explanatory variables included in the regression.

Finally, as discussed above, a necessary condition for a "pure" anticipation (or announcement) effect to be operative is $\beta^{R F}=0$. In this case no change in reserves at all need be associated with a current-day change in the target interest rate, controlling for expectations of future target rate changes. As a test of this hypothesis, the estimated equation also includes the current day's target rate change, $\Delta \bar{r}_{t}^{F}$, as well as prior changes, denoted $\Delta_{p} \bar{r}_{t}^{F}$ and defined as the change in the target rate occurring on any preceding day of the maintenance period.

These modifications yield the following regression specification,

$$
\begin{aligned}
\tilde{R}_{t}^{s}= & \rho_{1}^{s} \tilde{R}_{t-1}^{s}+\rho_{2}^{s} \tilde{R}_{t-2}^{s}+\theta_{1}^{s} R_{t-1}^{X}+\theta_{2}^{s} \Delta \bar{r}_{t}^{F}+\theta_{3}^{s} \Delta_{p} \bar{r}_{t}^{F}+\theta_{4}^{s} \bar{r}_{t}^{F}+ \\
& \varphi^{s}\left(E_{t-1} r_{t}^{F}-\bar{r}_{t}^{F}\right)+\sum_{j=1}^{3} \psi_{j}^{s} c_{j t}+\tilde{u}_{t}^{R}
\end{aligned}
$$

where $\varphi^{s}$ corresponds to $\lambda \gamma$ in (14). The forward-looking specification of the supply of reserves is estimated using as a regressor the $t$-dated interest rate deviation, instrumented with a set of variables dated $t-1$ that plausibly predict the next day's interest rate: the observed deviation of the interest rate from target, the average rate for the current month implied by the federal funds futures market, and the futures-implied average rate for the remainder of the maintenance period. For comparison, Table 6 also shows results for a backward-looking version of the reserve supply equation, in which $E_{t-1} r_{t}^{F}-\bar{r}_{t}^{F}$ is replaced by $r_{t-1}^{F}-\bar{r}^{F}$. The table also shows results for a third variant, estimated using the unexpected change in the federal funds rate, computed from the futures data, as an instrument for the observed change. ${ }^{76}$

The first important result that appears in the results reported in Table 6 is that there is no statistically significant tendency for the Federal Reserve to vary the supply of reserves systematically with the level of interest rates. The estimated coefficient on the level of the target federal funds rate is consistently insignificant. This finding is consistent with the evidence of a vertical reserve demand curve reported in Section 3 above.

Nor is there much evidence that a change in the interest rate target is accompanied by a change in the quantity of reserves supplied. The coefficient on the change in the target rate in the weighted-least-squares backward-looking regression, shown in the table's first column, is negative $(-0.022$, meaning a $\$ 550$ million reduction in reserves for a typical 25 basis point increase in the target rate) and statistically significant. But this effect disap-

\footnotetext{
${ }^{76}$ If the relevant market behavior exhibits an anticipation effect, but banks are not anticipating a change in the target rate, then the central bank would need to change the supply of reserves-on the day of the change in the target-in a way that otherwise would not be necessary. In this case the actual interest rate change would be a noisy measure of the expectation that matters for purposes of the regression being estimated. A plausible solution to the resulting errors-in-variables problem is to use the surprise component of the rate change as an instrument for the observed change.
} 
pears in the forward-looking regressions, where the expected interest rate deviation is used instead of the lagged deviation. With this change, the estimated coefficient is very small, and statistically indistinguishable from zero, regardless of whether the target rate change is treated as exogenous (second column) or instrumented with the surprise element of the change constructed from the futures-market data (third column).

By contrast, there is statistically significant evidence that the Federal Reserve tends to adjust the supply of reserves in the days following changes in the target rate. The estimated coefficient of -0.016 - the estimate is the same for all specifications-implies that a 25 basis point increase (decrease) in the target federal funds rate is, on average, followed by a $\$ 400$ million decrease (increase) in reserve supply on subsequent days within the maintenance period. At first sight this finding may appear puzzling; as the discussion below explains, however, on reflection it is readily understandable.

Most importantly, the results in Table 6 show that the Federal Reserve responds forcefully to expected deviations of the federal funds rate from target, corroborating an analogous finding in Carpenter \& Demiralp (2006a). The relevant coefficient is consistently large and statistically significant. In the backward-looking specification, the estimated coefficient on the lagged deviation is 0.014 , implying that an expected positive 10 basis point deviation would lead the Federal Reserve to supply an additional \$140 million in reserves. The response is much stronger in the forward-looking specification. In either version, the estimated coefficient of 0.049 implies that a positive 10 basis point deviation would lead the Federal Reserve to add $\$ 490$ million in additional reserves. ${ }^{77}$

These estimates seem quite large compared with the average level of excess reserves of \$1.9 billion over the 1994-2007 sample period. Three considerations are relevant. First, despite the low average level, excess reserves are quite volatile (see again Figures 2-4); the daily standard deviation over this sample is $\$ 4.2$ billion. Compared to this degree of daily volatility, a $\$ 490$ million change in supply is not necessarily large.

Second, at least according to the estimates reported here, these relatively large effects all involve rearranging reserve supply within the maintenance period, leaving the average supply of reserves for the period as a whole largely unaffected; the entire effect of the interest rate is on the distribution of reserve holdings across days within the maintenance period, not on the average level of reserves held for the period as a whole. This pattern is clearly visible in Figure 13, based on the same daily data for 1994-2007, which shows the changes in reserves on days surrounding a change in the target, together with the associated 90 percent confidence intervals. Presumably because of banks' expectations of the forthcoming change, in the days just prior to an increase (decrease) in the target rate banks are seeking to hold more (fewer) reserves in order to take advantage of the lower cost of satisfying their reserve needs for the maintenance period, and so the Federal Reserve is increasing (decreasing) the reserve supply in response. The volume of reserves held then

\footnotetext{
${ }^{77}$ These estimates are substantially larger than those reported by Feinman (1993a), whose full-sample results implied an $\$ 81$ million response to a 10 basis point interest rate deviation. Two factors could account for the much larger estimates here. One is the forward-looking econometric specification. The other is that Feinman's sample was for a period when the Federal Reserve was using a borrowed reserves operating procedure, under which higher-than-expected interest rates led banks to increase their borrowing from the discount window.
} 
falls (increases), once the target rate change actually occurs.

Third, the coefficients estimated here represent the Federal Reserve's response to ceteris paribus experiments that would not normally be observed in the data. An anticipated future federal funds rate increase, for example, would put upward pressure on the current rate, which would in turn lead the Federal Reserve to increase the supply of reserves. But this reserve addition would tend to increase the cumulative excess reserve position, as of the next day-which, according to the estimated model (in any of the three variants shown in Table 6), would then exert the opposite effect on the supply of reserves. For this reason, the observed magnitude of reserve supply changes surrounding movements in the target interest rate are very likely to be smaller in practice than these coefficient estimates, taken at face value, would imply. Indeed, as Figures 1-4 above show, this is the case.

Taken together, the estimated reserve supply and demand equations reported in Table 5 and 6 confirm that only very small changes in reserves are required to effect movements in the Federal Reserve's policy interest rate-including, as the estimated supply curve indicates, virtually none on the actual day when the target rate changes. As the model above makes clear, this finding is actually consistent with what amounts, in effect, to a horizontal reserve demand curve on a day-to-day basis within the reserve maintenance period. The implication that follows is that anticipation effects, along the lines analyzed in Section 5 above, play a significant role in moving the policy interest rate to the central bank's new target within the maintenance period. It is not surprising, therefore, that it would be so difficult, in exercises like those reported in Section 4, to discern in the data any regular relationship between the quantity of reserves supplied and the either the target or the effective market interest rate.

\section{New Possibilities Following the 2007-9 Crisis}

The 2007-9 financial crisis and economic downturn represented one of the most significant economic events since World War II. In many countries the real economic costs-costs in terms of reduced production, lost jobs, shrunken investment, and foregone incomes and profits-exceeded that of any prior post-war decline. In the United States, the peak-totrough decline in real output was 3.8 percent, a post-war record (although only slightly greater than in the recession of 1957-8). In the Euro-area the decline was 5.4 percent, the first outright decline since the establishment of the European Central Bank. In Japan, the decline was 8.4 percent, also a post-war record. The decline affected countries in nearly all parts of the world. In 2009 the volume of world trade was down by 12 percent. $^{78}$

It was in the financial sector, however, that this episode primarily stood out. The collapse of major financial firms, the decline in asset values and consequent destruction of paper wealth, the interruption of credit flows, the loss of confidence both in firms and in credit market instruments, the fear of default by counterparties, and above all the intervention by central banks and other governmental institutions-both in scale and in form-were extraordinary. Whether this latest episode constituted the worst real economic downturn

\footnotetext{
${ }^{78}$ Data on world trade are from the IMF.
} 
since World War II was, for many countries, a close call. But there was no question that for the world's financial system what happened was the greatest crisis since the 1930s.

Large-scale and unusual events often bring forth unusual responses, in private economic behavior and public policy alike, and in this respect the 2007-9 financial crisis was no exception. Governments in many countries turned to discretionary anti-cyclical fiscal policies in ways that they had not for decades. Both governments and central banks undertook massive lender-of-last resort actions_-not just limited to banks but including nonfinancial firms such as General Motors and Chrysler too. More to the point for purposes of this chapter, monetary policy in many countries also took unprecedented paths. Some aspects of what central banks did amounted to using existing powers and institutional arrangements in novel ways. As the discussion in Section 4 above has already indicated, however, countries like the United States and Japan also changed the institutional structure within which their central banks carry out monetary policy (in both countries by authorizing the central bank to pay interest on banks' holdings of reserves).

What lessons to draw from such an extraordinary experience for more normal times is always a difficult question. For this reason, the empirical analysis presented in Sections 4 and 6 above relies on sample periods that end no later than mid 2007-before the crisis took hold. It is useful nonetheless to consider in what ways the new forms of action that central banks have taken during the crisis, and especially the new institutional arrangements associated with monetary policy like those in the U.S. and Japan, may affect the implementation of monetary policy on an ongoing basis.

\subsection{The Crisis and the Policy Response}

The broad narrative of the financial crisis that began in 2007 is well known and requires only the briefest summary here. ${ }^{79}$ The crisis originated in the United States, and in particular in the market for residential mortgage lending. Beginning in the late 1990s, but especially once the relatively mild 2001 U.S. recession had ended, house prices rose rapidly. Increasingly lax mortgage underwriting standards-high loan-to-value ratios, back-loaded payment schemes, and little if any documentation-were both a cause and a consequence of the rise in prices: less onerous lending conditions spurred demand for houses, while the rising value of the underlying collateral lessened concerns for the creditworthiness of borrowers. Securitization of a large fraction of the newly issued mortgages further lessened the originators' interest in their integrity. Investors in the created securities, or in derivatives based on them, either misled themselves (for example, similarly counting on rising house prices to nullify the implications of borrowers' lack of creditworthiness) or were misled by rating agencies that carried out inadequate analysis and also faced serious conflicts of interest. Importantly, many of these investors were non-U.S. entities.

\footnotetext{
${ }^{79}$ There are numerous useful accounts that provide helpful narrative and detailed supporting statistical information. See, for example, the IMF's October 2009 Global Financial Stability Report and Ch. 3-4 of the October 2009 World Economic Outlook; Part I of the OECD's December 2009 Financial Market Trends; and Ch. 2 of the BIS's December 2009 Quarterly Review; also previous issues of the same publications. Central banks have also issued numerous useful accounts.
} 
At the same time, two more general developments, one concerning financial institutions and the other concerning financial instruments, rendered the U.S. financial system, and those who participated in it, more vulnerable. First, the distinction between banking and trading mostly disappeared - and not simply as a consequence of the formal repeal in 1999 of what remained of the Depression-era Glass-Steagall separation, which had largely eroded long before. Most of the large U.S. commercial banks, facing the need to raise their own capital in competitive securities markets, relied increasingly on trading profits, in effect turning themselves into hedge funds. (Otherwise they would have had little reason to retain shares of the mortgage-backed securities for which they earned fee income on by packaging and selling.) Meanwhile, most of the large investment banks, which already had significant trading operations, increasingly used the repurchase-agreement market to fund themselves with what, in effect, amounted to short-term deposits.

Second, the continuing development of the market for financial derivatives moved beyond the role of enabling investors (including financial institutions) to hedge risks that they already bore and instead increasingly provided vehicles for taking on new, unrelated risks-permitting participants either to speculate on changes in the market price of those risks or simply to generate a new form of fee income. As a result, many of the risks to which investors became exposed bore little or no connection to fluctuations in any component of the economy's actual wealth. The risks borne, increasingly, were merely bets on one side or the other of a zero-sum game.

Given the vulnerability created by these two more fundamental developments, it is not surprising in retrospect that a sufficient catalyst would trigger a widespread crisis. The turnaround in U.S. house prices that began in late 2006 provided such a catalyst. By late 2007 house prices on a nationwide basis were falling at a double-digit annual rate. By late 2008 the rate of decline, nationwide, was nearly 20 percent. In some states, and in many local residential markets, the declines were significantly greater. (Because what matters for any individual mortgage is the specific house collateralizing that loan, the dispersion of price changes around a given average rate of decline worsens the probability of default.) Especially in the market for "sub-prime" mortgages, delinquencies and defaults increased. In time, so did foreclosures. In some areas spreading foreclosures helped drive house prices down still further.

The resulting loss of value on mortgage-related securities accrued not only to investors but also to many of the banks and other firms that had sponsored and distributed these securities (again, because they were acting as traders in addition to their role as originators and distributors). With only thin capitalization-leverage ratios of $12-15$ to one for a typical large commercial bank and 25-30 to one for a typical investment bank-the institutions taking the largest paper losses also lost the confidence of both equity investors and creditors. Rolling over their short-term funding therefore became problematic; in effect, institutions that were not banks sustained "bank runs" on liabilities that were not deposits. (In the U.K., where deposit insurance had long been inadequate, there were actual deposit runs on banks.) Interbank lending markets became subject to unprecedentedly wide spreads, and in many cases largely ceased to function. ${ }^{80}$ Further, once financial institutions

\footnotetext{
${ }^{80}$ See Taylor \& Williams (2009) for an account of the interbank-lending market during this period.
} 
lost the market's confidence they became unable to participate in a wide variety of auxiliary transactions from which they ordinarily earned fee income; the counterparty risk that they presented was too great. Except for repurchases involving government bonds (and, for some counterparties, even on those), the repo market ceased to function as well. ${ }^{81}$

With so many banks and other lending institutions impaired in any or all these ways, credit for nonfinancial borrowers became increasingly scarce-and not just for housing finance. In August 2008, the month before the Lehman Brothers failure, U.S. banks' commercial and industrial loans outstanding totaled $\$ 1,558$ billion. ${ }^{82}$ By December 2009 outstandings were only $\$ 1,343$ billion. Over the same period consumer loans, from banks as well as other lenders, declined from $\$ 2,578$ billion to $\$ 2,449$ billion. The contraction of credit was much sharper in capital markets. ${ }^{83}$ The volume of asset-backed commercial paper outstanding dropped from \$1,208 billion in July 2007 to only $\$ 489$ billion in December 2009. Unsecured commercial paper issued by nonfinancial firms continued to increase irregularly through December 2008, reaching \$206 billion, but then fell to just \$108 billion in December 2009. The total volume of new bond issues sold in the United States on behalf of U.S. corporations fell from \$2.3 trillion in 2006 to only \$749 billion in all of 2008 .

In addition, declining asset values imposed a sizeable loss of real wealth on both household and firms. The value of corporate equities outstanding in U.S. markets dropped from $\$ 26.4$ trillion in the summer of 2007 to $\$ 13.9$ trillion in early 2009 . The value of residential real estate owned by households declined from $\$ 22.9$ trillion at yearend 2006 to $\$ 15.7$ trillion in early 2009. Both the unavailability of credit and the loss of wealth presumably played a part in the drop in spending that ensued. Similar patterns, in greater or lesser degree, appeared in many other countries as well.

The sequence of actions that many of the world's central banks took in response to these events was extraordinary. At the beginning, central banks addressed the crisis by carrying out conventional monetary policy, though often in unconventional ways. In September 2007 the U.S. federal funds rate was 5-1/4 percent. By January 2008 the Federal Reserve had lowered the rate to 3 percent. In October 2008 - after the Lehman collapse-it lowered the rate to just 1 percent, and in December 2008 it went to zero. The ECB, with its nearexclusive statutory focus on price stability, waited until October 2008 to lower its main refinancing rate, from 4-1/4 percent to 3-3/4 percent. By January 2009 the main refinancing rate was down to 2 percent. In March 2009 the ECB lowered it to 1-1/2 percent, in April 2009 to 1-1/4 percent, and in May 2009 to 1 percent. The Bank of Japan waited until the very end of October 2008 to ease monetary policy, cutting the uncollateralized call loan rate from $1 / 2$ percent to 0.3 percent. In December 2008 it reduced the rate further, to 0.1 percent. Figure 14 shows these patterns of continual reduction in the policy interest rates of all three of these central banks. (Because of the prior history of a zero interest rate in Japan, the bottom panel in the figure covers not just the 2007-9 crisis period but the experience since the mid 1990s.)

\footnotetext{
${ }^{81}$ See Gorton (2008) and Gorton \& Metrick (2009).

${ }^{82}$ Data, here and below, are from the Federal Reserve System.

${ }^{83}$ Adrian \& Shin (2010) described this evaporation of wholesale funding and attributed it to institutions' efforts to reduce their risk exposure.
} 
Especially after the Lehman failure, the degree of international coordination among central banks in taking these actions also moved to an unprecedented level. In October 2008 - three weeks after Lehman failed - the Federal Reserve, the ECB, the Bank of England, the Swiss National Bank, the People's Bank of China, the Bank of Canada and the Sveriges Riksbank all cut their policy interest rates simultaneously. Most of the major central banks also preemptively established swap lines, or enlarged existing ones, to enable them to extend the provision of central bank liquidity beyond national borders, for currencies (like the dollar and the euro) used internationally.

But the actions that central banks took extended well beyond the realm of interest rate movements and exchange market operations. In the United States, the initial indication of extraordinary action came in December 2007 when the Federal Reserve System implemented the first of what would become a series of new credit facilities, the "Term Auction Facility" (TAF) to channel additional central bank credit to commercial banks needing reserves. In March 2008 the Federal Reserve established two further credit facilities, the "Term Securities Lending Facility" (TSLF) and the "Primary Dealer Credit Facility" (PDCF) to extend central bank credit against a broader class of collateral, and also to nonbanks. In May it expanded the TSLF to accept high-rated asset-backed securities as collateral. In October it introduced a "Commercial Paper Funding Facility" and a "Money Market Investor Funding Facility" and also expanded several of its existing new facilities. In November it began direct purchases of obligations issued by the government-sponsored mortgage agencies Fannie Mae and Freddie Mac. In February 2009 the Federal Reserve expanded its recently created "Term Asset-Backed Securities Loan Facility" to \$1 trillion and further widened the range of eligible collateral. The actions taken continued on through 2009. Most significantly, in March 2009 the Federal Reserve began purchasing securities backed by residential mortgages; as of yearend 2009 its holdings amounted to $\$ 900$ billion.

In conjunction with the U.S. Treasury and the Federal Deposit Insurance Corporation, the Federal Reserve also undertook a variety of lender-of-last resort actions: an emergency loan to J.P. Morgan to facilitate the bank's take-over of failing investment bank Bear Stearns; allowing the investment banks Goldman Sachs and Morgan Stanley to become bank holding companies for the purpose of access to the central bank's discount window facility; raising the limit on FDIC deposit insurance to $\$ 250,000$ per account, and later guaranteeing the senior indebtedness of all regulated financial institutions; placing Fannie Mae and Freddie Mac in receivership; injecting capital directly into key financial institutions (and changing the definition of Tier I capital to include stock purchased by the Treasury); extending emergency loans to insurance company AIG, and special aid (including nonrecourse loans from the Federal Reserve) to Citigroup and Bank of America. While many of these actions may well have been important in their handling of the financial crisis, they nonetheless lie outside the scope of this chapter.

Outside the United States extraordinary actions to arrest the crisis began even earlier. In August 2007, the ECB undertook a special intervention, injecting $€ 95$ billion and declaring that it was ready to provide unlimited liquidity to Euro area banks. September 2008, the ECB undertook a special term-refinancing operation in the amount of $€ 120$ billion. As the crisis deepened, in October 2008 the ECB reduced to 50 basis points the "corridor" 
between the interest rates on its two standing facilities and the main refinancing rate. ${ }^{84}$ In May 2009 the Bank announced that its tender procedure for its regular monetary policy operations would revert to a fixed-rate tender system with no cap on the volume, effectively providing unlimited liquidity to the banking system at the target main refinancing rate. In addition, the ECB lengthened the average maturity of its operations, expanded its list of eligible collateral, and introduced several special facilities allowing the bank to transact with new counterparties or to undertake new kinds of transactions. ${ }^{85}$

The Bank of Japan had already been employing extraordinary policy measures since the late 1990s, so that by the time the 2007-9 crisis occurred they no longer seemed so extraordinary in the Japanese context. Facing a series of bank failures that began in 1995, the BOJ cut interest rates steadily throughout the decade, reaching zero in February 1999. In parallel with its interest rate policy, the BOJ expanded its securities lending facility, expanded the range of private securities eligible for repurchase, and undertook a limited program to provide funding for Japanese corporations. With the further deterioration in macroeconomic conditions in 2000, in March 2001 the BOJ embarked on its "Quantitative Easing Policy," which, by mid-2004, had increased current account balances to $¥ 33$ trillion. Also during the QEP period, the BOJ increased both its outright purchases of Japanese Government securities, introduced outright purchases of commercial paper and even purchased small amounts of corporate equities. ${ }^{86}$

Figures 15 and 16 show, for the U.S., the Euro-system and Japan, the extent to which central banks' balance sheets reflected these extraordinary measures. Figure 15 shows the sharp increase in the total liabilities of each central bank, together with an underlying breakdown between currency and reserves (and, for the ECB deposits at the standing deposit facility). What stands out here-not surprisingly-is that the surge in central bank liabilities was almost entirely in reserves (or ECB deposits); currency outstanding departed little from prior trends. Figure 16 shows the parallel increase in total assets, together with a breakdown according to major categories of assets held. Here the unusual nature of the action taken is most readily apparent at the Federal Reserve, which initially provided liquidity to key markets through various facilities like the TAF and the CPFF and then embarked on its large-volume acquisition of residential mortgage-backed securities, in effect taking on itself part of the intermediation function that the private sector (both banks and the securities markets) were no longer able to perform. But the expansion of the ECB's long-term repurchase operations and dollar-denominated loans (to Euro-area entities), and of the BOJ's direct loan portfolio (which stood at nearly zero at the beginning of 2006), are readily evident as well.

\footnotetext{
${ }^{84}$ The ECB re-established a 100 basis point spread on January 21,2009 , but subsequently narrowed it to 75 basis points on May 13, 2009.

${ }^{85}$ See Lenza et al. (2010) for an account of the ECBs actions in response to the crisis.

${ }^{86}$ See Shiratsuka (2009) for a comprehensive summary of the BOJ's experience with the QEP. See Kuttner (2010) for a comparison of the BOJ's unconventional policies during 1995-2006 with those of the Federal Reserve during the 2007-9 crisis.
} 


\subsection{Implications for the Future Conduct of Monetary Policy}

Three aspects of these responses to the crisis on the part of central banks, taken together, potentially open up new avenues for the implementation of monetary policy. First, as Figures 15 and 16 both show, central banks were willing under these circumstances to undertake very large expansions of their balance sheets. Among the three central banks included in the figure, this move is most evident at the Federal Reserve System. In December 2007 U.S. banks' total reserves were (as usual) $\$ 43$ billion. By December 2008 they were $\$ 820$ billion. By December 2009 they were $\$ 1,153$ billion. But the Federal Reserve was not unique in this regard. The comparable increase at the Bank of England was even larger in relation to the economy. The BofE's total liabilities are normally around 5 percent of U.K gross domestic product; by 2009 they were nearly 17 percent.

Second, as Figure 16 shows, in the context of this large increase in their total liabilities central banks also deployed the asset side of their balance sheets in highly unusual ways, involving extension of credit not just to banks but to their economies' private sectors more generall. Their doing so involved the assumption of not just market risk (from holding longer-maturity instruments) but credit risk as well. Here again, the departure is most evident at the Federal Reserve, with its holding first of large volumes of money market instruments, like commercial paper, and later on even larger volumes of mortgage-backed securities.

Third, in the setting of the crisis both the Federal Reserve and the BOJ followed the ECB in putting in place the makings of a two-sided "corridor" system for influencing their respective policy interest rates. In addition to the reserve lending facilities that these two central banks had had in place since earlier in the decade, each one instituted a standing facility for absorbing reserves back from banks at a designated rate of remuneration tied to its target for its monetary policy interest rate.

The potential implications are profound. Under the traditional view of how central banks implement monetary policy, as illustrated in Figure 5, the central bank has only one policy instrument at its disposal; that is, it has only one choice to make. It can set the quantity of reserves or it can set the relevant (short-term) interest rate. In either case, its decision amounts to choosing a point along the downward-sloping reserve demand curve that it faces, representing the behavior of banks in adjusting their holdings of reserves and other liquid assets. (The central bank can also supply reserves with some finite elasticityimplementing an upward-sloping reserve supply function-but in this case too, for purposes of this discussion there is one choice to be made: at what point the reserve supply schedule intersects the downward-sloping demand schedule.) What the central bank cannot do, under the traditional view, is independently choose both the interest rate and the quantity of reserves.

One immediate implication of the crisis situation, once central bank policy interest rates went to zero (see again the panels of Figure 14 for the U.S. and Japan), was that the central bank could vary the supply of reserves without any consequence for the interest rate. As Figure 17 shows, the downward-sloping reserve demand schedule of Figure 5 presumably becomes horizontal once it reaches the horizontal axis; the nominal interest rate cannot go below zero (apart from a tax on reserve balances, which no central bank 
has ever implemented). ${ }^{87}$ As long as the reserve quantity that the central bank chooses is equal to or greater than the amount at which reserve demand becomes horizontal at the zero interest rate, therefore, the central bank could supply whatever amount of reservesand therefore acquire whatever volume of assets - that it chose, without any effect on the policy interest rate, which would simply remain at zero.

Why would the central bank choose to supply a quantity of reserves greater than necessary for consistency with a zero interest rate? By creating yet more reserves, the central bank necessarily takes on yet more assets. The difference in quantity may make little or no difference from the perspective of the liability side of the central bank's balance sheetsince reserves and Treasury bills become close to perfect substitutes at a zero interest rate, it probably makes little difference which one banks hold—but the difference may matter on the asset side. If the assets that the central bank purchases as the counterpart to its creating additional reserves provide liquidity to key nonbank markets that have become impaired (for example, the Federal Reserve's purchases of commercial paper under the CPFF) or otherwise transfer to the central bank credit risk that the private sector is willing to bear only at an increasing price with increasing quantity (for example, the Federal Reserve's purchases of residential mortgage-backed securities), then those purchases may also help advance the objectives of monetary policy even without any movement in the policy interest rate, which would remain unchanged at zero.

The situation depicted in Figure 17 does not strictly violate the traditional presumption that the central bank has only one instrument at its disposal. Within the conventional framework of price (interest rate) and quantity in the market for reserves, the central bank is still making only one choice: the quantity of reserves it supplies. There is no implication for an accompanying movement of the interest rate, because the interest rate is bounded from below, at zero. As Goodfriend (1994), Gertler \& Karadi (2009), Borio \& Disyatat (2009), Woodford and Curida (2010a, 2010b), Ashcraft et al. (2010) and others have pointed out, however, in a broader context that takes into account such factors as the impact of providing liquidity to impaired markets, or taking on credit-risk in price-sensitive markets, the central bank $i s$ making a second choice: the composition of the asset side of its balance sheet. In principle, the central bank would always have that further choice at its disposal, whether its policy interest rate were at zero or not.

What does potentially contradict the presumption that the central bank can make only one decision within the price-quantity representation of the reserves market is payment of interest on reserves. ${ }^{88}$ The form of standing facility that central banks currently have, however-including the Federal Reserve, the ECB and the BOJ-is sufficient for this purpose only if the central bank is willing to abandon the effort to achieve its target for its policy interest rate. Figure 18 depicts a "corridor" system in which banks' reserve demand

\footnotetext{
${ }^{87}$ Keister \& McAndrews (2009) provided evidence, for the U.S., that banks' demand for excess reserves in fact does approach becoming horizontal at near-zero interest rates. Goodfriend (2000) raised the possibility of a "carry tax" on currency, in the context of the concern (never realized) that the U.S. might get to a zero federal funds rate in the 2001 recession.

${ }^{88}$ For analyses along these lines, see Goodfriend (2002) and Keister et al. (2008). Bowman et al. (2010) examined the recent experience in this regard of nine central banks, including the three that are the focus of attention here as well as those of Australia, Canada, New Zealand, Norway, Sweden and the U.K.
} 
is effectively horizontal at the interest rate paid by the central bank's deposit facility and the central bank's reserve supply is horizontal at the rate charged by its lending facility, where both rates are tied to the central bank's target rate. (Following the traditional view in other respects, the figure abstracts from the question, considered in detail above, of whether reserve demand is interest inelastic at a daily frequency.) In between the effective upper and lower bounds, the central bank faces the usual choice corresponding to picking a point on the downward-sloping reserve demand curve. The central bank can arbitrarily increase the supply of reserves, thereby enlarging its balance sheet so as to be able to undertake expanded asset purchases; but if it does so then beyond a certain point (designated $Q$ in the figure), the policy interest rate will not equal the target rate $\bar{r}$ but rather the rate paid on excess reserves $r_{l}$, which stands at a fixed distance below the target rate. Hence the central bank's freedom to choose arbitrarily the reserve quantity, and therefore the volume of central bank asset purchases, comes at the expense of its ability to enforce its interest rate target. ${ }^{89}$ Importantly, however, in contrast to the situation without payment of interest on reserves, the resulting downward movement of the policy interest rate is bounded not by zero but by the rate paid on excess reserves. ${ }^{90}$

Alternatively, if the standing facility for remunerating banks' excess reserve holdings relied on a specific designated rate (unlike the facilities currently in place at the Federal Reserve, the ECB and the BOJ), then the central bank would be able to choose both the interest rate and the quantity of reserves supplied - and choose them more or less independentlywithout having to accept that the equilibrium market level of its policy interest rate will be below target. In this case, depicted in Figure 19, the central bank is able to enforce the target rate by remunerating excess reserve holdings at the target rate itself. Any reserve supply quantity equal or greater than $Q$ then results in the same level for the market interest rate on reserves: the target rate. Here again, implementing monetary policy in this way presumably makes little or no difference from the perspective of the liability side of the central bank's balance sheet; supplying additional reserves, which banks then simply hold as excess reserves, is unlikely to affect their credit- or deposit-creating activity. By contrast, the balance sheet counterpart is a greater volume of assets purchased by the central bank-which could matter importantly, depending on the choice of assets and on market circumstances.

\footnotetext{
${ }^{89}$ This situation approximately describes conditions in the Euro-system from 2009 through the time of writing. During this period the EONIA has mostly traded some 8-9 basis points above the ECB's deposit facility rate ( 0.25 percent), and well below the main refinancing rate (1 percent). For practical purposes, therefore, it is the deposit rate that has mattered, not the main refinancing rate. (On the other side of the "corridor," borrowing from the ECB's marginal lending facility has mostly been limited to banks that, because of concerns about their suitability as counterparties, are unable to obtain funds readily in the market.) See Lenza et al. (2010).

${ }^{90}$ In a "corridor" system like New Zealand's, in which the interest rates on the two standing facilities are set in relation to the market rate on overnight reserves, rather than the central bank's target, even this limited expansion of the central bank's choice set is unavailable. As the market rate falls, with increasing reserve supply along the downward-sloping reserve demand schedule, the rate paid on reserves moves downward. Under these arrangements, the only rate at which the central bank can increase reserve supply arbitrarily without affecting the interest rate is zero.
} 


\subsection{Some Theoretical and Empirical Implications}

One question that arises in this context, given the discussion in Section 1 above, is whether the central bank's ability to vary the supply of reserves without affecting the market interest rate, under the institutional arrangements in place since 2008 in the U.S. and Japan and in the euro-system since inception (or as amended to allow the central bank to specify the excess reserve remuneration rate as equal to, rather than some set number of basis points below, the target interest rate), violates the basic principle articulated by Wicksell a century ago. In short, the answer is no.

In the case of the central bank's ability to vary the interest rate without having to change the supply of reserves - the focus of much of the discussion in Sections 2, 3 and 5 here - the reason turns largely on matters of institutional detail and time horizon. As the discussion above explains, the apparent puzzle that movements in the central bank's policy interest rate require little or no change in reserve supply is, in the first instance, a consequence of arrangements, like lagged reserved accounting and averaging over the maintenance period, that make banks' demand for reserves highly inelastic on a day-to-day basis. This does not mean that the central bank can indefinitely maintain the interest rate at any arbitrarily chosen level without consequence for the demand for reserves. As Wicksell explained, indefinitely keeping the interest rate lower than "normal" presumably leads to an everincreasing demand for credit. If the use to which borrowers put that credit also increases nominal aggregate demand and output, the demand for deposits presumably increases as well. To the extent that these additional deposits bear reserve requirements, banks' demand for reserves therefore increases in parallel. Wicksell's point was that the only way for the central bank to keep the market interest rate on reserves from rising back to "normal" is to keep increasing the corresponding supply.

Panel (b) of Figure 7 above nicely illustrates Wicksell's argument (although without the element of the interest rate's being held below "normal"). Reserves held by banks in the Euro-system have increased steadily since the monetary union, as outstanding deposits have grown. If the ECB had not supplied sufficient reserves to meet this demand, the market interest rate would have risen, at least temporarily until the higher interest rate level reduced aggregate demand and output and in turn the demand for deposits. The fact that reserve balances have not similarly increased over time in the United States and Japan (see panels (a) and (c) of Figure 7) reflects aspects of the demand for and supply of different kinds of deposits (in the U.S., for example, the introduction of sweep accounts), which lie beyond the focus of this chapter on the implementation of monetary policy and therefore on the market for reserves.

The reverse situation - in which the central bank supplies an arbitrarily large quantity of reserves, while using the reserve remuneration rate to keep the market interest rate from falling - is different, but it too does not strictly contradict Wicksell's principle. To the extent that the central bank is merely supplying reserves through open market operations and absorbing them back through the standing deposit facility, these "neutralized" (or "idled") reserves do not enter Wicksell's reasoning. Whether the central bank re-absorbs them via its reserve deposit facility, or by reversing the open market operations that created them in the first place, is irrelevant. From the perspective of his argument, they are not a part of 
the supply of reserves at all. Indeed, as the discussion above emphasizes, creating these reserves matters only in so far as the central bank uses the asset purchases that are their counterpart in ways that matter; but this possibility is not a part of Wicksell's analysis.

Finally, is there evidence that targeted asset purchases by the central bank matter-for market interest rate relationships, or for the functioning of financial markets more broadly, or for nonfinancial economic activity? The experience with such actions is too recent, and the events of the 2007-9 crisis and downturn not yet sufficiently analyzed, to offer any firm judgment, especially for nonfinancial activity. There is at least some evidence, however, to suggest that the large-scale asset purchases undertaken by the Federal Reserve System did affect interest rate relationships and the functioning of some markets that had been impaired in the crisis.

In October 2008, at the height of the financial crisis, the Federal Reserve created a new facility, the Commercial Paper Funding Facility, to purchase newly issued commercial paper. As panel (a) of Figure 16 shows, the volume of assets purchased under this facility grew rapidly. By early 2009 the CPFF held $\$ 350$ billion of commercial paper. As Figure 20 shows, at the time when the CPFF was created, the spread between the interest rate on three-month AA-rated commercial paper issued by financial companies and the three-month overnight-interest-swap rate had widened to historically unprecedented levels. ${ }^{91}$ Rates that had been approximately identical before the crisis, and had widened to 50-100 basis points apart as the crisis began to unfold, reached more than 250 basis points apart after the Lehman failure. In parallel, compared to gross weekly issuance of more than $\$ 100$ billion during the summer months, the volume of new financing fell below $\$ 50$ billion per week. It was largely to this widening of spreads, and the inability of firms to finance themselves in the commercial paper market that it represented, that the Federal Reserve was responding in creating the CPFF. ${ }^{92}$ As panel (a) of Figure 16 shows, the volume of assets that it held under this facility grew rapidly. By early 2009, the CPFF held $\$ 350$ billion of commercial paper. As these holdings grew, the commercial paper-OIS spread narrowed sharply (except for a one-day spike on January 28, 2009-exactly three months and one day after the CPFF's creation-associated with market concerns surrounding the refinancing of the first vintage of CPFF-purchased paper to come to maturity). In parallel, new-issue volume in the commercial paper market recovered as well.

A limited amount of empirical research to date has attempted to analyze these rough correspondences to determine what part of the narrowing of the interest rate spread, and

\footnotetext{
${ }^{91}$ See Adrian et al. (2010) for an account of events in the commercial paper market and the creation of the CPFF. See also Taylor \& Williams (2009) for a discussion of the broader breakdown in the functioning of money markets at this time, including inter-bank markets.

${ }^{92}$ Other new facilities created by the Federal Reserve that were relevant to the commercial paper market, although not directly involved in buying commercial paper, included the Primary Dealer Credit Facility (established in March 2008 to extend credit directly to primary securities dealers including nonblank dealers), the Asset-Backed Commercial Paper Money Market Mutual Fund Facility (established in September 2008, just after the Lehman failure, to provide funding to depository institutions to facilitate private-sector purchases of asset-backed commercial paper), and the Money Market Investor Funding Facility (created in October 2008 to provide funding to privately-managed special purpose vehicles to facilitate their purchases of various money market instruments, including but not limited to commercial paper). See Hilton (2008) for an account of earlier Federal Reserve actions (mid 2007 through mid 2008).
} 
the recovery of new issue volume, is plausibly attributable to the actions that the Federal Reserve took. ${ }^{93}$ Kacperczyk \& Schnabl (2010) outlined the channels by which the crisis affected the commercial paper market, and by which the Federal Reserve's purchases could have made a difference, but did not actually attempt quantitative estimates. Anderson \& Gascon (2009) concluded that the CPFF's purchases had little impact on the volume of commercial paper issuance, arguing that new-issue volume had largely recovered by the time CPFF purchases became significant. ${ }^{94}$ Adrian et al. (2010), by contrast, concluded that the CPFF had both narrowed commercial paper spreads and increased issuance. Motley (2010), using an estimated model of the supply-demand equilibrium in the commercial paper market, concluded that the CPFF reduced the AA-rated three-month financial paperOIS spread by 50 basis points, and the AA-rated three-month asset-backed spread by 35 basis points. At a one-month maturity, Motley's analogous estimates were 22 basis points for financial company paper and 14-32 basis points for asset-backed paper.

As panel (a) of Figure 16 shows, by far the largest use of the Federal Reserve's balance sheet in this way was its purchase of residential mortgage-backed securities under the Term Asset-Backed Securities Loan Facility. The Federal Reserve established the TALF in March 2008, but did not begin to purchase securities under it until March 2009. Once begun, however, these purchases increased rapidly, and continued to do so through early 2010. As of the time of writing, the volume held was in excess of $\$ 1.1$ trillion.

Figure 21 plots the spread between the respective U.S. interest rates on thirty-year fixedrate mortgages and ten-year Treasury bonds. ${ }^{95}$ Both the motivation for the Federal Reserve's purchases of mortgage-backed securities and at least the rough appearance of their impact are readily apparent. Before the crisis, the spread fluctuated narrowly in the range of 140-180 basis points. It began to grow wider at mid-year 2007, eventually reaching nearly 300 basis points by late 2008. It then began to narrow, after the announcement of the program but before the Federal Reserve had actually purchased any securities-just as would be expected, in a market for long-term assets, if market participants anticipated an action that would affect the market's supply-demand equilibrium. By May 2009 the spread had returned to the 140-180 basis point range that prevailed before the crisis. As of the time of writing there has been no formal econometric analysis of this sequence of events, but the correspondence is sufficiently strong that in all likelihood the challenge for such research, when it is done, will be to overturn the appearance of a substantial impact rather than to find evidence of one.

A more extensive empirical literature exists on the effects of the BOJ's unconventional policy actions on financial markets. One question concerns the extent to which the expansion in current account balances prescribed by the QEP in and of itself affected asset

\footnotetext{
${ }^{93}$ For more theoretical treatments, see Armentier et al. (2008), Fleming et al. (2009) and Reis (2010). Several papers have empirically analyzed various of the Federal Reserve's other facilities: the TAF, Adrian et al. (2010), Wu (2010), McAndrews et al. (2008), Christiansen et al. (2009) and Taylor \& Williams (2009); the TSLF, Fleming et al. (2009), Ashcraft et al. (2009) and Thornton (2009); and purchases of long term Treasuries and MBS, Gagnon et al. (2010).

${ }^{94}$ Taylor's (2009) informal analysis drew a similar conclusion.

${ }^{95}$ Because of pre-payments, thirty-year mortgages are more comparable in average life to a ten-year Treasury security than the thirty-year Treasury.
} 
returns and risk premiums. In his comprehensive summary of the evidence, Ugai (2008) characterized the evidence as mixed, with the majority of studies reporting effects that were either statistically insignificant or quantitatively small. ${ }^{96}$ None of the studies cited found a statistically significant response of long-term interest rates to the BOJ's purchases of government bonds, a finding seemly at odds with the findings of Gagnon et al. (2010) for the U.S. One plausible reason for the different results is that the bulk of the Fed's asset purchases were mortgage backed securities, which are not risk free, whereas the BOJ's purchases consisted almost exclusively of risk-free government bonds. The Fed's policy was therefore more likely to reduce risk premiums than the BOJ's.

To what extent these new ways of conducting central bank policy suggest a path for the future is, of course, impossible to predict. One possible outcome is that central banks will regard such actions as a feature of crisis situations only, not to be used in more normal times. Another possibility is that while central banks may try to use their balance sheets in these ways, they will find that such actions are efficacious in crisis situations but not otherwise, and they will abandon the effort as useless under normal market conditions. A third possibility, however, is that the lessons learned from these crisis-motivated actions will carry over to more ordinary times, and that in the future the implementation of monetary policy will be two-dimensional in a way it has not traditionally been in the past.

\section{Conclusion}

Central banks no longer implement monetary policy - that is, they no longer set the shortterm interest rates that they target for monetary policy purposes-in the way described in standard economics textbooks. The traditional model in which the central bank increases or decreases the supply of its own liabilities, against a fixed but interest-elastic demand for those liabilities, is of course logically coherent; it simply does not reflect what central banks actually do. Instead, central banks today mostly control their policy interest rates with little or no variation in the supply of their own liabilities, importantly including bank reserves. The fact that standard textbooks in the field do not reflect this practice is a failure of the textbooks, not a reflection of misunderstanding on the part of monetary policymakers.

The absence of a relationship between interest rates and the quantity of bank reserves over long horizons - a year or two, or even more-lies beyond the scope of this chapter on monetary policy implementation. The explanation presumably has to do with depositholders' preferences for one form of monetary instrument versus another, together with banks' ability to influence deposit-holders' choices in this regard. The proper focus of that story is the market for deposits.

The focus in this chapter is the market for bank reserves, and therefore on how central banks implement monetary policy on a day-to-day basis. The phenomenon that this chapter addresses - the puzzle from the perspective of the standard textbook model of how monetary policy works - is the absence of a relationship between interest rates and the quantity of reserves over shorter frequencies.

\footnotetext{
${ }^{96}$ Oda \& Ueda (2005) did find some evidence that changes in the target for current account balances did reduce bond yields by signaling the length of the BOJ's commitment to its zero interest rate policy.
} 
The explanation for this phenomenon advanced here involves several features of how central banks actually implement monetary policy decisions in the current era. Prominent on this list are reserve averaging procedures, under which banks meet their reserve requirements not on a single-day basis but on average over a period of days and even weeks; lagged reserve accounting procedures, under which banks' required reserve holdings for each such period are predetermined when the period begins; and standing facilities, by which (some) central banks either lend reserves to banks or pay interest on banks' holdings of excess reserves. In various combinations, these features of modern central banking practice render banks' demand for reserves interest-elastic on a day-to-day basis, for given expectations of interest rates during the remainder of the reserve maintenance period, but interest-inelastic on a longer-term basis. Whatever leads participants in the reserves market to change their expectations of future interest rates-an announcement of intention by the central bank is just one example-will, in effect, shift the traditional downward-sloping reserve demand schedule. As a result, a different market-clearing interest rate on reserves is possible with no change in reserve supply. Alternatively, the central bank can alter the supply of reserves, and thereby expand or contract its balance sheet, with no change in its policy interest rate. The implications for central bank practice are profound.

The empirical evidence for today's three large central banks provided in this chapter largely supports this interpretation of the modern implementation of monetary policy. Event studies consistently show no relationship between movements in policy interest rates and the supply of reserves for any of the United States, the Euro-system, or Japan. Structural estimates of reserve demand, at a frequency corresponding to the reserve maintenance period, show no evidence of interest elasticity for the U.S. or the Euro-system (although reserve demand at a one-month frequency is interest-elastic in Japan). Structural estimates of daily reserve demand, carried out here for the U.S. only, document the role of expected future overnight interest rates in shifting banks' reserve demand. Structural estimates of daily reserve supply, again carried out for the U.S. only, show no evidence of changes in reserve supply associated with the level of the federal funds rate or a change in the Federal Reserve System's publicly announced target for the federal funds rate.

Finally, although any firm judgment would be premature at the time of writing, this chapter's review of the changes in monetary policy implementation triggered by the 20079 financial crisis suggests that the extraordinary actions taken by central banks during this period could open the way for new forms of policy in the future. Most importantly, the ability to choose the level of its policy interest rate and the size of its balance sheet independently, over time horizons long enough to matter for macroeconomic purposes-in effect, to fix not the interest rate or the quantity of reserves but the interest rate and the quantity of reserves - represents a fundamental departure from decades of thinking about the scope of central bank action. 
Figure 1: Scaled changes in nonborrowed reserves and the federal funds rate

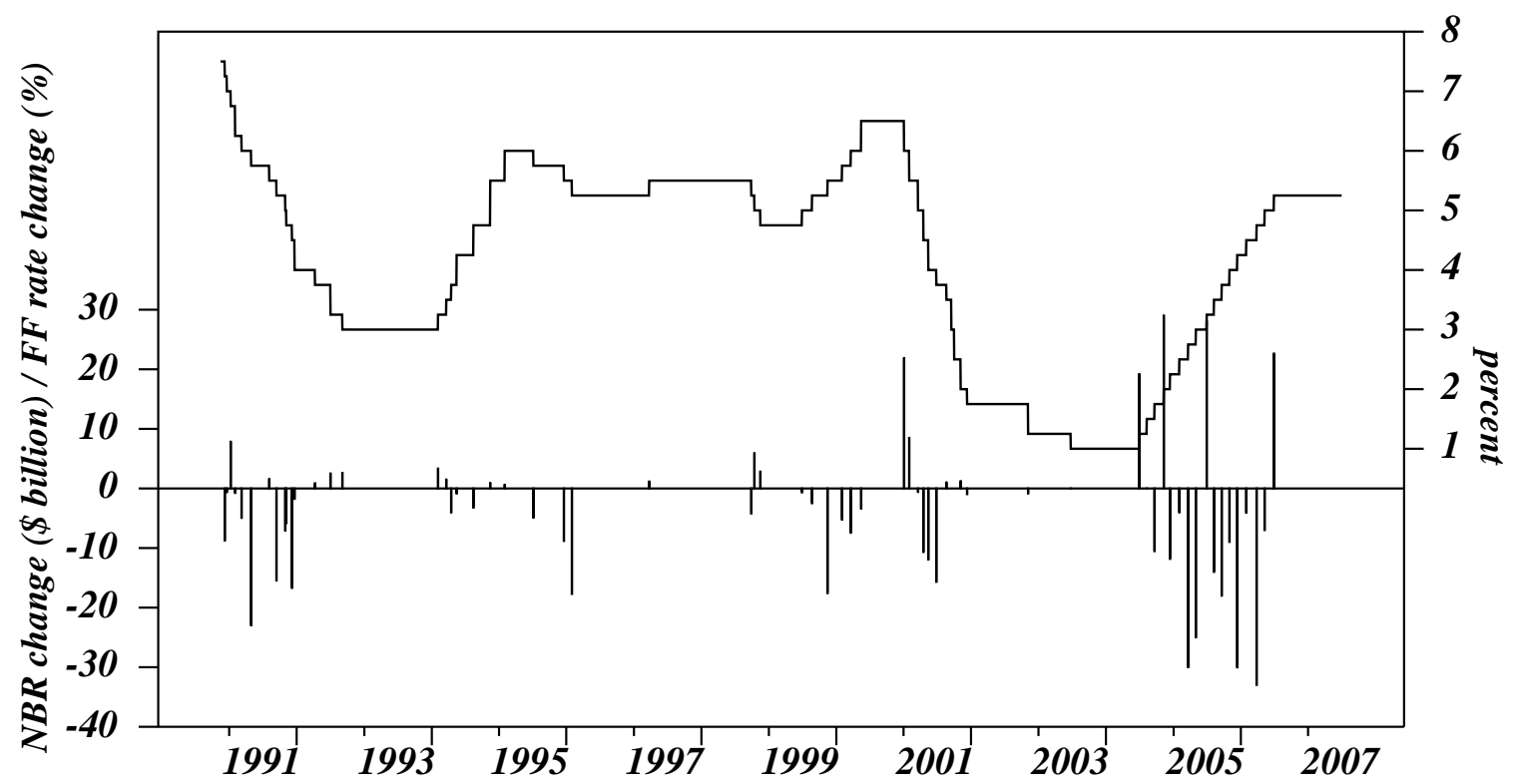

Figure 2: Nonborrowed reserves and the target funds rate, 1994-95

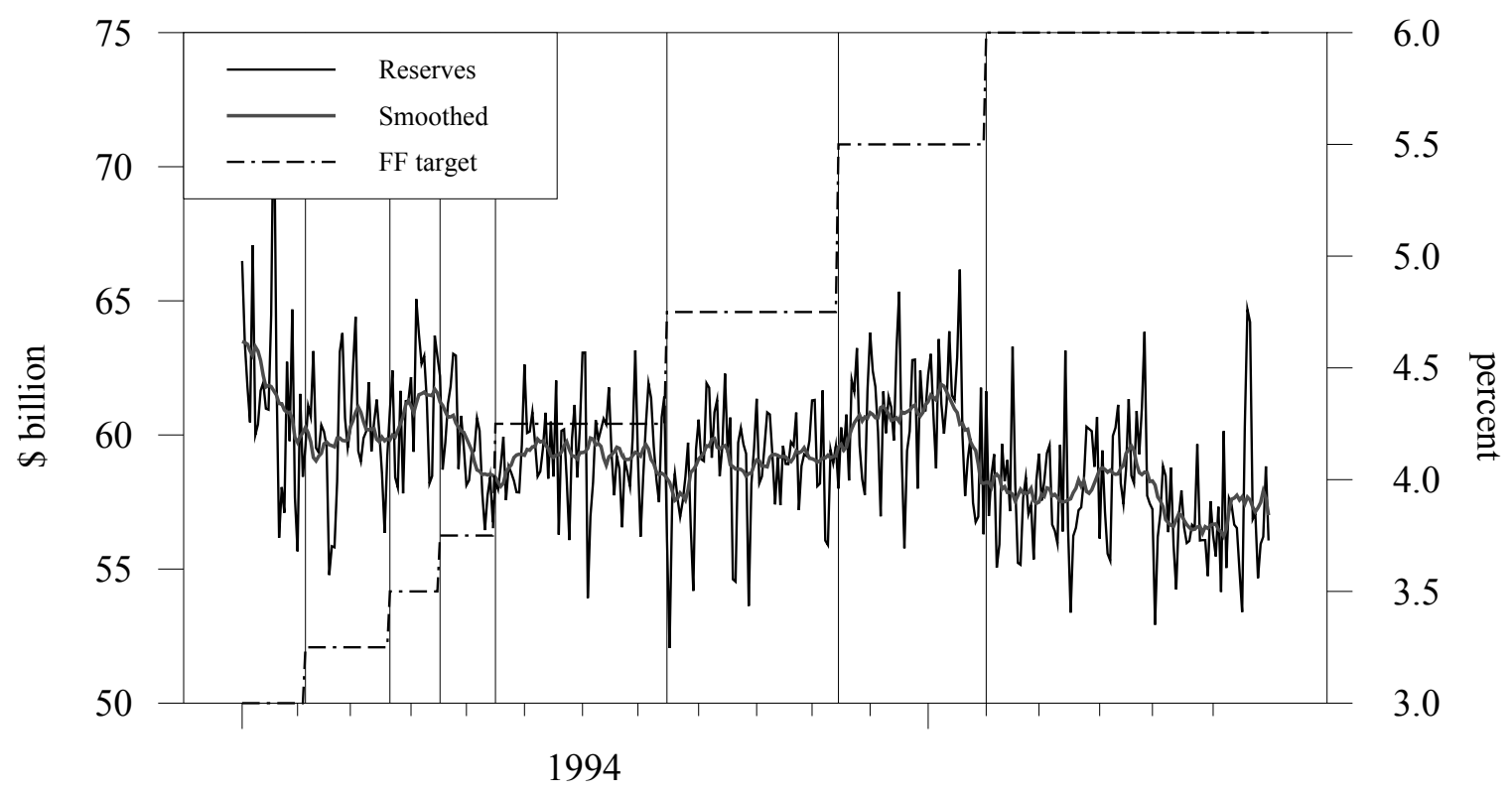


Figure 3: Nonborrowed reserves and the target funds rate, 2000-01

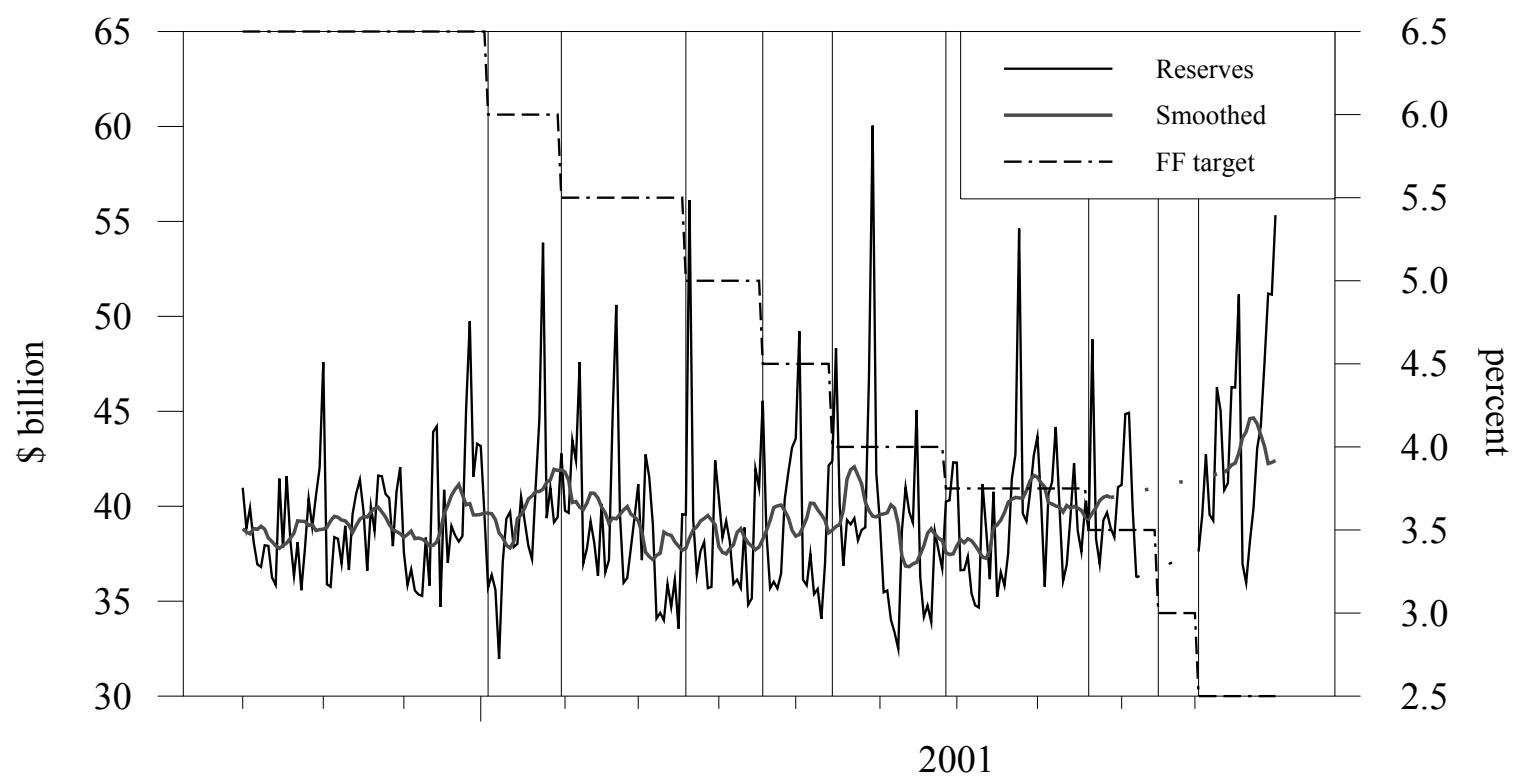

Figure 4: Nonborrowed reserves and the target funds rate, 2004-06

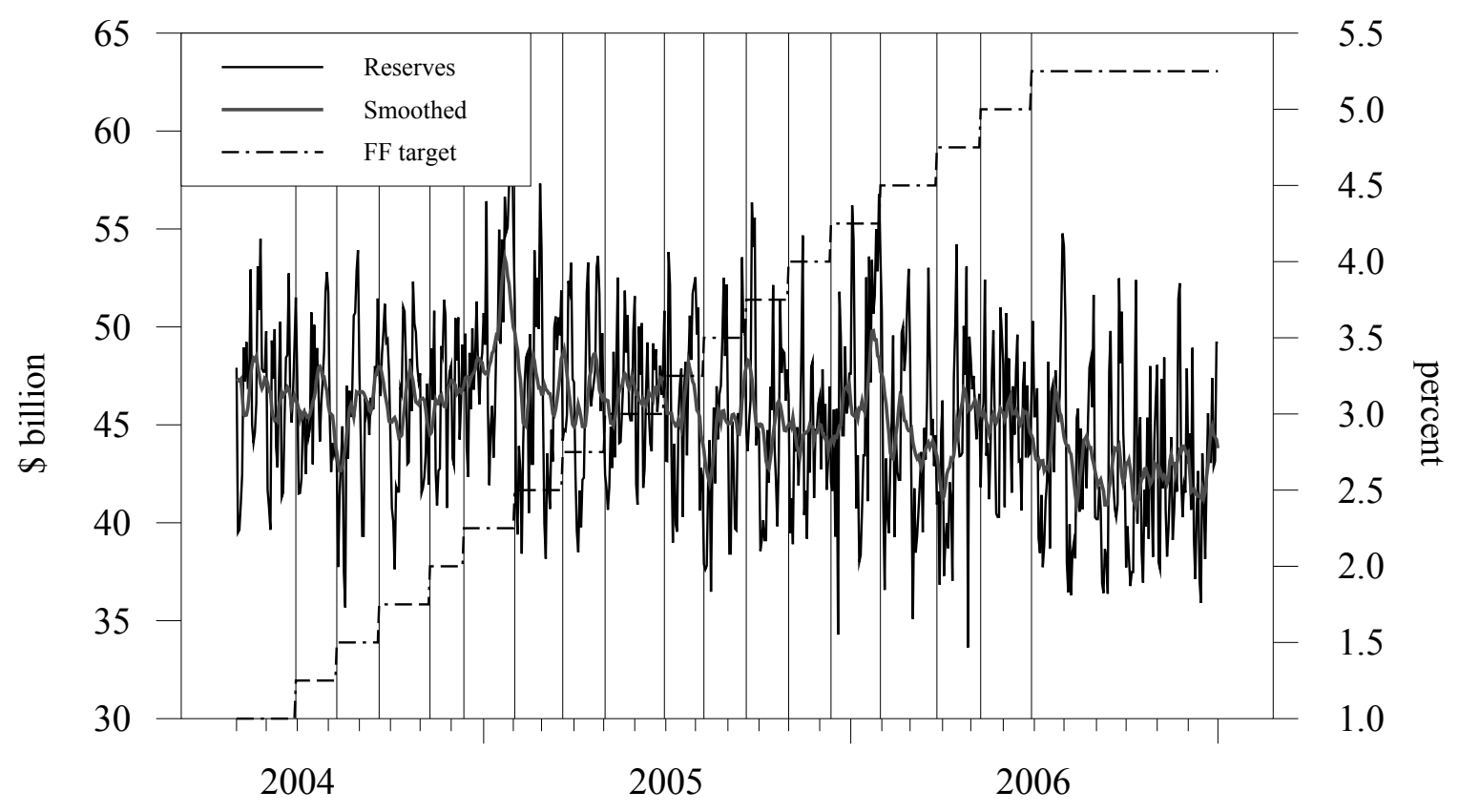


Figure 5: The "traditional view" of monetary policy implementation

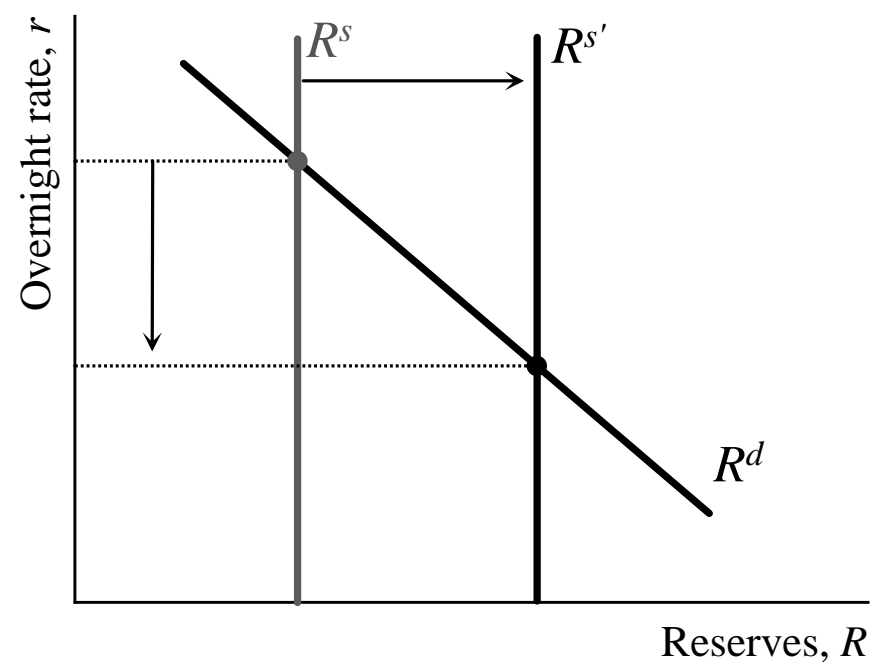

Figure 6: Implementing monetary policy by changing reserve demand

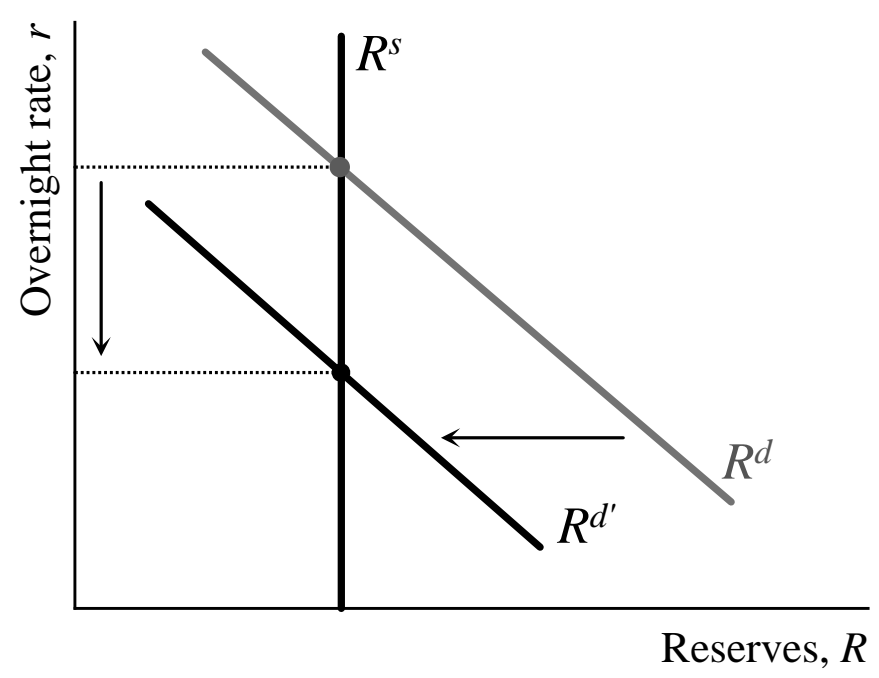


Figure 7: Reserves and overnight interest rates

(a) United States

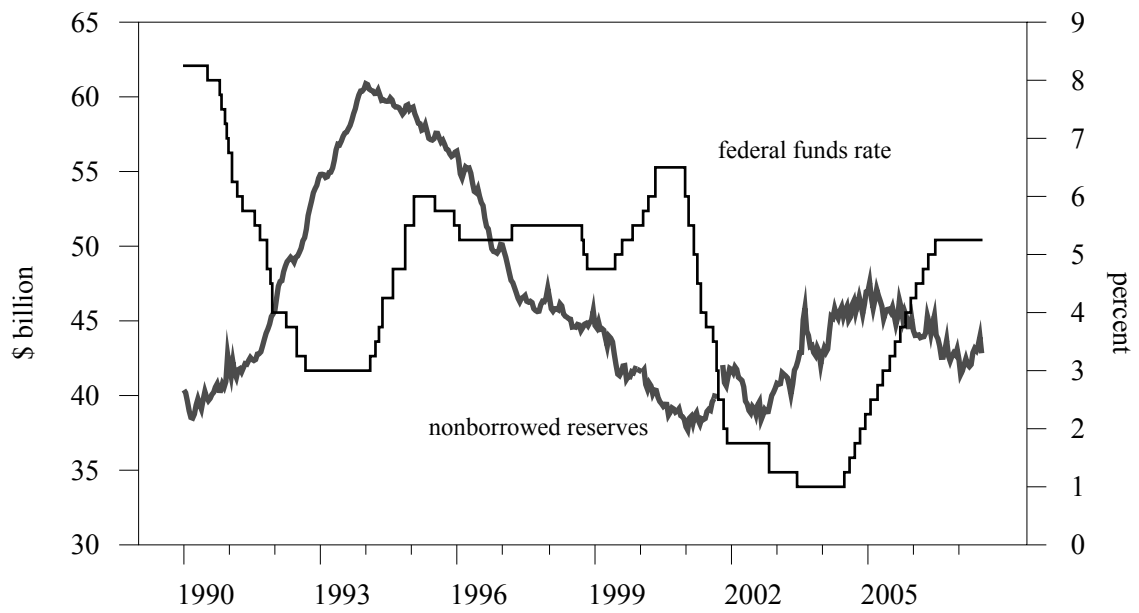

(b) Euro area

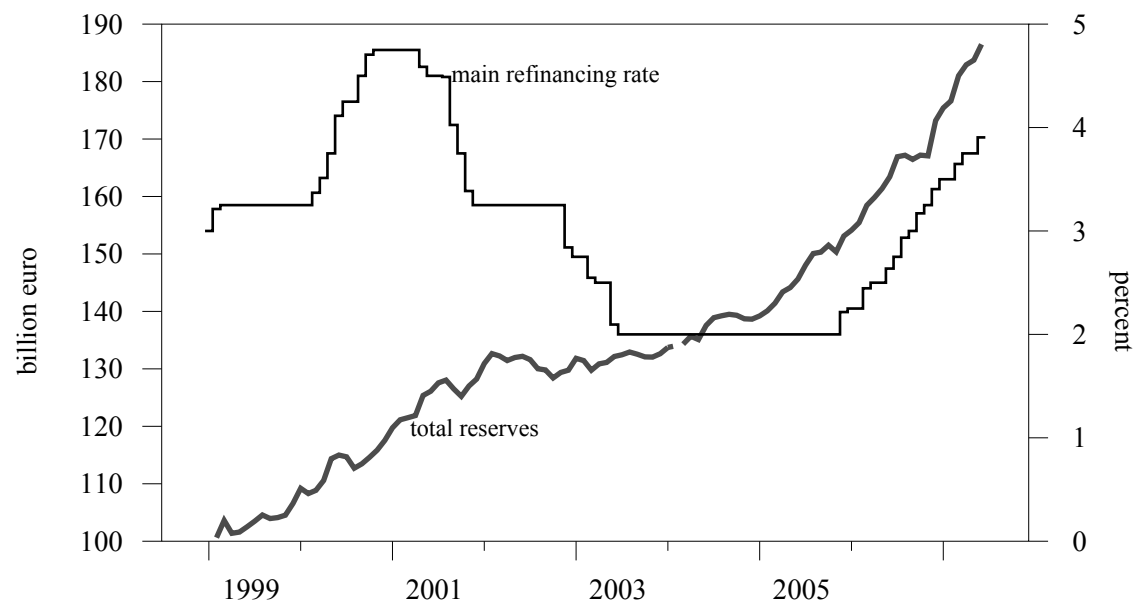

(c) Japan

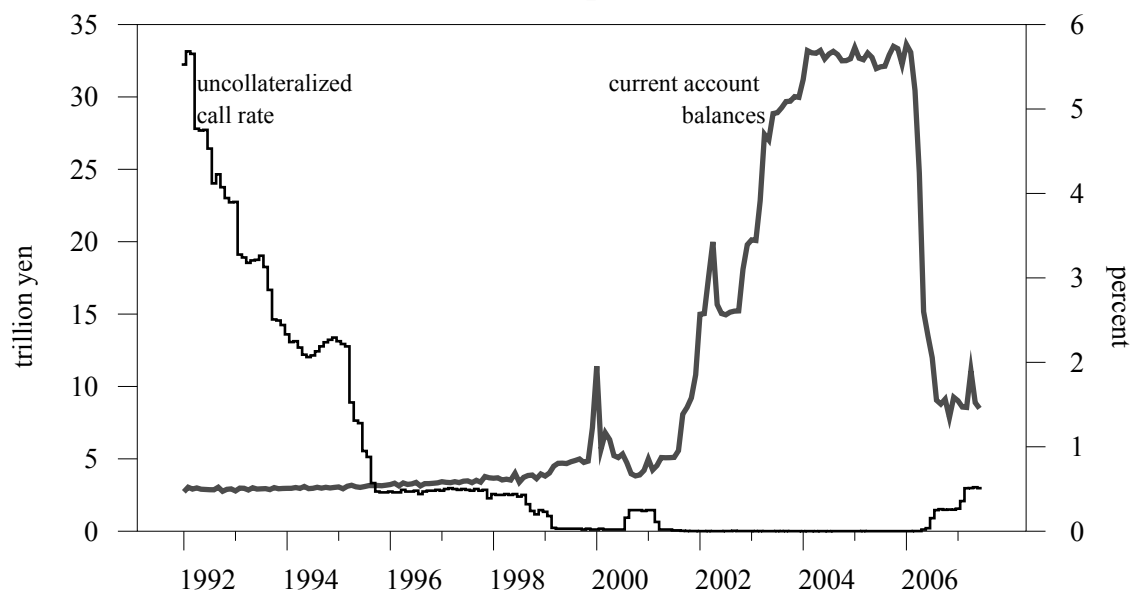


Figure 8: Response of excess reserves to changes in the target interest rate

(a) United States

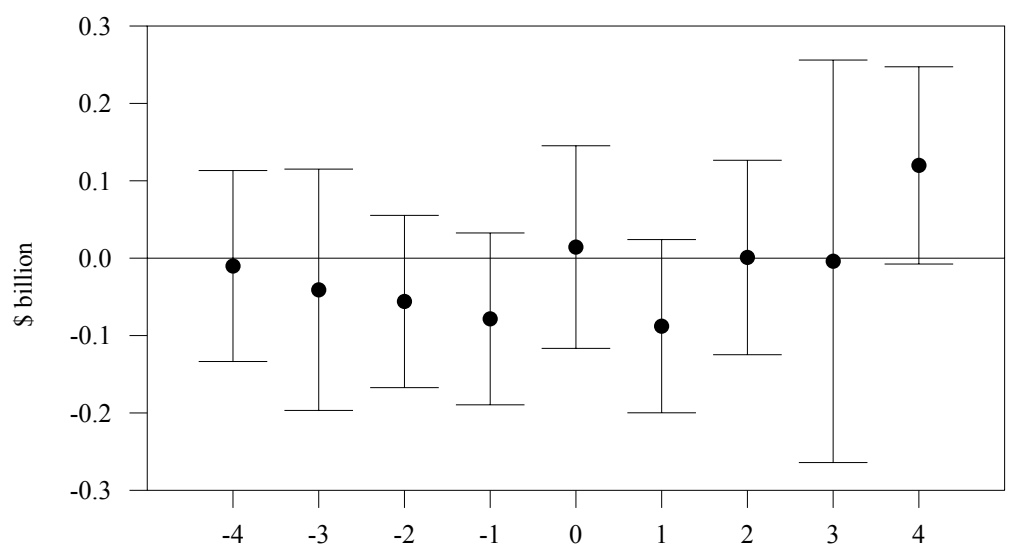

periods before (negative numbers) or after (positive numbers) target rate change

(b) Euro area

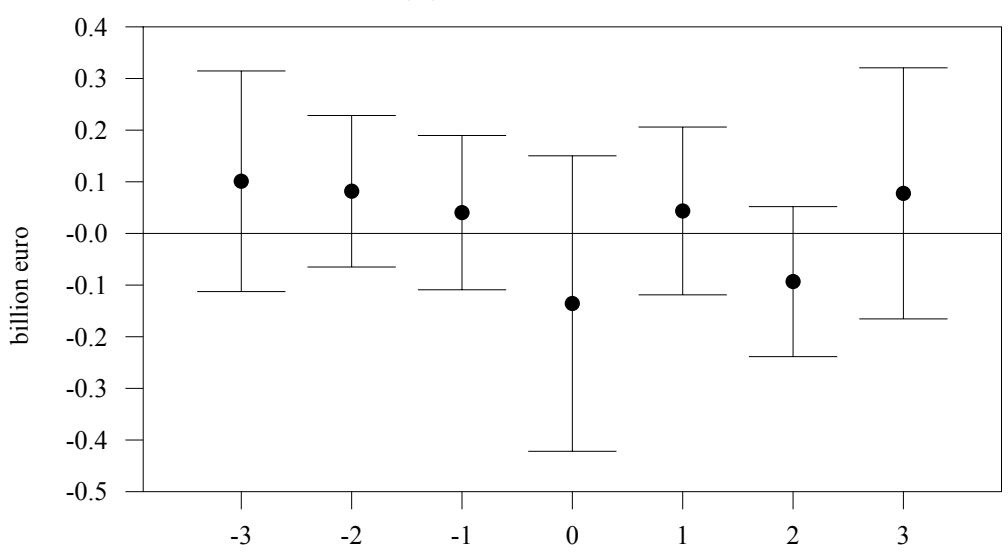

periods before (negative numbers) or after (positive numbers) target rate change

(c) Japan

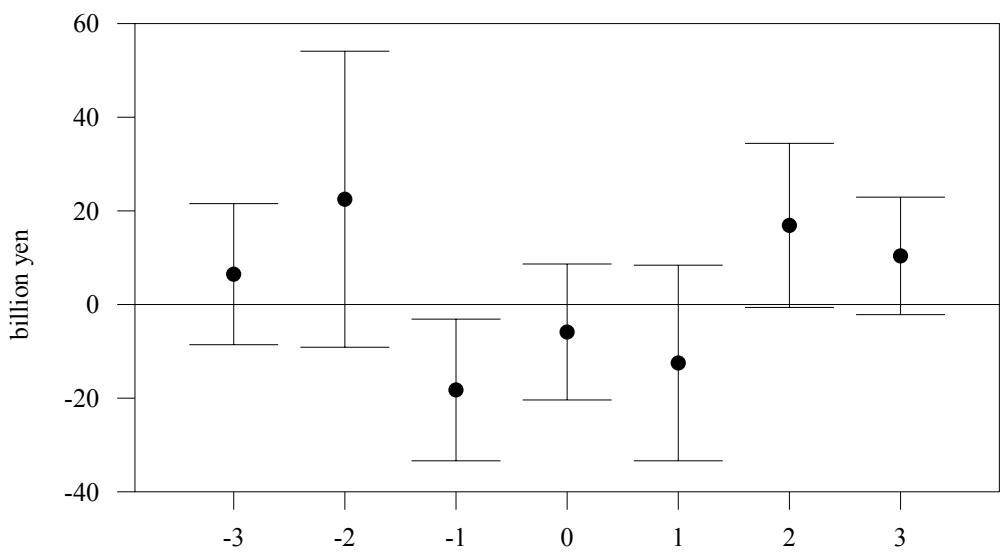

periods before (negative numbers) or after (positive numbers) target rate change 
Figure 9: Scatterplots of excess reserves against short-term interest rates

(a) United States

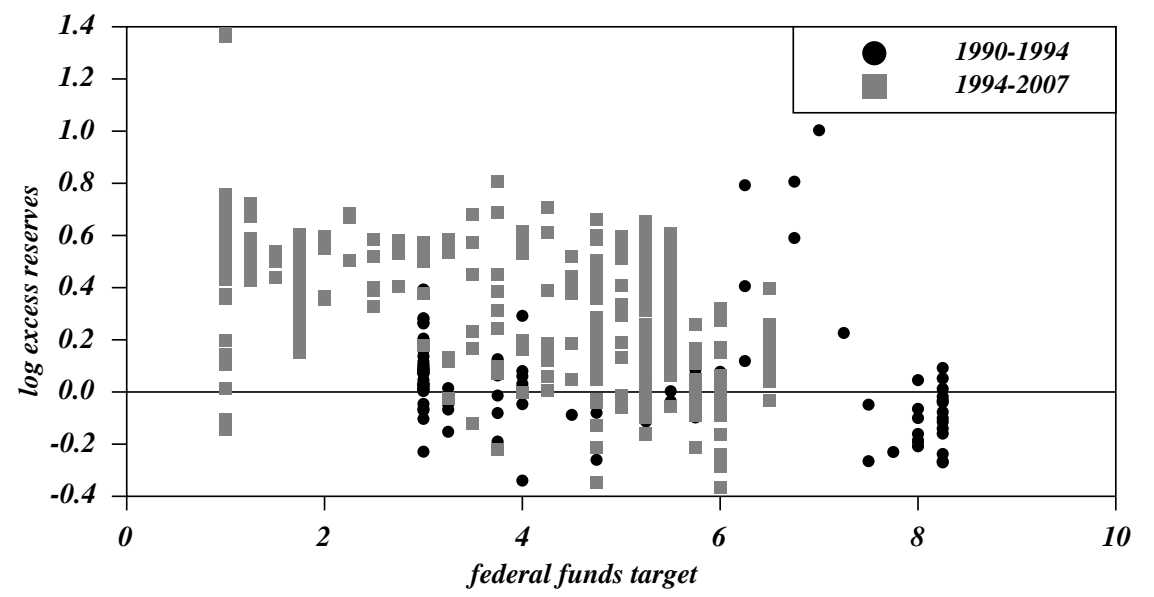

(b) Euro area

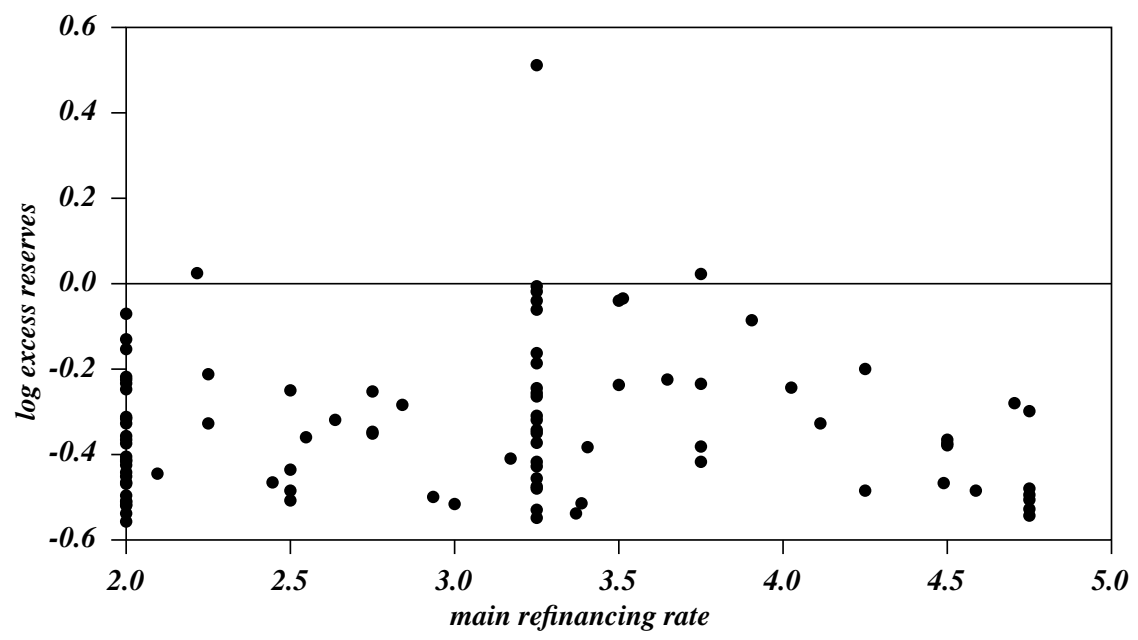

(c) Japan

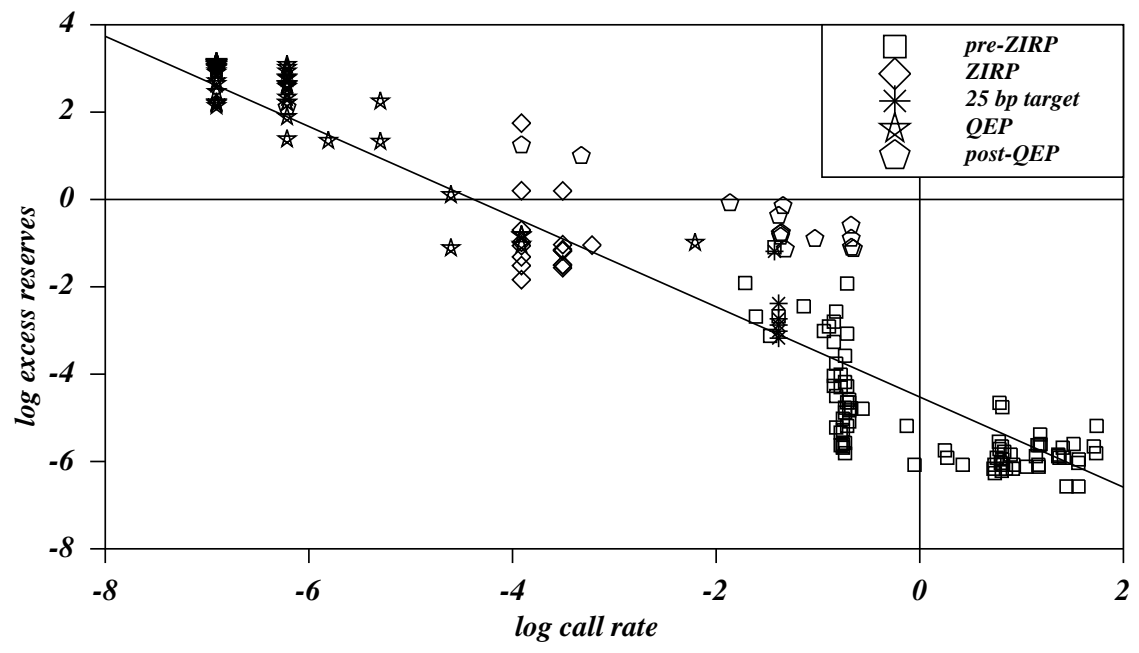


Figure 10: Supply-induced interest rate changes with no change in reserves

(a) The perfectly elastic case

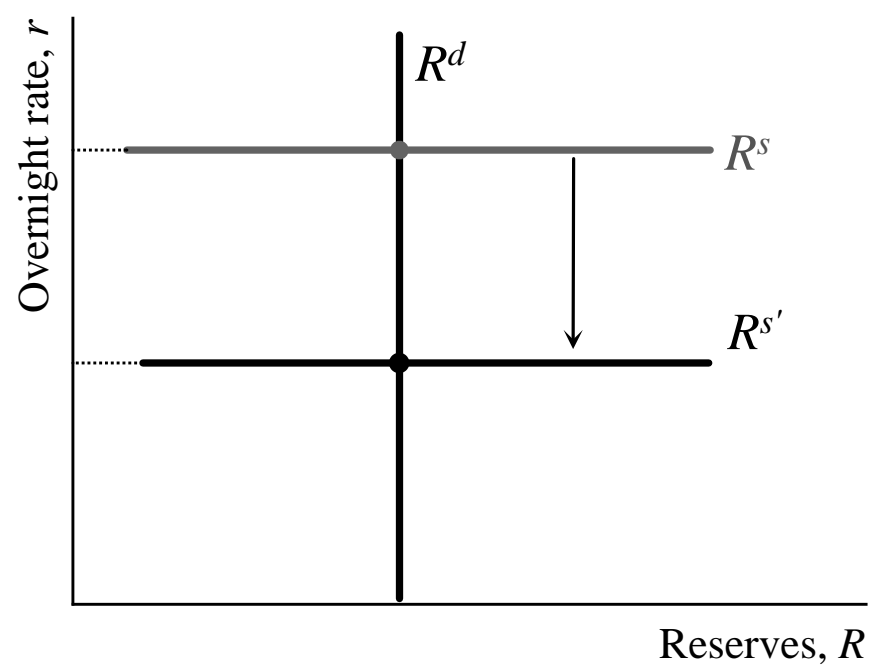

(b) The less than perfectly elastic case

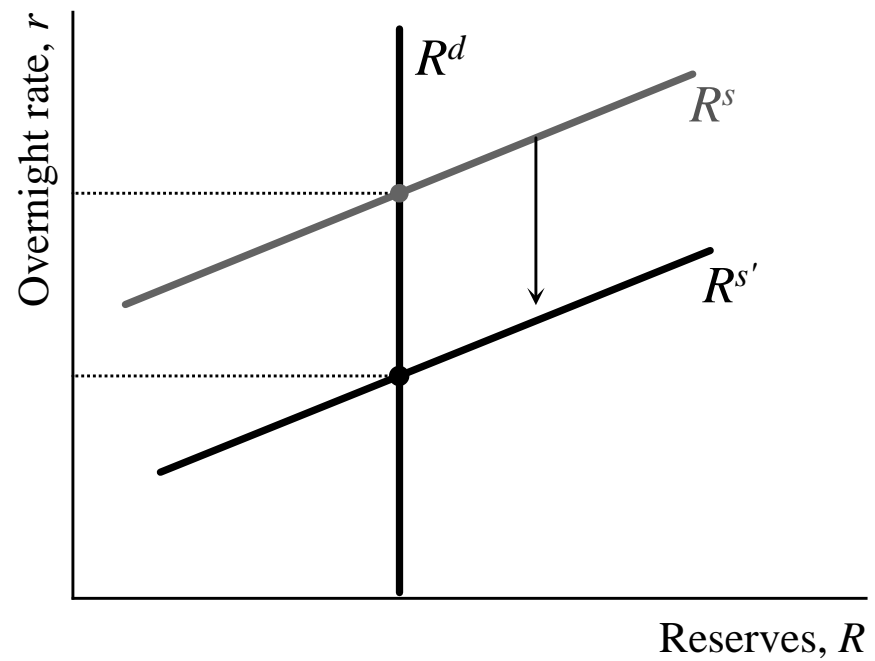


Figure 11: Target and market interest rates

(a) United States

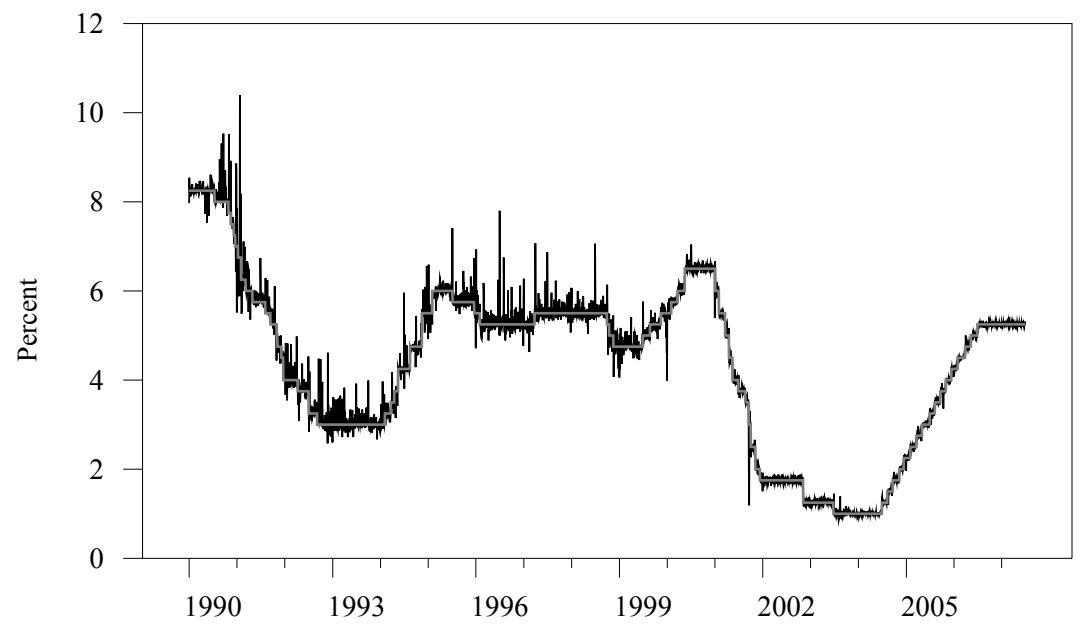

(b) Euro area

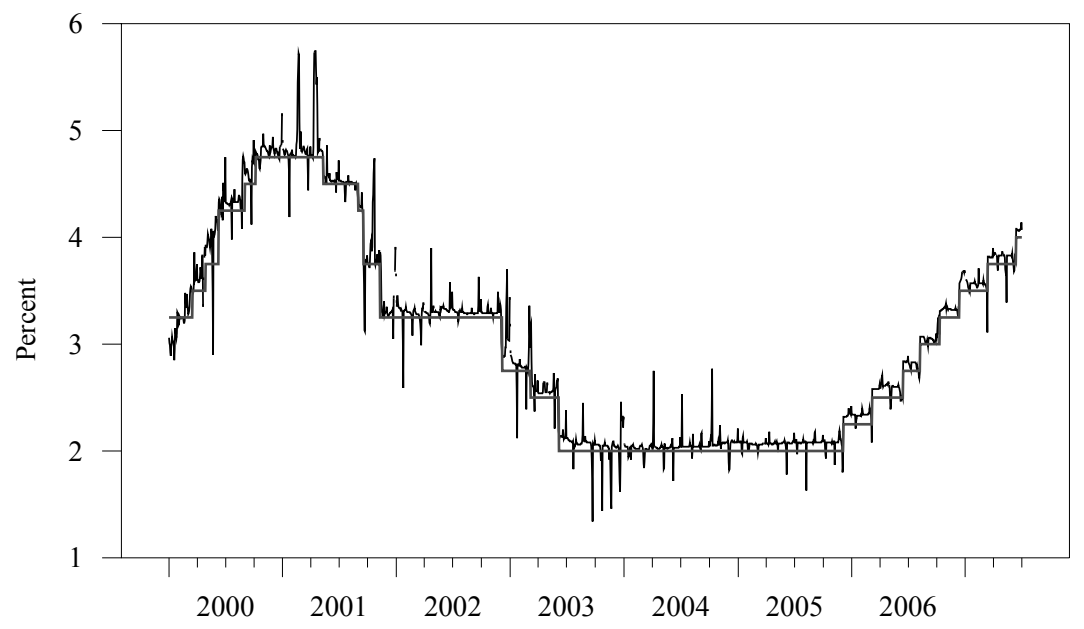

(c) Japan

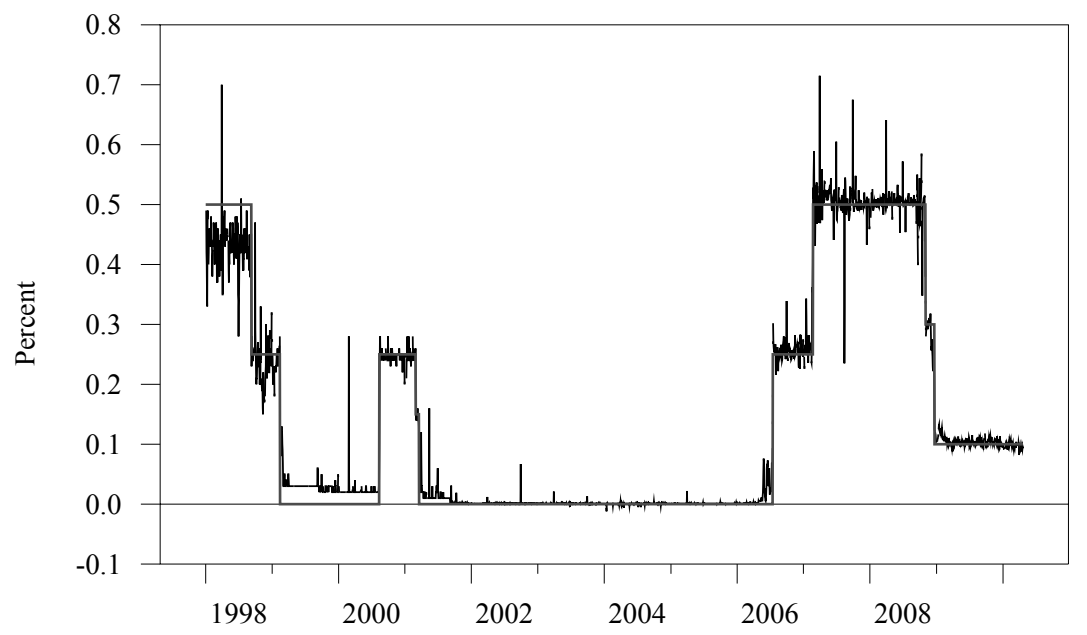


Figure 12: The pure announcement effect

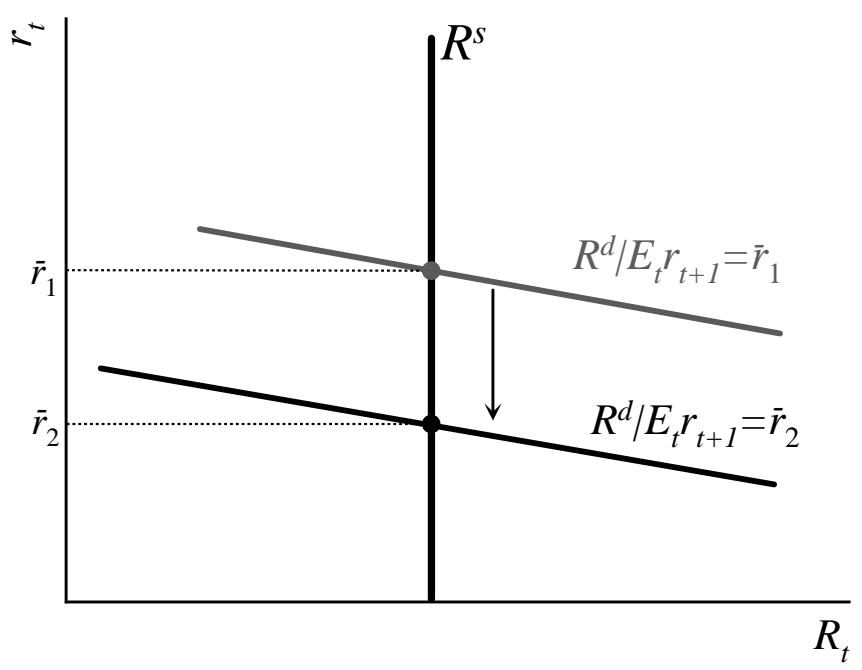

Figure 13: Response of excess reserves to changes in the target interest rate, daily data

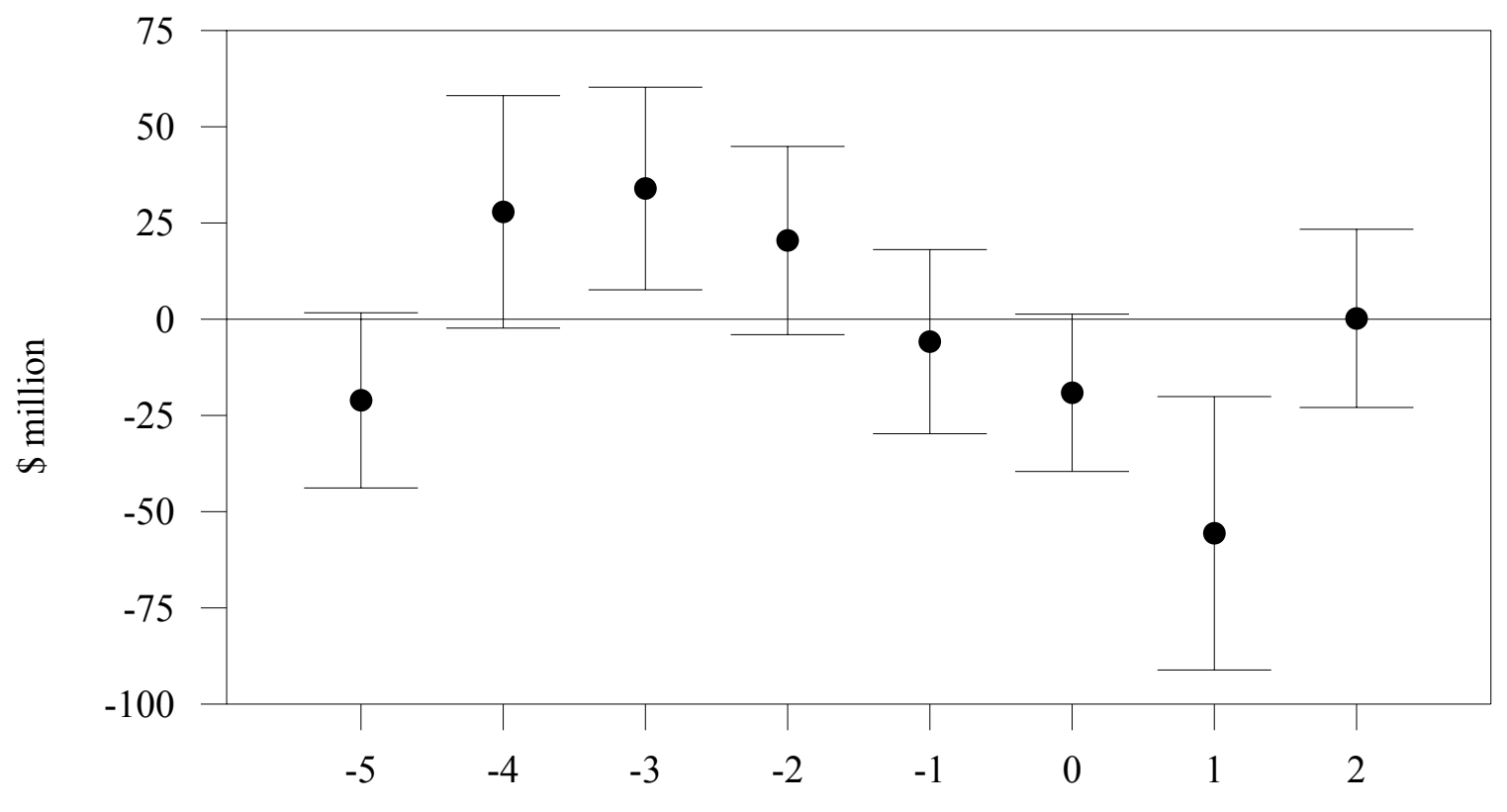

days before (negative numbers) or after (positive numbers) target rate change 
Figure 14: Policy interest rates during financial crises

(a) United States

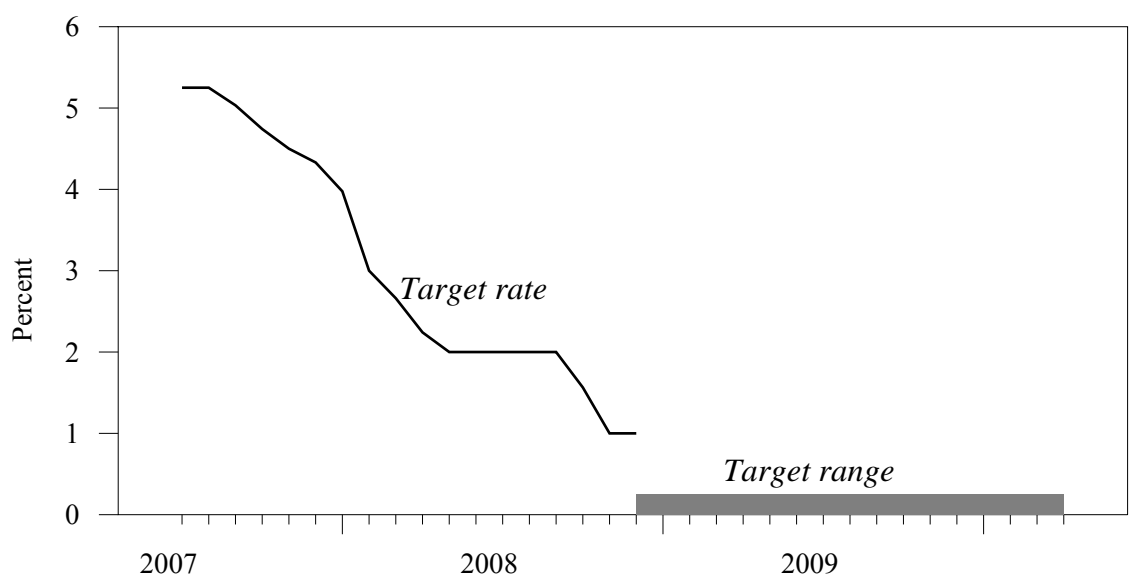

(b) Euro area

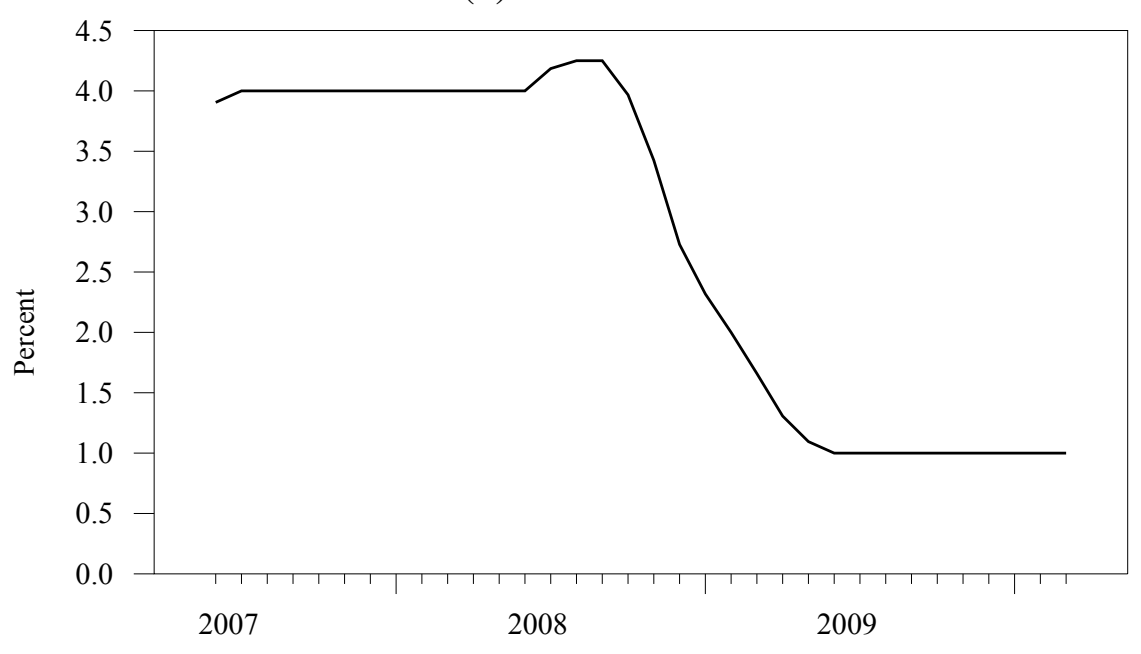

(c) Japan

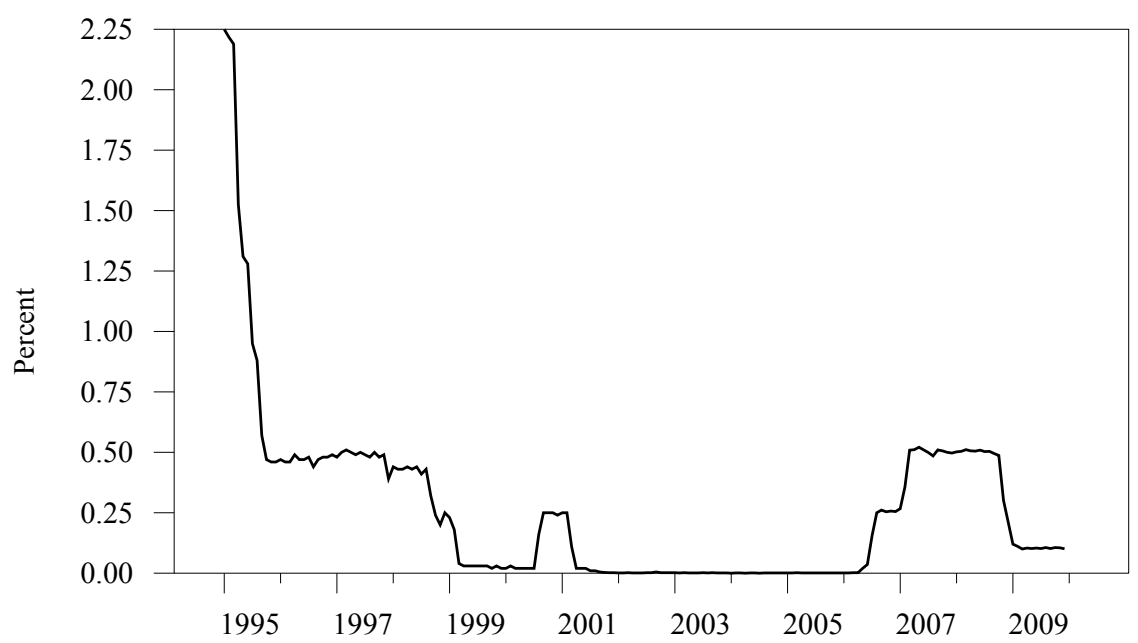


Figure 15: Central bank liabilities during financial crises

(a) United States

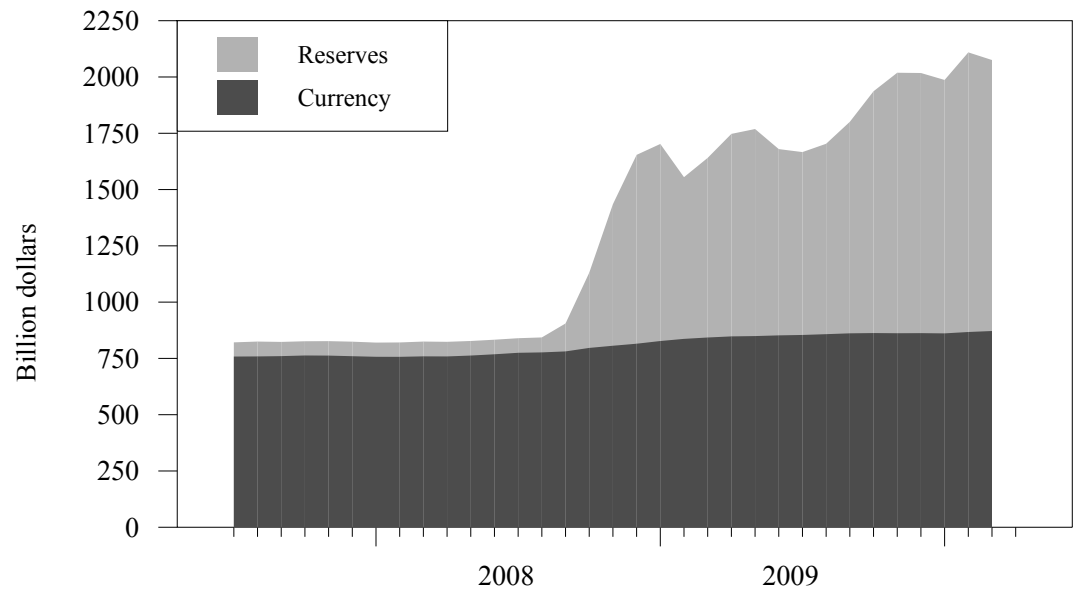

(b) Euro area

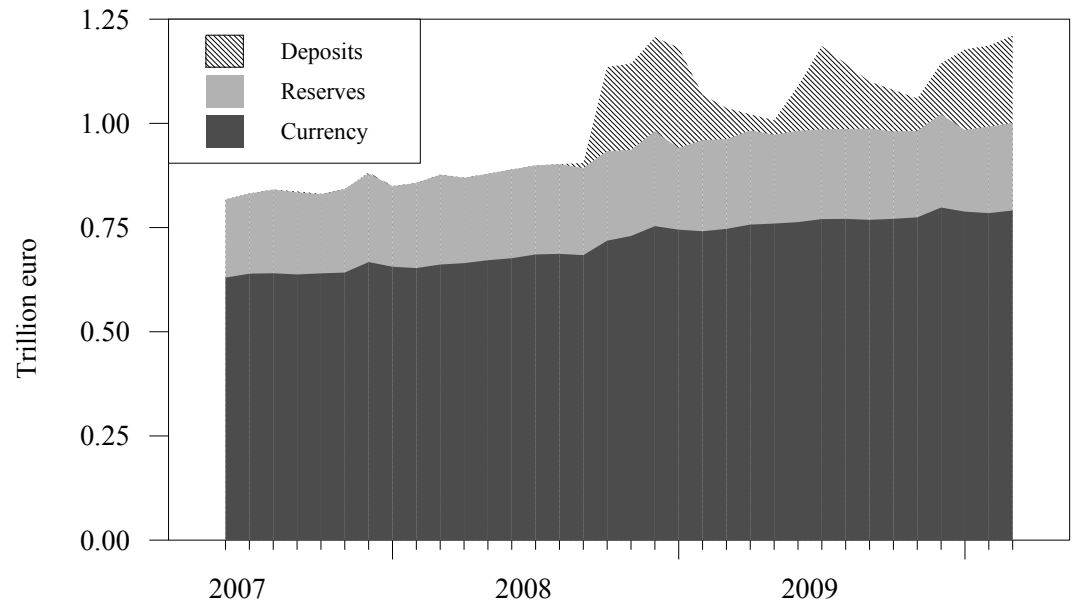

(c) Japan

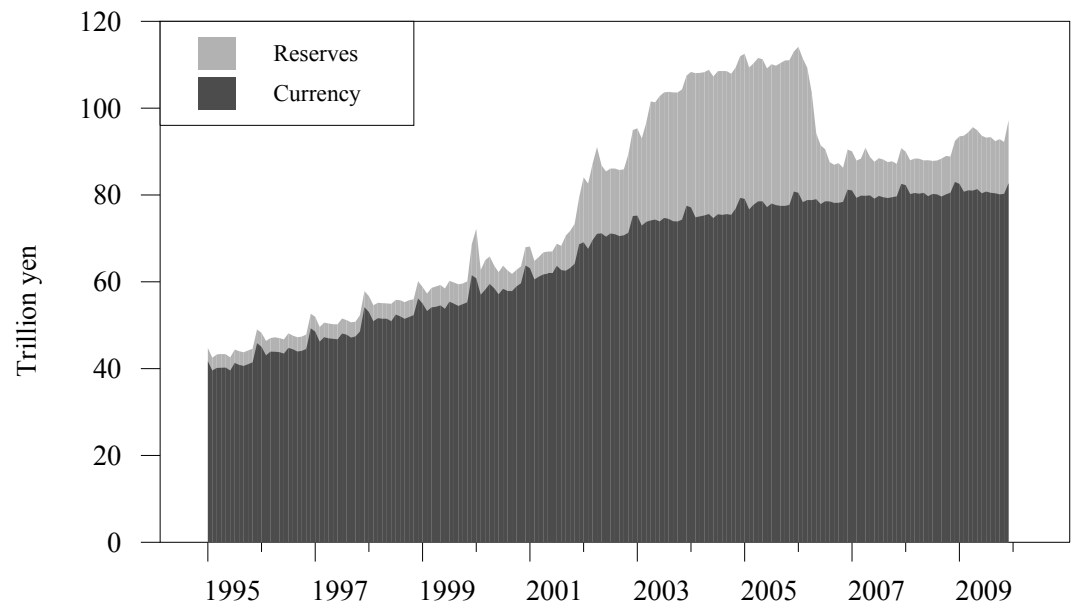


Figure 16: Central bank assets during financial crises

(a) United States

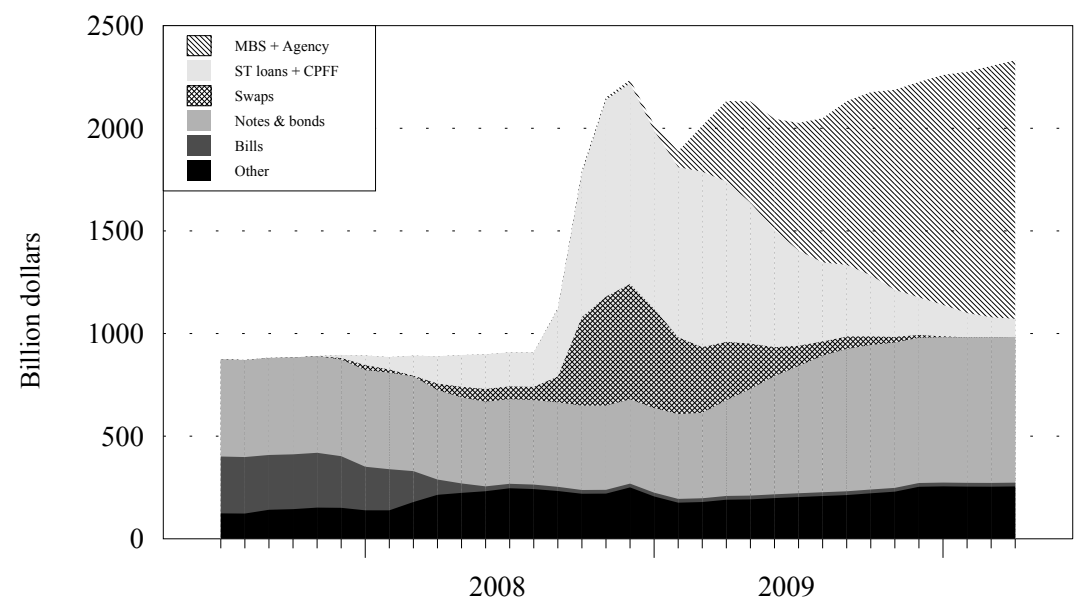

(b) Euro area

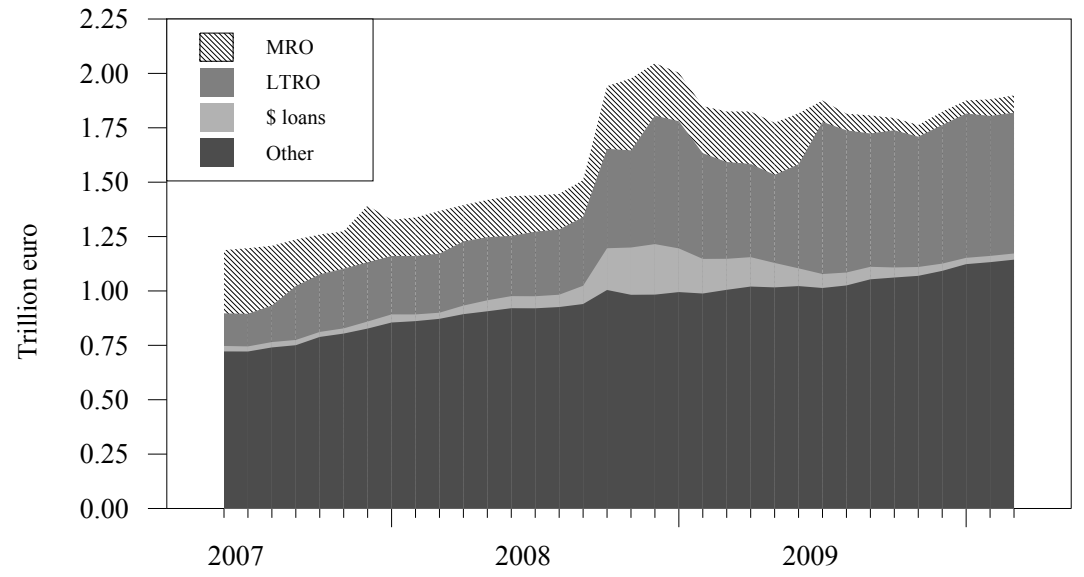

(c) Japan

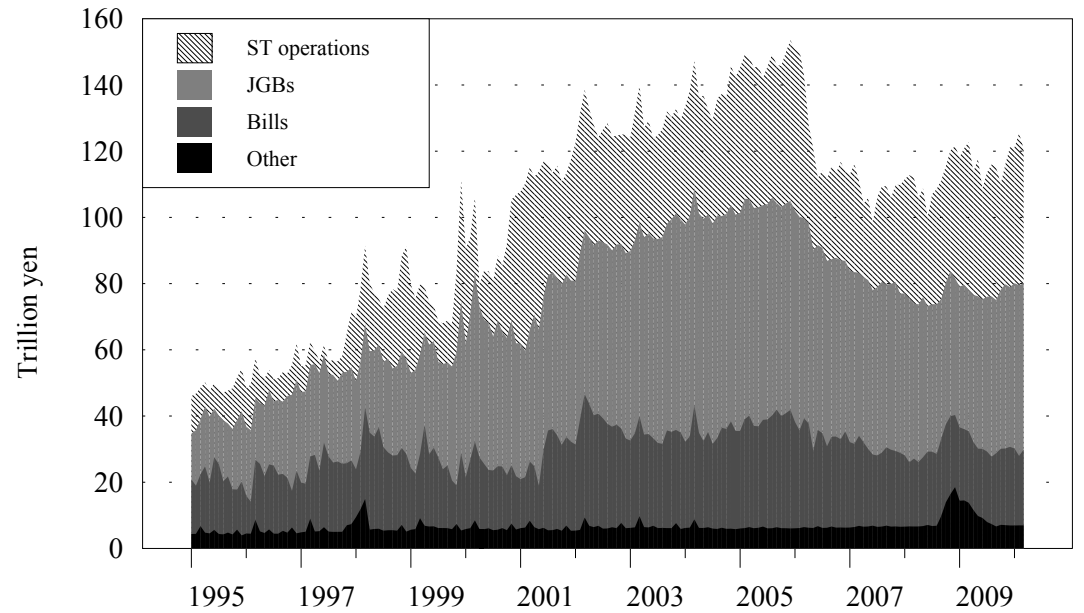


Figure 17: The zero lower bound in the reserves market

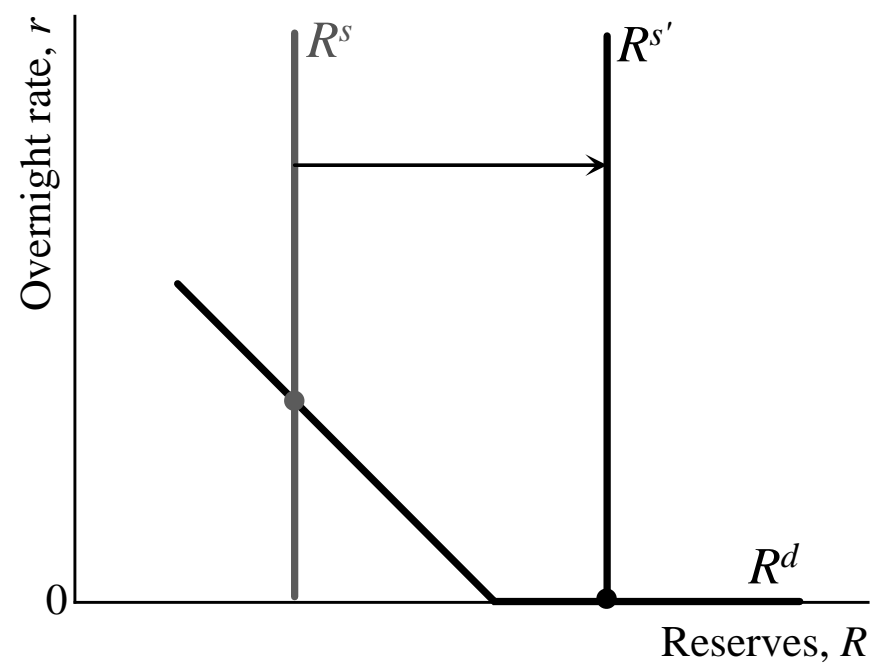

Figure 18: Quantitative easing in a corridor system

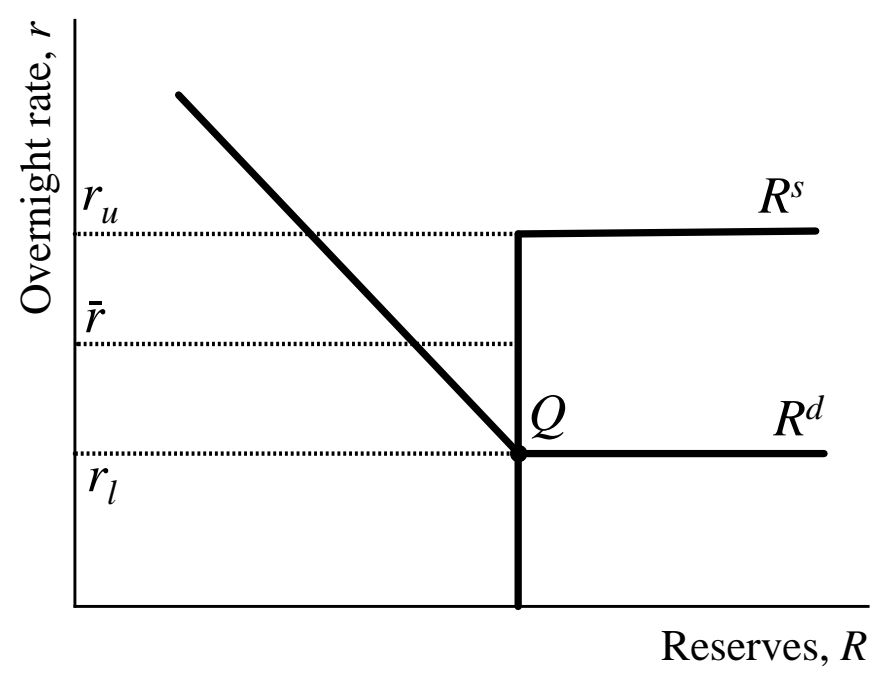


Figure 19: Quantitative easing with reserve remuneration

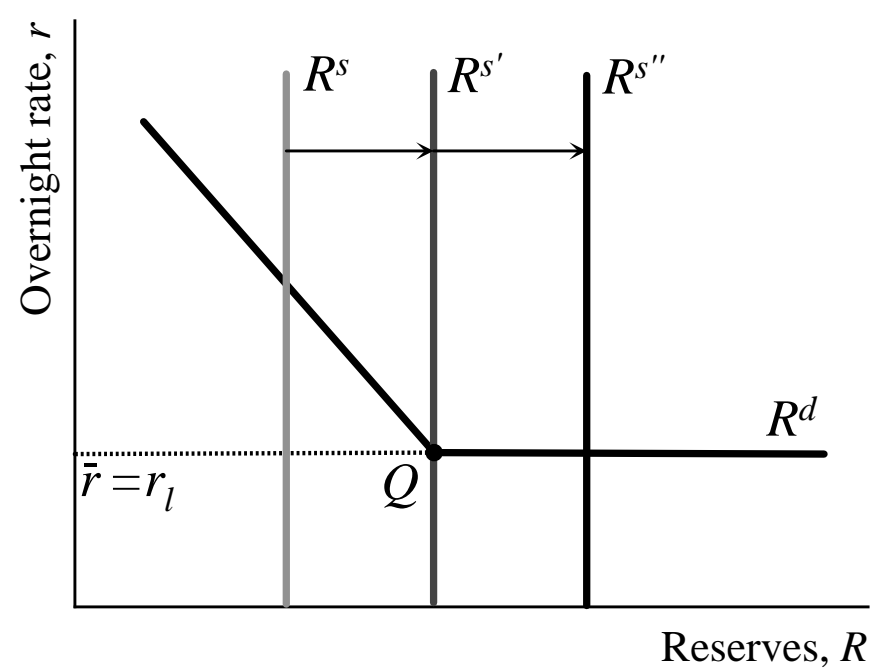


Figure 20: Three-month financial CP to OIS spread

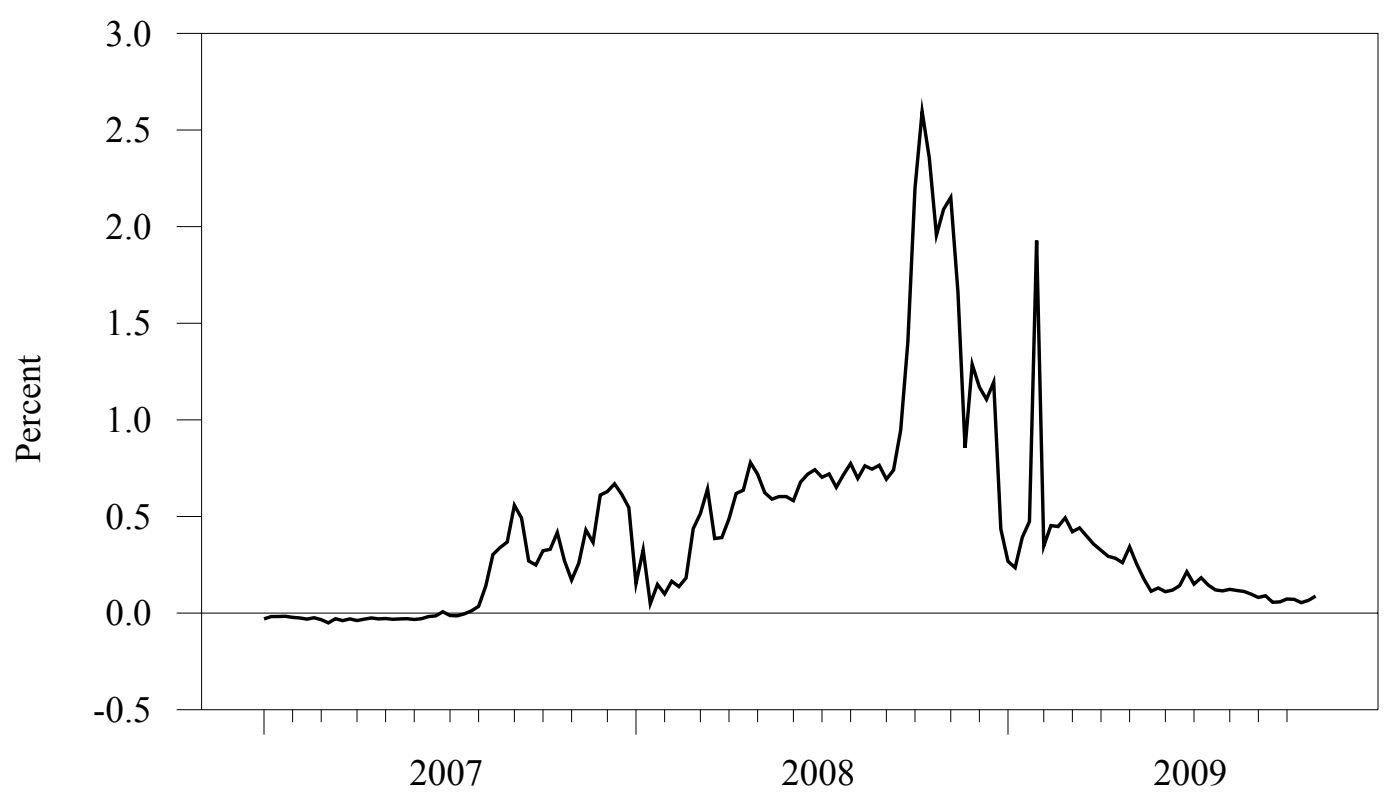

Figure 21: 30-year fixed rate mortgage to 10-year Treasury spread

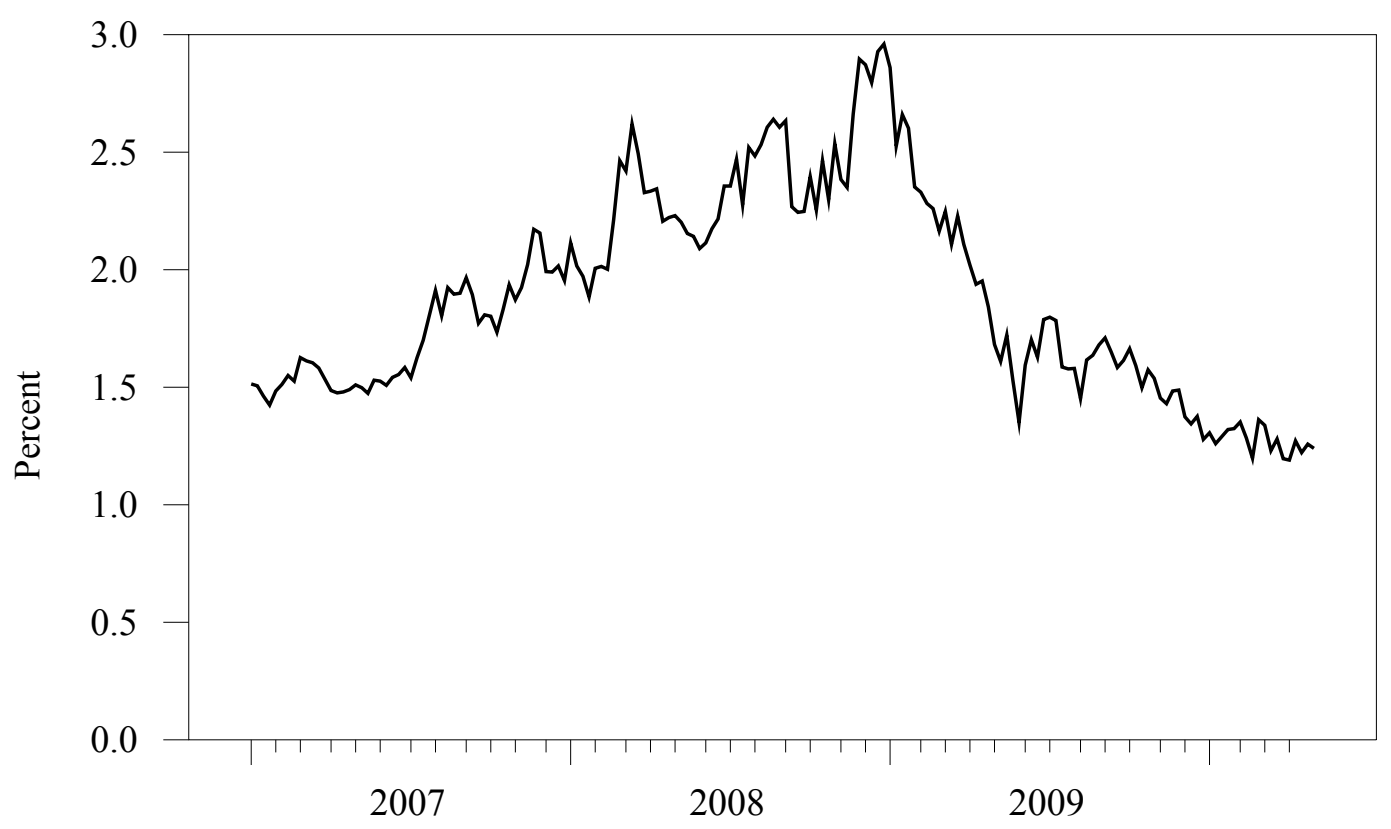


Table 1: Estimates of excess reserve demand for the U.S.

\begin{tabular}{lcccc}
\hline \multirow{2}{*}{ Regressor } & 10 Jan 1990- & 10 Jan 1990- & 2 Feb 1994 - & 12 Aug 1998 - \\
& 4 July 2007 & 2 Feb 1994 & 4 July 2007 & 4 July 2007 \\
\hline Intercept & $5.4 \times 10^{-3}$ & $-1.9 \times 10^{-1}$ & $1.4 \times 10^{-2}$ & $2.2 \times 10^{-2}$ \\
& $\left(2.0 \times 10^{-2}\right)$ & $\left(2.0 \times 10^{-2}\right)$ & $\left(2.8 \times 10^{-2}\right)$ & $\left(4.6 \times 10^{-2}\right)$ \\
Time trend & $4.4 \times 10^{-4 * * *}$ & $1.9 \times 10^{-3 * *}$ & $5.0 \times 10^{-4 * * *}$ & $5.3 \times 10^{-4 * * *}$ \\
& $\left(7.0 \times 10^{5}\right)$ & $\left(9.4 \times 10^{4}\right)$ & $\left(1.1 \times 10^{4}\right)$ & $\left(1.8 \times 10^{4}\right)$ \\
Current target funds rate & -0.083 & -0.376 & 0.011 & 0.003 \\
& $(0.075)$ & $(0.232)$ & $(0.041)$ & $(0.050)$ \\
Target funds rate, & 0.077 & 0.394 & -0.018 & -0.013 \\
$\quad$ lagged 1 period & $(0.076)$ & $(0.240)$ & $(0.040)$ & $(0.050)$ \\
Excess reserves, & $0.81^{* * *}$ & $0.68^{* * *}$ & $0.86^{* * *}$ & $0.84^{* * *}$ \\
$\quad$ lagged 1 period & $(0.05)$ & $(0.05)$ & $(0.05)$ & $(0.05)$ \\
Excess reserves, & $-0.16^{* * *}$ & -0.10 & $-0.19^{* * *}$ & $-0.17^{* * *}$ \\
$\quad$ lagged 2 periods & $(0.04)$ & $(0.08)$ & $(0.05)$ & $(0.05)$ \\
Sum of funds rate & -0.006 & 0.017 & -0.007 & -0.009 \\
$\quad$ coefficients & $(0.004)$ & $(0.018)$ & $(0.005)$ & $(0.004)$ \\
Joint significance of funds & & & & \\
rate coefficients, p-value & 0.13 & 0.25 & 0.40 & 0.28 \\
Observations & 447 & 105 & 343 & 225 \\
R-squared & 0.780 & 0.482 & 0.801 & 0.771 \\
\hline
\end{tabular}

Notes: The dependent variable is the log of excess reserves. Data are biweekly. NeweyWest standard errors are in parentheses. Asterisks indicate statistical significance: *** for $1 \%, * *$ for $5 \%$ and $*$ for $10 \%$. Y2K dummies. The regression excludes observations associated with 9/11/2001, and includes dummies for Y2K and three outliers in August and September 2003. 
Table 2: Estimates of excess reserve demand for the Euro area

\begin{tabular}{lcccc}
\hline & \multicolumn{2}{c}{ June 1999 - June 2007 } & March 2002 - June 2007 \\
\cline { 2 - 5 } & Reserves & $\begin{array}{c}\text { Deposits }+ \\
\text { reserves }\end{array}$ & $\begin{array}{c}\text { Reserves } \\
\text { reserves }\end{array}$ \\
\hline Intercept & $-0.23^{* * *}$ & $-0.17^{* *}$ & $-0.30^{* * *}$ & $-0.29^{* *}$ \\
& $(0.07)$ & $(0.07)$ & $(0.09)$ & $(0.13)$ \\
Main refinancing rate & -0.003 & $0.054 * *$ & 0.035 & 0.072 \\
& $(0.018)$ & $(0.024)$ & $(0.032)$ & $(0.055)$ \\
Reserves, lagged 1 period & $0.32^{* * *}$ & $0.42^{* * *}$ & $0.39^{* * *}$ & 0.05 \\
& $(0.13)$ & $(0.09)$ & $(0.09)$ & $(0.11)$ \\
January 2002 dummy & $0.77^{* * *}$ & $0.54^{* * *}$ & & \\
February 2002 dummy & $(0.05)$ & $(0.07)$ & & 62 \\
Number of observations & -0.012 & $-0.45^{* * *}$ & & 0.067 \\
R-squared & $(0.11)$ & $(0.08)$ & & \\
\hline
\end{tabular}

Notes: The reserves variables are in logarithms. Data are monthly. Newey-West standard errors are in parentheses. Asterisks indicate statistical significance: *** for $1 \%, * *$ for $5 \%$ and $*$ for $10 \%$. 
Table 3: Estimates of excess reserve demand for Japan

\begin{tabular}{lcccc}
\hline & \multicolumn{4}{c}{ Sample } \\
\cline { 2 - 5 } Regressor & Jan 1992- & March 1999- & \\
& Feb 1999 & June 2007 & January 1992 - June 2007 \\
\hline Intercept & $-1.81^{* * *}$ & $-1.03^{* *}$ & $-1.19^{* * *}$ & $-1.71^{* * *}$ \\
& $(0.41)$ & $(0.43)$ & $(0.41)$ & $(0.42)$ \\
Log of call rate & $-0.36^{* * *}$ & $-0.29^{* * *}$ & $-0.29^{* * *}$ & $-0.34^{* * *}$ \\
& $(0.09)$ & $(0.11)$ & $(0.10)$ & $(0.09)$ \\
Lagged excess reserves & $0.63^{* * *}$ & $0.67^{* * *}$ & $0.74^{* * *}$ & $0.65^{* * *}$ \\
& $(0.08)$ & $(0.12)$ & $(0.08)$ & $(0.08)$ \\
Dummy for zero interest & & & & $0.83^{* * *}$ \\
rate policy (ZIRP) & & & & $(0.32)$ \\
Dummy for quantitative & & & & $0.65^{* *}$ \\
$\quad$ easing policy (QEP) & & & & $(0.28)$ \\
ZIRP dummy $\times$ & & & & $0.17^{*}$ \\
log of call rate & & & & $(0.09)$ \\
Number of observations & 86 & 0.909 & 0.965 & 183 \\
R-squared & 0.710 & & & 0.968 \\
\hline
\end{tabular}

Notes: The dependent variable is the log of excess reserves. Data are monthly. Newey-West corrected standard errors are in parentheses. Asterisks indicate statistical significance: *** for $1 \%, * *$ for $5 \%$ and $*$ for $10 \%$. 


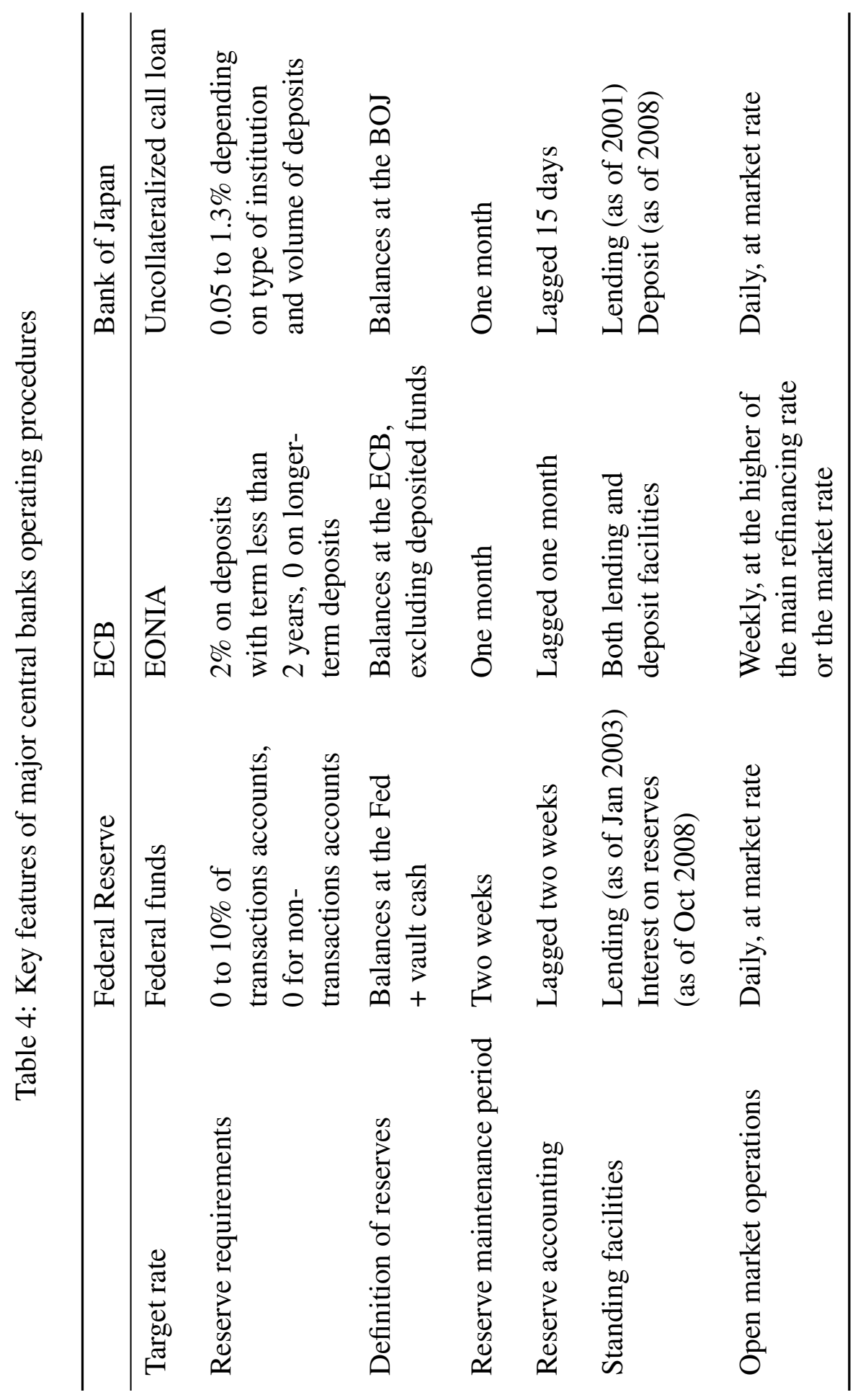


Table 5: Estimates of intra-maintenance period reserve demand

Dependent variable $=$ deviation of funds rate from target (basis points)

\begin{tabular}{|c|c|c|}
\hline \multirow[b]{2}{*}{ Regressor } & \multicolumn{2}{|c|}{ Estimation method } \\
\hline & Weighted least squares & Weighted 2SLS \\
\hline Lagged reserve accounting dummy & $-1.9^{* * *}$ & $-1.4^{* * *}$ \\
\hline Last day of maintenance period dummy & -1.1 & $2.8^{*}$ \\
\hline End of month dummy & $10.4^{* * *}$ & $14.0^{* * *}$ \\
\hline Funds rate deviation, lagged 1 day & $0.350^{* * *}$ & $0.403^{* * *}$ \\
\hline Funds rate deviation, lagged 2 days & $-0.095^{* * *}$ & $-0.111^{* * *}$ \\
\hline Funds rate deviation, lagged 10 days & $0.111^{* * *}$ & $0.130^{* * *}$ \\
\hline Expected funds rate change on: & & \\
\hline $\begin{array}{l}\text { day } 1 \text { of maintenance period } \\
\text { day } 2 \text { of maintenance period }\end{array}$ & $\begin{array}{l}0.310^{* * *} \\
0.279^{* * *}\end{array}$ & $\begin{array}{l}0.305^{* * *} \\
0.297^{* * *}\end{array}$ \\
\hline $\begin{array}{l}\text { day } 2 \text { of maintenance period } \\
\text { day } 3 \text { of maintenance period }\end{array}$ & $\begin{array}{l}0.279^{* * *} \\
0.122^{* * *}\end{array}$ & $0.135^{* * *}$ \\
\hline day 4 of maintenance period & $0.118^{* * *}$ & $0.134^{* * *}$ \\
\hline day 5 of maintenance period & -0.004 & 0.012 \\
\hline day 6 of maintenance period & -0.009 & 0.026 \\
\hline day 7 of maintenance period & 0.059 & 0.071 \\
\hline day 8 of maintenance period & -0.010 & 0.010 \\
\hline day 9 of maintenance period & 0.001 & -0.044 \\
\hline Expected change when no FOMC meeting & -0.010 & -0.015 \\
\hline Cumulative excess reserves ( $\$$ billion) & $\begin{array}{c}-0.506^{* * *} \\
(0.133)\end{array}$ & $\begin{array}{c}-0.592^{* * *} \\
(0.134)\end{array}$ \\
\hline Target fed funds rate (percent) & $\begin{array}{c}0.056 \\
(0.093)\end{array}$ & $\begin{array}{c}0.004 \\
(0.104)\end{array}$ \\
\hline Reserves “miss” (\$ billion) & $\begin{array}{c}-0.750^{* * *} \\
(0.210)\end{array}$ & \\
\hline Excess reserves ( $\$$ billion) & & $\begin{array}{c}-0.919^{* * *} \\
(0.287)\end{array}$ \\
\hline Adjusted R-squared & 0.233 & \\
\hline
\end{tabular}

Notes: daily data, January 261994 through July 2 2007, 3468 observations. Y2K and 9/11 observations are excluded. The instruments used for the 2SLS regression are the reserves miss, the other exogenous regressors. The weights are the estimated residual variance pre- and post- July 20 1998. Robust Newey-West standard errors are in parentheses. Asterisks denote level of statistical significance: $* * *$ for $1 \%, * *$ for $5 \%$ and $*$ for $10 \%$. The regressions also include an intercept and dummies for days $2-9$ of the maintenance period. 
Table 6: Estimates of intra-maintenance period reserve supply

Dependent variable $=$ excess reserves $(\$$ billion $)$

\begin{tabular}{|c|c|c|c|}
\hline \multirow[b]{3}{*}{ Regressor } & \multicolumn{3}{|c|}{ Method } \\
\hline & \multirow[b]{2}{*}{ WLS } & \multicolumn{2}{|c|}{ Weighted 2SLS } \\
\hline & & (a) & (b) \\
\hline Lagged reserve accounting dummy & $0.312^{* * *}$ & $0.382^{* * *}$ & $0.382^{* * *}$ \\
\hline Last day of maintenance period dummy & $3.153^{* * *}$ & $3.025^{* * *}$ & $3.025^{* * *}$ \\
\hline End of month dummy & $2.880^{* * *}$ & $2.056^{* * *}$ & $2.062^{* * *}$ \\
\hline Excess reserves, lagged 1 day & $0.552^{* * *}$ & $0.540^{* * *}$ & $0.540^{* * *}$ \\
\hline Excess reserves, lagged 2 days & $-0.087^{* * *}$ & $-0.062^{* * *}$ & $-0.063^{* * *}$ \\
\hline Cumulative excess reserves ( $\$$ billion) & $\begin{array}{c}-0.408^{* * *} \\
(0.039)\end{array}$ & $\begin{array}{c}-0.381^{\text {*** }} \\
(0.039)\end{array}$ & $\begin{array}{c}-0.382^{\text {*** }} \\
(0.039)\end{array}$ \\
\hline Target federal funds rate (percent) & $\begin{array}{r}-0.015 \\
(0.027)\end{array}$ & $\begin{array}{r}-0.021 \\
(0.027)\end{array}$ & $\begin{array}{r}-0.021 \\
(0.027)\end{array}$ \\
\hline Prior target rate change (bp) & $\begin{array}{c}-0.016^{* *} \\
(0.006)\end{array}$ & $\begin{array}{c}-0.016^{* * *} \\
(0.006)\end{array}$ & $\begin{array}{c}-0.016^{* * *} \\
(0.006)\end{array}$ \\
\hline Change in target rate $(\mathrm{bp})$ & $\begin{array}{c}-0.022^{* *} \\
(0.010)\end{array}$ & $\begin{array}{c}0.002 \\
(0.010)\end{array}$ & $\begin{array}{c}0.004 \\
(0.014)\end{array}$ \\
\hline Lagged funds rate deviation (bp) & $\begin{array}{l}0.014^{* * *} \\
(0.005)\end{array}$ & & \\
\hline Expected funds rate deviation (bp) & & $\begin{array}{l}0.049^{* * *} \\
(0.013)\end{array}$ & $\begin{array}{l}0.049^{* * *} \\
(0.013)\end{array}$ \\
\hline Adjusted R-squared & 0.466 & & \\
\hline $\mathrm{J}$ stat $\mathrm{p}$-value & & 0.254 & 0.256 \\
\hline
\end{tabular}

Notes: daily data, January 26, 1994 through July 2, 2007, 3468 observations. Y2K and 9/11 observations are excluded. Newey-West standard errors are in parentheses. Asterisks denote level of statistical significance: $* * *$ for $1 \%, * *$ for $5 \%$ and $*$ for $10 \%$. The regressions also include an intercept and dummies for days 2-9 of the maintenance period. In column (a), the expected funds rate deviation is taken as endogenous; in column (b), the target rate change is also instrumented. The instruments used for the 2SLS regressions are the lagged funds rate deviation, the lagged spotmonth fed funds futures rate, the lagged futures-implied funds rate change within the maintenance period, the futures-based funds rate surprise, and the other exogenous regressors. The weights are the estimated residual variance pre- and post- July 201998. 


\section{References}

Adrian, Tobias, \& Shin, Hyun Song. 2010. Banking and the monetary policy transmission mechanism. Handbook of Monetary Economics, forthcoming.

Adrian, Tobias, Kimbrough, Karin, \& Marchioni, Dina. 2010 (January). The Federal Reserve's Commercial Paper Funding Facility. Staff Report 423. Federal Reserve Bank of New York.

Anderson, R.G., \& Gascon, C.S. 2009. The Commercial Paper Market, the Fed, and the 2007-2009 Financial Crisis. Federal Reserve Bank of St. Louis Review, 91(6), 589-612.

Angelini, Paolo. 2008. Liquidity and Announcement Effects in the Euro Area. Giornale degli Economisti, 67(1), 1-20.

Armentier, Olivier, Kreiger, Sandra, \& McAndrews, James. 2008. The Federal Reserve's Term Auction Facility. Federal Reserve Bank of New York Current Issues in Economics and Finance, 14(July), 1-11.

Ashcraft, Adam, Malz, Allan, \& Rosenberg, Joshua. 2009. The Term Asset-Backed Securities Lending Facility. Working Paper. Federal Reserve Bank of New York.

Ashcraft, Adam, Gârleanu, Nicolae, \& Pedersen, Lasse Heje. 2010 (February). Two Monetary Tools: Interest Rates and Haircuts. Unpublished manuscript, Federal Reserve Bank of New York.

Ball, Laurence. 1999. Efficient Rules for Monetary Policy. International Finance, 2(April), 63-83.

Bank for International Settlements. 2008 (June). Monetary Policy Frameworks and Central Bank Market Operations. Markets Committee Compendium.

Bank of Canada. 2009. Annex: Framework for Conducting Monetary Policy at Low Interest Rates. Monetary Policy Report, April, 25-28.

Bartolini, Leonardo, Bertola, Giuseppe, \& Prati, Alessandro. 2002. Day-to-Day Monetary Policy and the Volatility of the Federal Funds Interest Rate. Journal of Money, Credit and Banking, 34(1), 137-159.

Bartolini, Leonardo, Prati, Alessandro, Angeloni, Ignazio, \& Claessens, Stijn. 2003. The Execution of Monetary Policy: A Tale of Two Central Banks. Economic Policy, 18(37), 437-467.

Bernanke, Ben S., \& Blinder, Alan S. 1988. Credit, Money, and Aggregate Demand. The American Economic Review, 78(2), 435-439.

Bernanke, Ben S., \& Mihov, Ilian. 1998. Measuring Monetary Policy. The Quarterly Journal of Economics, 113(3), 869-902. 
Bindseil, Ulrich. 2004. Monetary Policy Implementation: Theory, Past and Present. Oxford University Press.

Bindseil, Ulrich, \& Seitz, Franz. 2001 (February). The Supply and Demand for Eurosystem Deposits the First 18 Months. Working Paper 44. European Central Bank.

Blenck, Denis, Hasako, Harri, Hilton, Spence, \& Masaki, Kazuhiro. 2001 (December). The main features of the monetary policy frameworks of the Bank of Japan, the Federal Reserve and the Eurosystem. BIS Papers 9. Bank for International Settlements.

Borio, Claudio. 1997. The Implementation of Monetary Policy in Industrial Countries: A Survey. Economic Paper 47. Bank for International Settlements.

Borio, Claudio, \& Disyatat, Piti. 2009 (November). Unconventional monetary policies: An appraisal. Working Paper 292. Bank for International Settlements.

Bowman, David, Gagnon, Etienne, \& Leahy, Mike. 2010 (March). Interest on Excess Reserves as a Monetary Policy Instrument: The Experience of Foreign Central Banks. International Finance Discussion Paper 996. Board of Governors of the Federal Reserve System.

Brainard, William C. 1967. Uncertainty and the Effectiveness of Policy. The American Economic Review, 57(2), 411-425.

Brunner, Allan D., \& Meltzer, Allan. 1964. The Federal Reserve's Attachment to the Free Reserve Concept. U.S. Congress, House Committee on Banking and Currency, Subcommittee on Domestic Finance, 88th Congress, 2nd Session.

Carpenter, Seth B., \& Demiralp, Selva. 2006a. Anticipation of Monetary Policy and Open Market Operations. International Journal of Central Banking, 2(2), 25-63.

Carpenter, Seth B., \& Demiralp, Selva. 2006b. The Liquidity Effect in the Federal Funds Market: Evidence from Daily Open Market Operations. Journal of Money, Credit and Banking, 38(4), 901-920.

Carpenter, Seth B., \& Demiralp, Selva. 2008. The liquidity effect in the federal funds market: Evidence at the monthly frequency. Journal of Money, Credit and Banking, 40(1), 1-24.

Christiano, Lawrence J., \& Eichenbaum, Martin. 1992. Identification and the Liquidity Effect of a Monetary Policy Shock. Pages 335-370 of: Cukierman, A., Hercowitz, Z., \& Leiderman, L. (eds), Political Economy, Growth and Business Cycles. MIT Press.

Christiano, Lawrence J., \& Eichenbaum, Martin. 1995. Liquidity Effects, Monetary Policy, and the Business Cycle. Journal of Money, Credit and Banking, 27(4), 1113-1136. 
Christiano, Lawrence J., Eichenbaum, Martin, \& Evans, Charles. 1996a. The Effects of Monetary Policy Shocks: Evidence from the Flow of Funds. The Review of Economics and Statistics, 78(1), 16-34.

Christiano, Lawrence J., Eichenbaum, Martin, \& Evans, Charles L. 1996b. Identification and the Effects of Monetary Policy Shocks. Pages 36-74 of: Blejer, M., Eckstein, Z., Hercowitz, Z., \& Leiderman, L. (eds), Financial Factors in Economic Stabilization and Growth. Cambridge University Press.

Christiano, Lawrence J., Eichenbaum, Martin, \& Evans, Charles L. 1999. Monetary Shocks: What Have We Learned, and to What End? Chap. 2, pages 65-148 of: Taylor, John B., \& Woodford, Michael (eds), Handbook of Macroeconomics, vol. 1A. North Holland.

Christiansen, Jens, Lopez, Jose, \& Rudebusch, Glenn. 2009 (June). Do Central Bank Liquidity Facilities Affect Interbank Lending Rates? Working Paper 2009-13. Federal Reserve Bank of San Francisco.

Clarida, Richard, Galí, Jordi, \& Gertler, Mark. 1998. Monetary Rules in Practice: Some International Evidence. European Economic Review, 42, 1033-1067.

Clarida, Richard, Galí, Jordi, \& Gertler, Mark. 1999. The Science of Monetary Policy: A New Keynesian Perspective. Journal of Economic Literature, 37(4), 1661-1707.

Clarida, Richard, Galí, Jordi, \& Gertler, Mark. 2000. Monetary Policy Rules and Macroeconomic Stability: Evidence and Some Theory. Quarterly Journal of Economics, 115(1), 147-180.

Clouse, James A. 1994. Recent developments in discount window policy. Federal Reserve Bulletin, November.

Clouse, James A., \& Dow, J. 2002. A Computational Model of Banks' Optimal Reserve Management. Journal of Economic Dynamics and Control, 26(11), 1787-1814.

Curida, Vasco, \& Woodford, Michael. 2010a. The Central-Bank Balance Sheet as an Instrument of Monetary Policy. Carnegie-Rochester Conference Series on Public Policy, forthcoming.

Curida, Vasco, \& Woodford, Michael. 2010b. Credit Spreads and Monetary Policy. Journal of Money, Credit and Banking, forthcoming.

Demiralp, Selva. 2001 (December). Monetary Policy in a Changing World: Rising Role of Expectations and the Anticipation Effect. FEDS Working Paper 2001-55. Board of Governors of the Federal Reserve System.

Demiralp, Selva, \& Jordá, Oscar. 2002. The Announcement Effect: Evidence from Open Market Desk Data. Federal Reserve Bank of New York Economic Policy Review, 8(1), $29-48$. 
Disyatat, Piti. 2008 (December). Monetary policy implementation: Misconceptions and their consequences. Working Paper 269. Bank for International Settlements.

Ejerskov, Steen, Moss, Clara Martin, \& Stracca, Livio. 2003 (July). How does the ECB allot liquidity in its weekly main refinancing operations? A look at the empirical evidence. Working Paper 244. European Central Bank.

European Central Bank. 2008 (November). The Implementation of Monetary Policy in the Euro Area. General Documentation on Eurosystem Monetary Policy Instruments and Procedures.

Feinman, Joshua. 1993a. Estimating the Open Market Desk's Daily Reaction Function. Journal of Money, Credit and Banking, 25(2), 231-247.

Feinman, Joshua. 1993b. Reserve requirements: history, current practice, and potential reform. Federal Reserve Bulletin, 79, 569.

Fleming, Michael, Hrung, Warren B., \& Keane, Frank. 2009. The Term Securities Lending Facility: Origin, Design, and Effects. Federal Reserve Bank of New York Current Issues in Economics and Finance, 12(February).

Friedman, Benjamin M. 1999. The Future of Monetary Policy: The Central Bank as an Army with Only a Signal Corps? International Finance, 2(3), 321-328.

Friedman, Benjamin M., \& Roley, V. Vance. 1987. Aspects of Investors' Behavior Under Risk. In: Feiwel, G. R. (ed), Arrow and the Ascent of Modern Economic Theory. New York: New York University Press.

Furfine, Craig H. 2000. Interbank payments and the daily federal funds rate. Journal of Monetary Economics, 46(2), 535 - 553.

Gagnon, Joseph, Raskin, Matthew, Remache, Julie, \& Sack, Brian P. 2010 (March). LargeScale Asset Purchases by the Federal Reserve: Did They Work? Staff Report 441. Federal Reserve Bank of New York.

Garbade, Kenneth D., Partlan, John C., \& Santoro, Paul J. 2004. Recent Innovations in Treasury Cash Management. Federal Reserve Bank of New York Current Issues in Economics and Finance, 10(11).

Gertler, Mark, \& Karadi, Peter. 2009 (November). A Model of Unconventional Monetary Policy. Manuscript, New York University.

Goodfriend, Marvin. 1994. Why we Need an "Accord" for Federal Reserve Credit Policy: A Note. Journal of Money, Credit and Banking, 26(3), 572-580.

Goodfriend, Marvin. 2000. Overcoming the Zero Bound on Interest Rate Policy. Journal of Money, Credit and Banking, 32(4), 1007-1035. 
Goodfriend, Marvin. 2002. Interest on Reserves and Monetary Policy. Federal Reserve Bank of New York Economic Policy Review, 8(1), 77-84.

Goodhart, Charles. 2000. Can Central Banking Survive the IT Revolution? International Finance, 3(2), 189-209.

Gorton, Gary B. 2008. The Panic of 2007. In: Maintaining Stability in a Changing Financial System. Jackson Hole Symposium. Federal Reserve Bank of Kansas City.

Gorton, Gary B., \& Metrick, Andrew. 2009 (November). Securitized Banking and the Run on Repo. Working Paper 09-14. Yale ICF.

Guthrie, Graeme, \& Wright, Julian. 2000. Open mouth operations. Journal of Monetary Economics, 46(2), 489 - 516.

Hamilton, James D. 1996. The Daily Market for Federal Funds. The Journal of Political Economy, 104(1), 26-56.

Hamilton, James D. 1997. Measuring the Liquidity Effect. The American Economic Review, 87(1), 80-97.

Hamilton, James D. 1998. The supply and demand for Federal Reserve deposits. CarnegieRochester Conference Series on Public Policy, 49, 1-44.

Hanes, Christopher. 2004. The Rise of Open-Mouth Operations and the Disappearance of the Borrowing Function in the United States. Unpublished manuscript, SUNY Binghamton.

Hayashi, Fumio. 2001. Identifying a Liquidity Effect in the Japanese Interbank Market. International Economic Review, 42(2), 287-316.

Hilton, Spence. 2008. Recent Developments in Federal Reserve System Liquidity and Reserve Operations. Pages 179-204 of: Bloxham, Paul, \& Kent, Christopher (eds), Lessons from the Financial Turmoil of 2007 and 2008. Reserve Bank of Australia.

Hilton, Spence, \& Hrung, Warren B. 2010. The Impact of Banks' Cumulative Reserve Position on Federal Funds Rate Behavior. International Journal of Central Banking, forthcoming.

Ho, Corinne. 2008 (June). Implementing monetary policy in the 2000s: Operating procedures in Asia and beyond. Working Paper 253. Bank for International Settlements.

Jinushi, Toshiki, Takeda, Yosuke, \& Yajima, Yasuhide. 2004 (July). Asset Substitution in Response to Liquidity Demand and Monetary Policy: Evidence from the Flow of Funds Data in Japan. Unpublished manuscript, Sophia University.

Judd, J.P., \& Rudebusch, G.D. 1998. Taylor's Rule and the Fed: 1970-1997. Federal Reserve Bank of San Francisco Economic Review, 3-16. 
Kacperczyk, Marcin, \& Schnabl, Philip. 2010. When Safe Proved Risky: Commercial Paper during the Financial Crisis of 2007-2009. Journal of Economic Perspectives, 24(1), $29-50$.

Keister, Todd, \& McAndrews, James. 2009 (June). Why are banks holding so many excess reserves? Staff Report 380. Federal Reserve Bank of New York.

Keister, Todd, Martin, Antoine, \& McAndrews, James. 2008. Divorcing Money from Monetary Policy. Federal Reserve Bank of New York Economic Policy Review, September/October, 41-56.

King, Mervyn. 1997. Changes in UK Monetary Policy: Rules and Discretion in Practice. Journal of Monetary Economics, 39, 81-97.

Kuttner, Kenneth N. 2010. The Fed's response to the financial crisis: Pages from the BOJ playbook, or a whole new ball game? Public Policy Review, 6(3), 407-430.

Leeper, Eric M., \& Gordon, David B. 1992. In search of the liquidity effect. Journal of Monetary Economics, 29(3), 341 - 369.

Lenza, Michele, Pill, Huw, \& Reichlin, Lucrezia. 2010. Monetary Policy in Exceptional Times. Economic Policy, 25(62), 295-339.

Levin, Andrew T., Wieland, Volcker, \& Williams, John C. 2001. Robustness of SImple Monetary Rules under Model Uncertainty. In: Taylor, John B. (ed), Monetary Policy Rules. University of Chicago Press.

Manna, Michele, Pill, Huw, \& Quirós, Gabriel. 2001. The Eurosystem's Operational Framework in the Context of the ECB's Monetary Policy Strategy. International Finance, 4(1), 65-99.

McAndrews, James, Sarkar, Asani, \& Wang, Zhenyu. 2008 (July). The Effect of the Term Auction Facility on the London Inter-Bank Offered Rate. Staff Report 335. Federal Reserve Bank of New York.

McCallum, Bennett T. 1981. Price level determinacy with an interest rate policy rule and rational expectations. Journal of Monetary Economics, 8(3), 319-329.

McCallum, Bennett T. 1983. On non-uniqueness in rational expectations models: An attempt at perspective. Journal of Monetary Economics, 11(2), 139-168.

McCallum, Bennett T. 1986. Some issues concerning interest rate pegging, price level determinacy, and the real bills doctrine. Journal of Monetary Economics, 17(1), 135160 .

McCallum, Bennett T. 2001. Monetary Policy Analysis in Models Without Money. Federal Reserve Bank of Saint Louis Review, 83(July/August), 145-160. 
Meulendyke, Ann-Marie. 1998. U.S. Monetary Policy and Financial Markets. New York: Federal Reserve Bank of New York.

Miyanoya, Atsushi. 2000 (August). A Guide to Bank of Japan's Market Operations. Financial Markets Department Working Paper Series 00-E-3. Bank of Japan.

Motley, Colin. 2010. The Commercial Paper Funding Facility: Impact, Efficacy, and What It Tells Us about the Crisis in Commercial Paper from 2007-2009. Unpublished thesis, Harvard University.

Oda, N., \& Ueda, Kazuo. 2005. The Effects of the Bank of Japan's Zero Interest Rate Commitment and Quantitative Monetary Easing on the Yield Curve: A Macro-Finance Approach. Working Paper 05-E-6. Bank of Japan.

Okina, Kunio, Shirakawa, Masaaki, \& Shiratsuka, Shigenori. 2001. The Asset Price Bubble and Monetary Policy: Japan's Experience in the Late 1980s and the Lessons. Bank of Japan Monetary and Economic Studies (Special Edition), February, 395-450.

Orphanides, Athanasios. 2001. Commentary on 'Expectations, Open Market Operations, and Changes in the Federal Funds Rate'. Federal Reserve Bank of St. Louis Review, 83(4), 49-56.

Pagan, Adrian, \& Robertson, John. 1995. Resolving the Liquidity Effect. Federal Reserve Bank of Saint Louis Review, 77, 33-53.

Pagan, Adrian, \& Robertson, John. 1998. Structural models of the liquidity effect. Review of Economics and Statistics, 80(2), 202-217.

Parkin, Michael. 1978. A Comparison of Alternative Techniques of Monetary Control Under Rational Expectations. Manchester School, 46(September), 252-287.

Peersman, Gert, \& Smets, Frank. 1999. The Taylor Rule: A Useful Monetary Policy Benchmark for the Euro area? International Finance, 2, 85-116.

Reis, Ricardo. 2010 (January). Interpreting the Unconventional U.S. Monetary Policy of 2007-09. Working Paper 15662. National Bureau of Economic Research.

Roosa, Robert V. 1956. Federal Reserve Operations in the Money and Government Securities Markets. Federal Reserve Bank of New York.

Sargent, Thomas J., \& Wallace, Neil. 1975. 'Rational' Expectations, the Optimal Monetary Instrument, and the Optimal Money Supply Rule. The Journal of Political Economy, 83(2), 241-254.

Shioji, Etsuro. 2000. Identifying Monetary Policy Shocks in Japan. Journal of the Japanese and International Economies, 14(1), 22 - 42. 
Shiratsuka, Shigenori. 2009 (November). Size and Composition of the Central Bank Balance Sheet: Revisiting Japan's Experience of the Quantitative Easing Policy. Discussion Paper 2009-E-25. Institute for Monetary and Economic Studies.

Strongin, Steven H. 1995. The Identification of Monetary Policy Disturbances: Explaining the Liquidity Puzzle. Journal of Monetary Economics, 35(3), 463-497.

Svensson, Lars. 1997. Inflation forecast targeting: Implementing and monitoring inflation targets. European Economic Review, 41, 1111-1146.

Taylor, John B. 1993. Discretion Versus Policy Rules in Practice. Carnegie-Rochester Conference Series on Public Policy, 39, 195-214.

Taylor, John B. 1996. How Should Monetary Policy Respond to Shocks while Maintaining Long-Run Price Satbility? Pages 181-195 of: Achieving Price Stability, vol. Federal Reserve Bank of Kansas City.

Taylor, John B. 2001. Expectations, Open Market Operations, and Changes in the Federal Funds Rate. Federal Reserve Bank of Saint Louis Review, 83(4), 33-48.

Taylor, John B. 2009. Empirically Evaluating Economic Policy in Real Time: Inaugural Martin Feldstein Lecture. NBER Reporter, July, 1-5.

Taylor, John B., \& Williams, John C. 2009. A Black Swan in the Money Market. American Economic Association Journal of Macroeconomics, 1(1), 58-83.

Thornton, Daniel L. 2001a. The Federal Reserve's Operating Procedures, Nonborrowed Reserves, Borrowed Reserves and the Liquidity Effect. Journal of Banking \& Finance, 25(1717-1739).

Thornton, Daniel L. 2001b. Identifying the Liquidity Effect at the Daily Frequency. Federal Reserve Bank of St. Louis Review, July/August, 59-78.

Thornton, Daniel L. 2007. Open Market Operations and the Federal Funds Rate. Federal Reserve Bank of St. Louis Review, 89(November/December), 549-570.

Thornton, Daniel L. 2009. The Effect of the Fed's Purchase of Long-Term Treasuries on the Yield Curve. Federal Reserve Bank of Saint Louis Economic Synopses, 25.

Tinbergen, J. 1952. On the Theory of Economic Policy. North-Holland.

Tobin, James, \& Brainard, William C. 1963. Financial Intermediaries and the Effectiveness of Monetary Controls. The American Economic Review, 53(2), 383-400.

Uesugi, Iichiro. 2002. Measuring the Liquidity Effect: The Case of Japan. Journal of the Japanese and International Economies, 16(3), 289 - 316.

Ugai, Hiroshi. 2008. Effects of the Quantitative Easing Policy: A Survey of Empirical Analyses. Bank of Japan Monetary and Economic Studies, 25(1), 1-47. 
Vilasuso, Jon. 1999. The liquidity effect and the operating procedure of the Federal Reserve. Journal of Macroeconomics, 21(3), 443 - 461.

Wicksell, Knut. 1907. The Influence of the Rate of Interest on Prices. The Economic Journal, 17(66), 213-220.

Woodford, Michael. 2000. Monetary Policy in a World Without Money. International Finance, 3(2), 229-260.

Wu, Tao. 2010. The Term Auction Facility's Effectiveness in the Financial Crisis of 200709. Federal Reserve Bank of Dallas Economic Letter, 5(4).

Würtz, Flemming Reinhardt. 2003 (January). A comprehensive model on the euro overnight rate. Working Paper 207. European Central Bank. 